Portland State University

PDXScholar

Dissertations and Theses

Dissertations and Theses

Spring 6-3-2019

\title{
Snowy Plover Demography in Oregon
}

Eleanor Prindiville Gaines

Portland State University

Follow this and additional works at: https://pdxscholar.library.pdx.edu/open_access_etds

Part of the Biology Commons

Let us know how access to this document benefits you.

Recommended Citation

Gaines, Eleanor Prindiville, "Snowy Plover Demography in Oregon" (2019). Dissertations and Theses.

Paper 5004.

https://doi.org/10.15760/etd. 6880

This Dissertation is brought to you for free and open access. It has been accepted for inclusion in Dissertations and Theses by an authorized administrator of PDXScholar. Please contact us if we can make this document more accessible: pdxscholar@pdx.edu. 
Snowy Plover Demography in Oregon

by

Eleanor Prindiville Gaines

A dissertation submitted in partial fulfillment of the requirements for the degree of

Doctor of Philosophy

in

Biology

Dissertation Committee:

Michael T. Murphy, Chair

Stephen J. Dinsmore

Suzanne Estes

Elise Granek

Susan Masta

Portland State University

2019 
(C) 2019 Eleanor Prindiville Gaines 


\begin{abstract}
A thorough understanding of demographic parameters and their contribution to overall population growth is fundamental to effective conservation of small populations, but this information is often lacking. The Pacific Coast population of the Western Snowy Plover (Charadrius nivosus nivosus) is listed as threatened and has been the target of long-term, multi-pronged management in Oregon. The Oregon coastal population has been intensively monitored since 1990 , and over $80 \%$ of the population is color banded, but a comprehensive analysis of demographic parameters and the effect of management on vital rates and population growth has been unavailable until now. Here, I used capturemark-resight techniques to document survival at each life stage and to explore environmental and management factors that best explained variation in survival over a 25-year study period. I analyzed the effects of habitat restoration, exclosure use, and lethal predator management on survival at appropriate life stages and evaluated the effects of one management option, lethal predator control, on overall population growth. Chick survival to fledging improved dramatically after the chicks' $5^{\text {th }}$ day, was higher in years with lethal predator management, and was highest during the peak of the long brood-rearing season. Cold weather, particularly during the chicks' first 5 days, had a negative effect on survival to fledging. Juvenile survival from fledging to the following spring declined over the study period, but rebounded after implementation of lethal predator management. Adult survival was lower in wetter-than-average winters and higher in years with predator management. I used the survival analyses and productivity data collected over 25 years in a matrix population model to reveal that population
\end{abstract}


growth is most sensitive to changes in adult survival, and that while predator management is important for continued growth, its use may be scaled back by as much as $50 \%$ and still maintain a growing population. My results, encompassing all phases of this species' life cycle, demonstrate that with holistic and thoughtful adaptive management, and with the cooperation of numerous agencies, a balance can be struck between protection and control of native species to bring about recovery of species threatened with (local) extinction. 


\section{ACKNOWLEDGEMENTS}

First and foremost, I thank my family - nuclear and extended. I would never have finished this project without your inspiration, encouragement, and unwavering support. Thank you for putting up with all things plover these many years. Ron especially bore the brunt of my decision to go back to school and was consistently encouraging and supportive. Ron and Patrick shared photos of the project for use in presentations, Alison provided professional-grade editing, and Andrew gamely assisted with occasional window surveys when he had better things to be doing.

I thank my committee for their patience. I thank Michael Murphy for agreeing to work with an overextended student, broadening my perspective, and providing ongoing encouragement. He was able to look at my analyses with a less plover-centric view, and thus improved them immensely. I thank Steve Dinsmore of Iowa State University for agreeing to participate on a committee that was at best inconvenient, for teaching me what little I know about Program MARK and survival analyses, and for patiently answering the same questions repeatedly, always preceded by, 'That's a good question...'. His expertise in statistics in general, and Program MARK in particular, was invaluable.

I thank my colleagues at Institute for Natural Resources (INR) for encouragement and patience. When I approached Jimmy Kagan with a carefully thought out plan to pursue this degree while continuing my work at INR he quickly cut me off and told me to 'just do it', and then kept the pressure on to make sure I finished. Sue Vrilakas, Lindsey Wise, and Ray Brunner picked up slack at work without complaint as I focused on 
plovers more than I should have. Early, wide-ranging discussions with Joe Bernert helped clarify my questions and dust off long-dormant statistical skills. David Green encouraged me to be more ambitious with my analyses, and continues to work with me on more robust models.

Snowy Plover recovery in Oregon has been achieved through the committed persistence and coordination of hundreds of agency biologists and field technicians, and their work serves as a model for other recovery efforts. Partners from U. S. Fish and Wildlife Service, Bureau of Land Management, U. S. D. A. Forest Service, U. S. D. A. Animal Plant Health and Inspection Service Wildlife Services, U. S. Army Corps of Engineers, Oregon Department of Fish and Wildlife, Oregon Parks and Recreation Department, The Nature Conservancy, Oregon State University, and Portland State University participated in the Recovery Unit 1 Snowy Plover Working Team and provided funding or support for the monitoring work that made this analysis possible.

Finally, I thank the many Snowy Plover monitors over the years. Mark Stern of The Nature Conservancy started this project in 1990, never dreaming it would continue for 30 years and counting. Current monitors David Lauten and Kathleen Castelein have worked on the project an astounding 22 years and collected the majority of the data I report on. They were gracious enough to share it with me, and never failed to answer questions or discuss half-baked ideas. More-recent monitors J. Daniel Farrar (11 years), Adam Kotaich ( 8 years), and Erica Krygsman ( 4 years) have been patient with me as I have been stretched too thin. Their collective professionalism and dedication to the plovers has been an inspiration and made my life immeasurably easier. 


\section{TABLE OF CONTENTS}

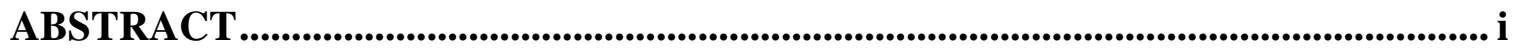

ACKNOWLEDGEMENTS ......................................................................................................... iii

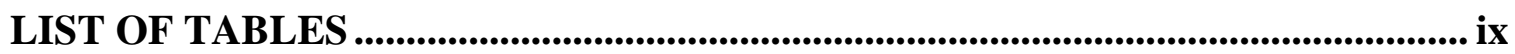

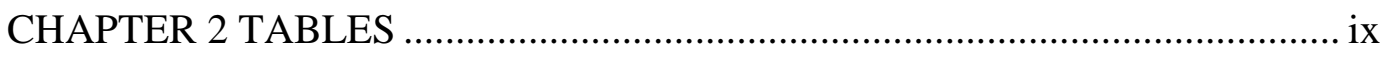

CHAPTER 3 TABLES ………………………….................................... ix

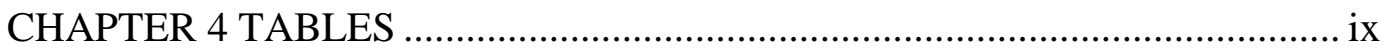

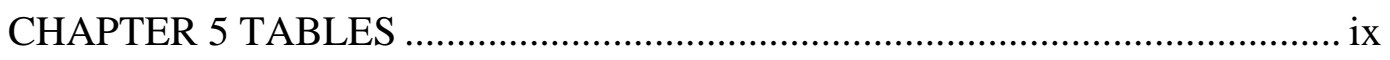

LIST OF FIGURES ................................................................................................................... xi

CHAPTER 1 Figures .............................................................................. $\mathrm{xi}$

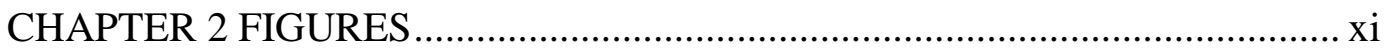

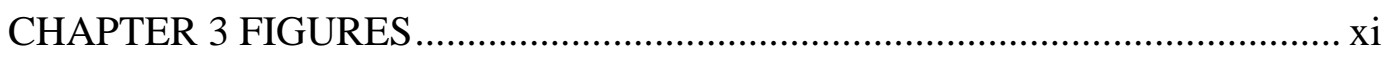

CHAPTER 4 FIGURES............................................................................. xii

CHAPTER 5 FIGURES......................................................................... xii

CHAPTER 1. INTRODUCTION AND BACKGROUND ............................................... 1

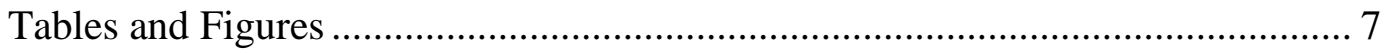

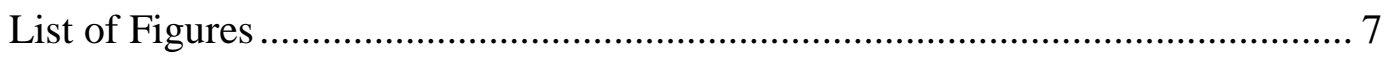

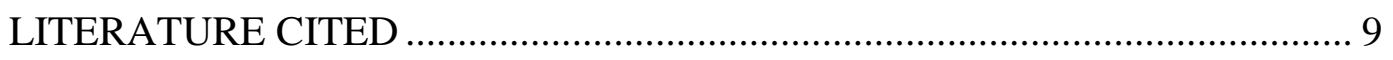

CHAPTER 2. SNOWY PLOVER CHICK SURVIVAL IN OREGON ..................... 14

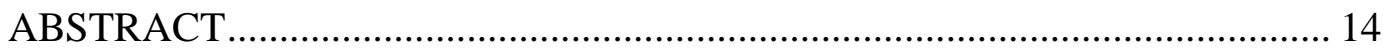

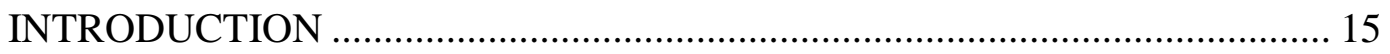

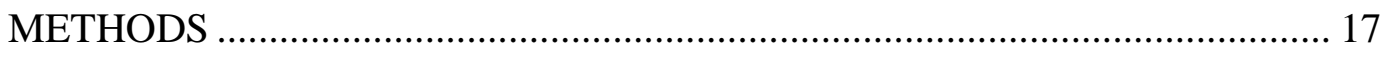




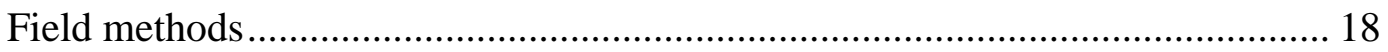

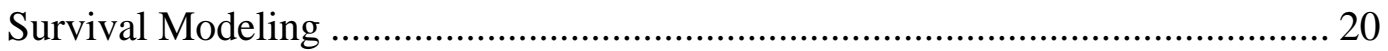

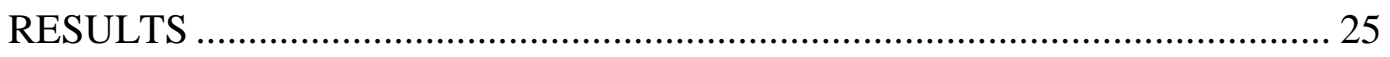

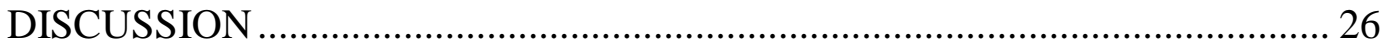

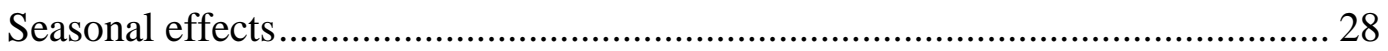

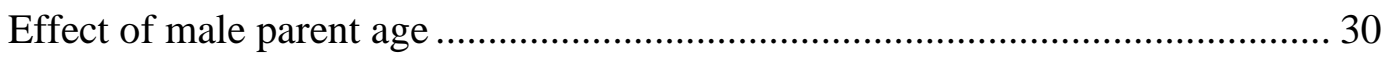

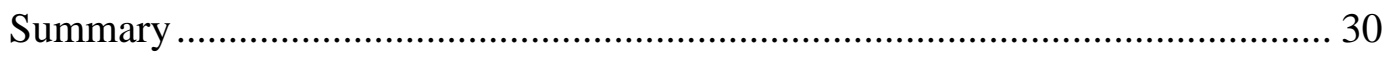

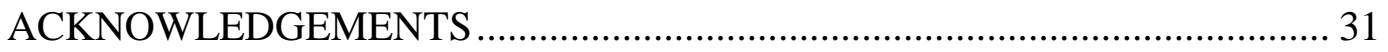

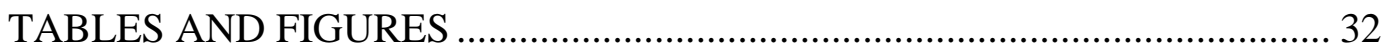

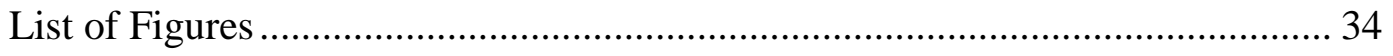

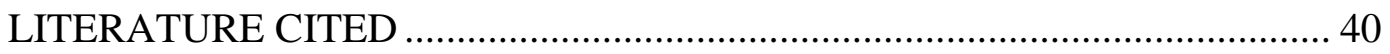

CHAPTER 3. SNOWY PLOVER JUVENILE SURVIVAL IN OREGON............... 47

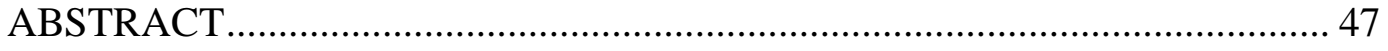

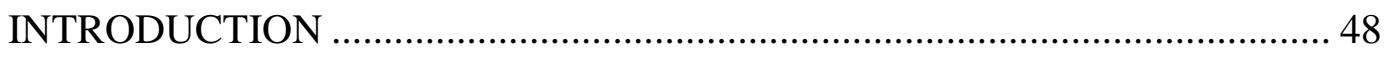

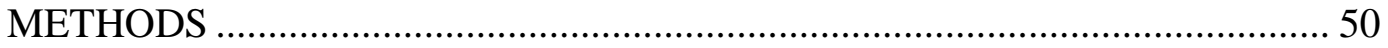

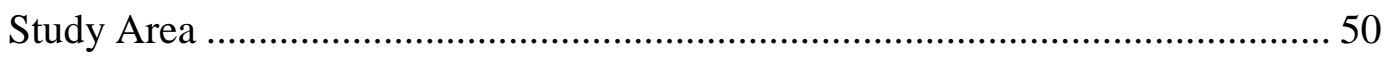

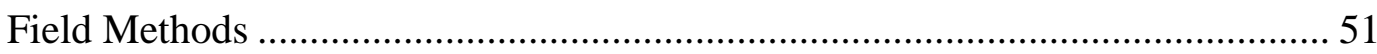

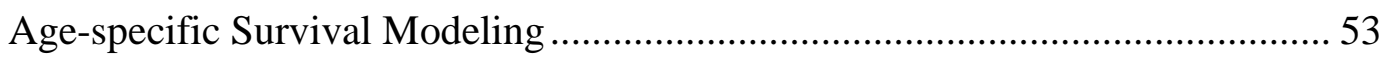

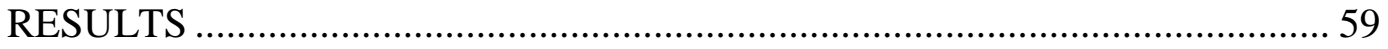




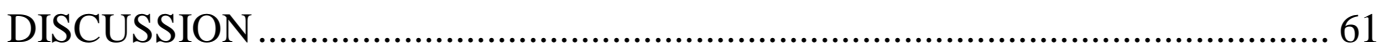

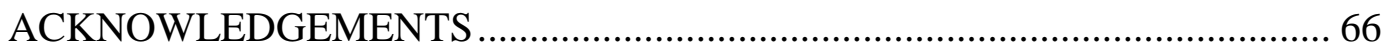

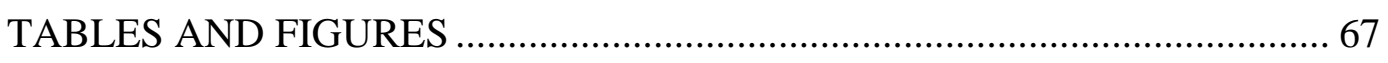

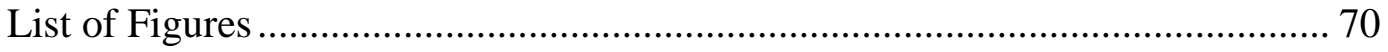

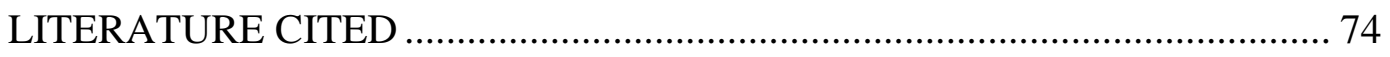

CHAPTER 4. THE EFFECT OF MANAGEMENT ON SNOWY PLOVER ADULT

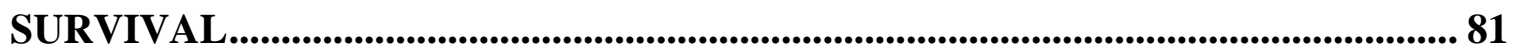

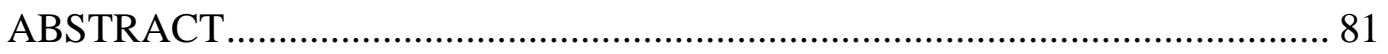

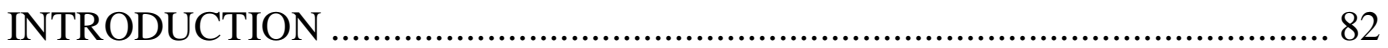

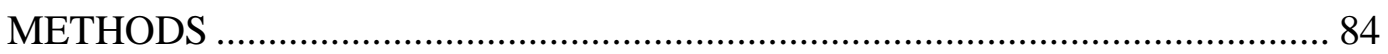

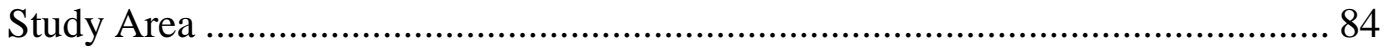

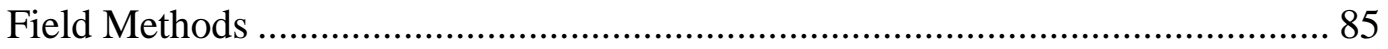

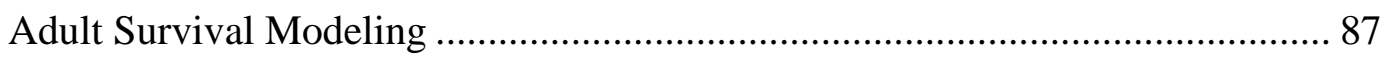

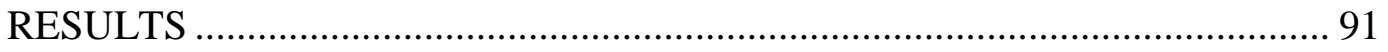

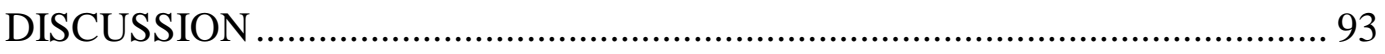

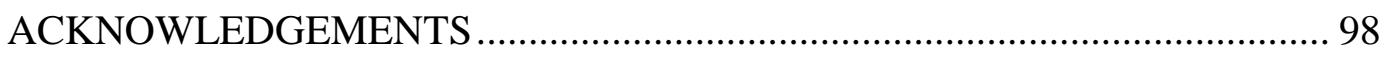

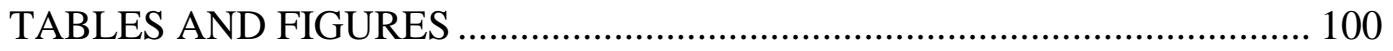

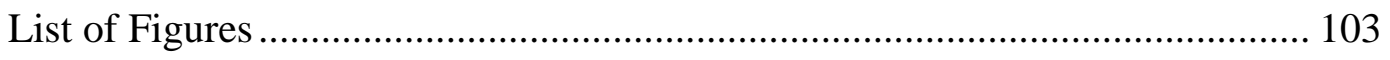

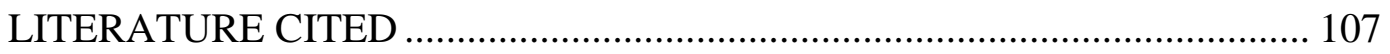


CHAPTER 5. A MATRIX MODEL TO COMPARE EFFECTS OF LETHAL PREDATOR MANAGEMENT ON SNOWY PLOVER POPULATION GROWTH

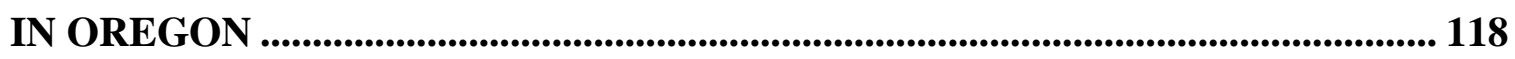

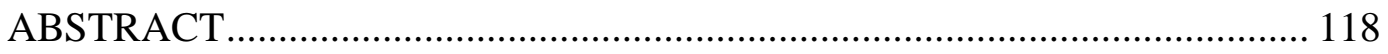

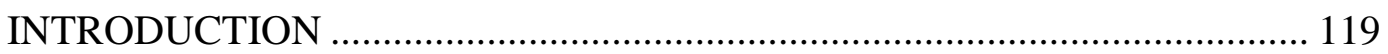

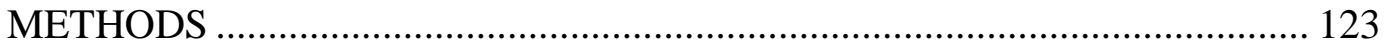

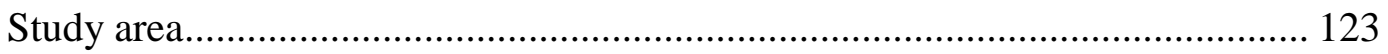

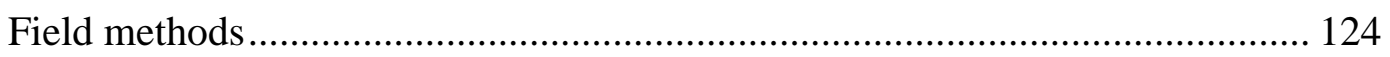

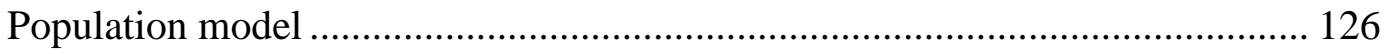

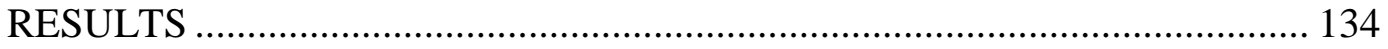

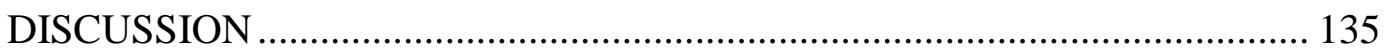

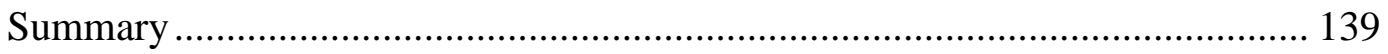

ACKNOWLEDGEMENTS ...................................................................... 140

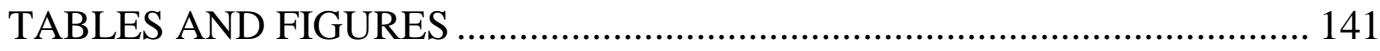

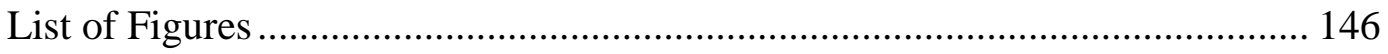

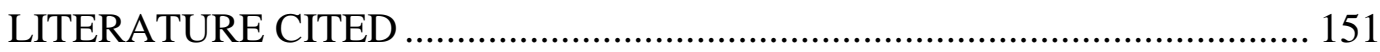

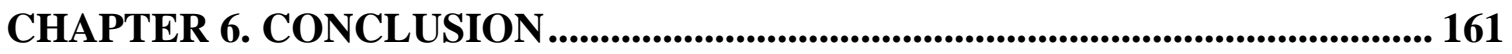

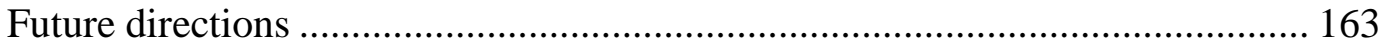

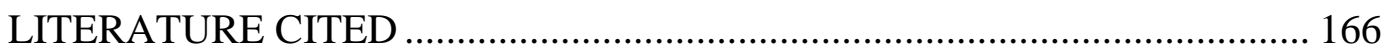




\section{LIST OF TABLES}

\section{CHAPTER 2 TABLES}

Table 1. Number of Snowy Plover broods in chick survival analysis by year (1990-2014) and site within Oregon.

Table 2. Model selection results for daily survival of Snowy Plover chicks along the

Oregon coast from 1990 to 2014. 33

\section{CHAPTER 3 TABLES}

Table 1. Adult sex ratio (ASR) and total population estimate of Snowy Plovers along the Oregon Coast, 1993 - 2014 67

Table 2. Number of Snowy Plover chicks banded and fledged annually in Oregon, 19902014. 68

Table 3. Model selection results for age specific survival $(\varphi)$ and detection probability $(p)$ of Snowy Plovers along the Oregon coast, 1990 - 2014 69

\section{CHAPTER 4 TABLES}

Table 1. Snowy Plover adult population estimates, percent of adult population banded, and percent of males in adult population along the Oregon Coast, $1990-2014 \ldots \ldots \ldots 100$ Table 2. Number of predators removed at Snowy Plover nesting sites, $2002-2014 \ldots 101$ Table 3. Model selection results for apparent survival $(\varphi)$ and detection probability $(p)$ of adult Snowy Plovers along the Oregon coast, 1990 - 2014

\section{CHAPTER 5 TABLES}

Table 1. Snowy Plover adult population estimates, percent of adult population banded, and percent of males in adult population along the Oregon Coast, $1990-2014$. 
Table 2. Number of predators removed at Snowy Plover nesting sites in Oregon, 2002 2014 .

Table 3. Snowy Plover mean vital rates and variances used in deterministic and stochastic models

Table 4. Elasticity of mean matrix values and underlying vital rates for deterministic matrix model for Snowy Plover population in Oregon.....

Table 5. Projected effect of variable levels of predator management on the Oregon

Snowy Plover population, $2014-2029$. 145 


\section{LIST OF FIGURES}

\section{CHAPTER 1 FIGURES}

Figure 1. Dissertation organization showing survival transitions and matrix population model for Oregon Coast Snowy Plover Population................................8

\section{CHAPTER 2 FIGURES}

Figure 1. Snowy Plover monitoring locations in coastal Oregon, 1990-2014...........35

Figure 2. Daily survival estimates (mean and 95\% CI) of Snowy Plover chicks during the 28-day fledging period based on model constraining age as a linear effect...............36

Figure 3. Probability of surviving to fledge at 28 days (95\% CI) for Snowy Plover chicks

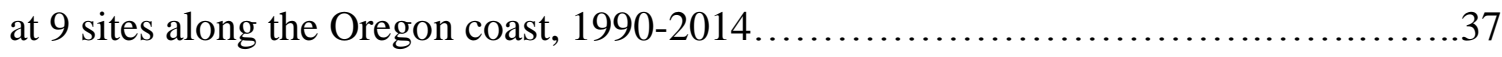

Figure 4. Effect of age and hatch date (mean and 95\% CI) on Snowy Plover daily chick

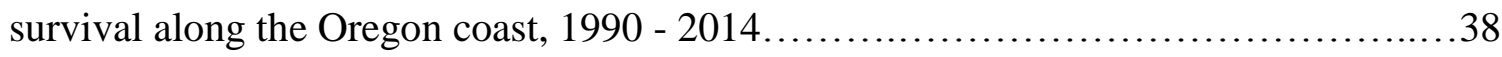

Figure 5. Effect of age and colder-than-average weather during fledging period (mean and 95\% CI) on daily survival of Snowy Plover chicks along the Oregon coast, 1990 -

2014.

\section{CHAPTER 3 FIGURES}

Figure 1. Snowy Plover breeding sites along Oregon coast, 1990 - 2014..............71

Figure 2. Snowy Plover juvenile survival with 95\% CI, 1990- 2014, based on model

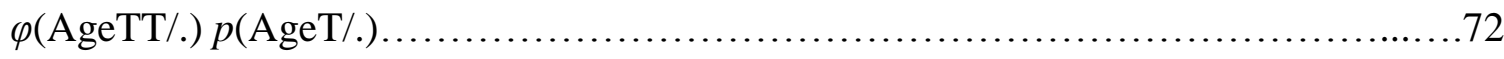

Figure 3. Apparent survival estimates with process variance only (sampling variation removed) and 95\% CI, for adult and juvenile Snowy Plovers along the Oregon coast, $1990-2014$ 


\section{CHAPTER 4 FIGURES}

Figure 1. Snowy Plover breeding sites along Oregon coast, 1990 - 2014, and location of North Bend weather station used for weather data.............................. 104

Figure 2. Effect of exclosure use on adult apparent survival, as estimated by model

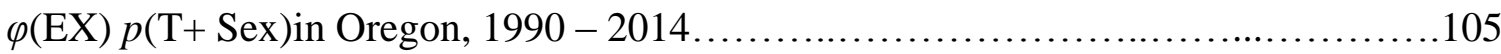

Figure 3. Adult male and female Snowy Plover apparent survival with $95 \%$ confidence intervals, in Oregon, $1990-2014$, based on model $\varphi(\mathrm{T}+\mathrm{Sex}) p(\mathrm{~T}+\mathrm{Sex}) \ldots \ldots \ldots \ldots \ldots . . .106$

\section{CHAPTER 5 FIGURES}

Figure 1. Snowy Plover nesting sites in Oregon, 1990-2014......................147

Figure 2. Life cycle diagram for Western Snowy Plover population in Oregon with postbreeding census and two life stages.......................................... 148

Figure 3. Histogram of population growth rate $\left(\lambda_{\mathrm{s}}\right)$ based on 10,000 iterations of stochastic model

Figure 4. Snowy Plover adult male population growth, based on 100 iterations of stochastic model, 1990 - 2029............................................ 150 


\section{CHAPTER 1. INTRODUCTION AND BACKGROUND}

Knowledge of the life history parameters that influence population growth is crucial to effective conservation, but this information is often lacking for species of conservation concern. Without a comprehensive understanding of a species' demography, management actions can be directed towards improving life history parameters that may have negligible effects on population growth (Heppell et al. 1996, Johnson et al. 2010). Given the limited resources available for recovery of declining species, it is important that efforts be directed where they will be most effective.

Population growth is a function of changes in recruitment, survival, and dispersal (Sibly and Hone 2002, Sandercock 2003, Anders and Marshall 2005, Stahl and Oli 2006). Recruitment of young in ground nesting birds is composed of nest success and survival of chicks to reproductive age. Recruitment may be poor in ground nesters because these species lose many nests to predators and fledge few young (Warriner et al. 1986, Fraga and Amat 1996). Conservation efforts often focus on improving nest success, because it is easier to monitor and affect nest fates than adult or fledgling survival and dispersal (Lebreton et al.1992, Sillett and Holmes 2002). However, without a clear understanding of these efforts' effects on the overall population, management directed at one vital rate may have unintended negative consequences at other life stages that can negate the efforts' benefits. Additionally, limited resources could be expended on ineffective management.

Western Snowy Plovers (Charadrius nivosus nivosus) are a wide-ranging and patchily distributed species of conservation concern. Adapted to ephemeral coastal dune habitats, the Pacific Coast population occurs from Damon Point, Washington to Bahia 
Magdalena, Baja California Sur, and is listed as Threatened (U.S. Fish and Wildlife Service 2007). Limiting factors include increasing predation from native and non-native predators (Neuman et al. 2004), human disturbance (Ruhlen et al. 2003, Lafferty et al. 2006), and habitat loss to development, exotic vegetation, recreational use, and potentially, sea level rise (Page and Stenzel 1981, U.S. Fish and Wildlife Service 1993, 2007, Page et al. 1995, Galbraith et al. 2002, Muir and Colwell 2010, Chu-Agor et al. 2011). These factors are intertwined; for example, human-associated trash attracts predators, and exotic vegetation provides cover for non-native and invasive native predators.

Along the Oregon coast, plovers have a long nesting seasons that extends from April through mid-August. Nests are simple depressions in the sand, occasionally lined with shell fragments or other beach debris, and are often placed near an object (e.g. a small plant or piece of driftwood) in an otherwise sparsely vegetated landscape (Wilson 1980, Page et al. 1985). Nests are cryptic and adults depend on early detection of approaching threats to avoid predation (Muir and Colwell 2010). Clutch size among plovers is commonly 4, but in Western Snowy Plovers clutch size is typically 3 eggs (range $2-6$ ); single egg clutches are rarely incubated (Warriner et al. 1986). Incubation is shared by the sexes, lasts 29 days, and begins when the clutch is complete. Snowy Plovers suffer high rates of nest failure, but renest readily (Warriner et al. 1986). In Oregon, American Crow (Corvus brachyrhynchos), Common Raven (Corvus corax), and red fox (Vulpes vulpes) are primary nest predators, but nests are also lost to weather, abandonment, and a host of other predators. 
Snowy Plovers have a sequentially polyandrous breeding system. Males raise the precocial chicks for approximately 28 days to fledging while females typically abandon broods shortly after hatching and attempt an additional nest with a new mate. Occasionally - especially if it is late in the breeding season - females will stay with a brood. Sexes are distinguishable in alternate (i.e., breeding) plumage; juveniles cannot be visually identified to sex (Page et al. 2009). The serial polyandrous system and the long breeding season allows female plovers in Oregon time for up to three successful nests. Because males must attend to chicks they can, at most, rear two broods per season. However, given high nest failure rates, few birds are this productive.

Snowy Plover populations along the Oregon coast have been heavily managed since they were listed in 1993 (U. S. Fish and Wildlife Service 1993, Oregon Department of Fish and Wildlife 2009). European beachgrass (Ammophila arenaria) was introduced along the Pacific coast in the early 1900s. Ammophila has since stabilized much of the ephemeral coastal dunes system, resulting in densely vegetated, steep dunes that are unsuitable for plover nesting and provide cover for predators (Wiedemann 1984, 1987, Muir and Colwell 2010). Habitat restoration projects have occurred at most Snowy Plover nesting sites in Oregon, and involve beachgrass removal and ongoing maintenance. Restrictions on recreation prohibit human use of active nesting areas from March 15 to September 15 (ICF International 2010); active nesting areas are roped off and marked with signs explaining the closure.

Nest predation takes its toll on plover reproductive success, and protective nest exclosures have been used to improve Snowy Plover nest success along the Oregon coast since 1991. Nesting birds are able to enter and exit through the openings in the wire mesh 
cages, but larger predators are excluded. Exclosures improve nest survival, but adult mortality has been documented at exclosed nests (Dinsmore et al. 2014).

Human-altered habitats often result in an increase in synanthropic native and nonnative predators, and these human-subsidized predators can have an outsized effect on small prey populations. This is indeed the case along the Oregon coast, where plover habitat and human recreation intersect. In Oregon, an integrated predator management plan for Snowy Plovers includes trash and carcass removal from nesting areas, predator harassment, protective nest exclosures, and since 2002, lethal control of crows, ravens and other predators exhibiting focused attention on plovers on nesting areas (U.S. Department of Agriculture and U.S. Department of Interior 2002). Lethal predator control, intended to improve chick survival to fledging, began along Oregon's south coast in 2002, and expanded to all regularly occupied nesting sites in 2004. Although the Oregon population has seen considerable growth since the implementation of lethal control, its effect across the life cycle is unknown. Predator removal is expensive, time intensive, and often controversial, so it is important to document its effect on different life stages and the overall demographic response (Lavers et al. 2010, Smith et al. 2010). Estimates of life stage-specific survival are critical to understanding population viability (Benton and Grant 1999, Sandercock 2003, Stenzel et al. 2007). The Oregon coastal population has been intensively monitored since 1990 , and more than $80 \%$ of the population is color banded, but a comprehensive analysis of demographic parameters and the effect of management on vital rates and population growth has been lacking until now. Here, I analyze the effects of habitat restoration, exclosure use, and lethal predator management on appropriate life stages, identify relative importance of each life stage, 
and evaluate the effects of one management option, lethal predator control, on overall population growth. I chose to explore the effects of predator management on population growth because of its effect on multiple life stages.

This dissertation is a compilation of four papers intended for publication in peerreviewed journals. Chapters 2 through 4 use mark-resight analyses in Program MARK to document Snowy Plover survival and the factors affecting survival at each life stage during a 25-year study period (1990 - 2014; Figure 1). Chapter 2 updates a previous analysis (Dinsmore et al. 2017) to include 4 new years of data and additional covariates to document chick survival from hatching to fledging at 28 days. Chapter 3 uses an agespecific model to estimate juvenile survival from fledging to the following spring, and identifies environmental and management covariates that influence survival during this period. Chapter 4 explores factors affecting adult annual survival. In Chapter 5, I pull information from the previous chapters together in a matrix population model to assess relative contribution of vital rates to population growth, project population viability through 2029, and investigate the effect of limiting lethal predator management on Snowy Plover population growth. The matrix model shows that the population growth rate is most sensitive to changes in adult survival, meaning improvements in this vital rate will have the largest effect on overall population growth. Previous work explored factors affecting nest survival to hatching using data from 1990 - 2011 (Dinsmore et al. 2014). I re-ran this analysis using nest data through 2014, almost doubling the number of nests in the analysis. The results of this expanded analysis were identical to Dinsmore et al.'s original work (2014), so I do not include a separate chapter on nest survival here, but 
used the nest survival estimates from the expanded analysis in the matrix population model.

Age-specific survival and viability information from the Oregon population will help fine tune range-wide population analyses, direct effective local management, and inform allocation of conservation resources. Future modifications of the model could include adding spatial information to describe relative contributions of each site to overall growth. Additionally, Oregon data could be combined with information from other recovery units to analyze survival and population growth at a larger scale, explicitly accounting for dispersal. I did not find evidence of density-dependent variation in survival, but as the Oregon population grows, such effects are expected. Adding additional years of data (e.g., 2015 - 2019) could allow further exploration of interactions between population density and growth. I chose to focus on predator management because it affected survival across the life cycle, but the model could easily be modified to predict effects of altering other management strategies (e.g., recreation restrictions or habitat restoration) on plover population growth. Although management is best informed by comprehensive, local demographic data (Anders and Marshall 2005, McNew et al. 2012), such data are lacking for most species, and thus this model could be generalized to other species with similar life histories but little available demographic data, to make informed a priori predictions about proposed management actions. 


\section{TABLES AND FIGURES}

\section{List of Figures}

Figure 1. Dissertation organization showing survival transitions and matrix population model for Oregon Coast Snowy Plover Population. 

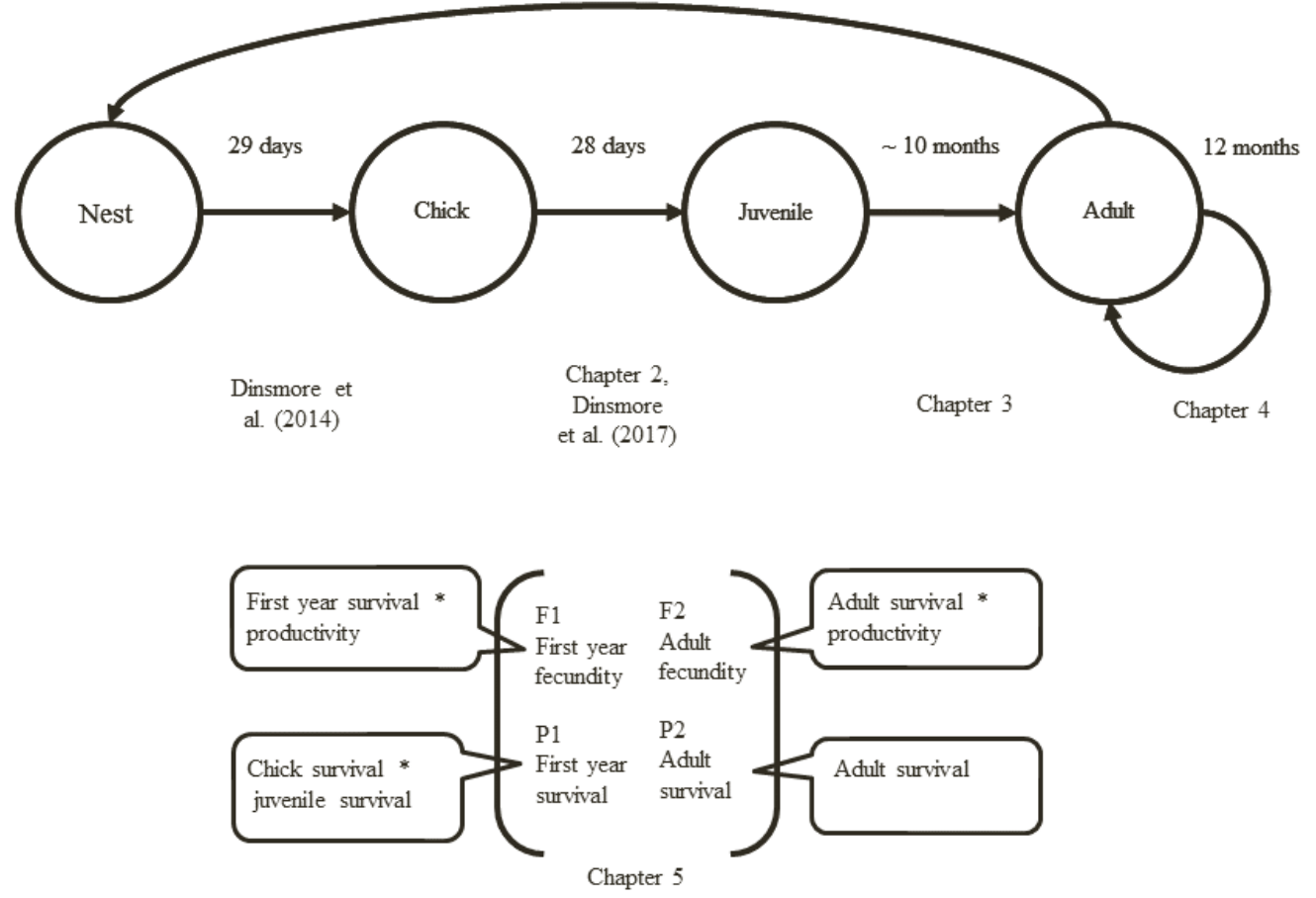

Figure 1. Dissertation organization showing survival transitions and matrix population model for Oregon Coast Snowy Plover Population. Nest survival reported in Dinsmore et al. (2014). Chick survival from hatching to fledging reported in Chapter 2, based on Dinsmore et al. (2017). Juvenile survival from fledging to Age 1 reported in Chapter 3. Adult annual survival reported in Chapter 4. Two stage matrix population model combining survival and productivity estimates covered in Chapter 5 . 


\section{LITERATURE CITED}

Anders, A. D., and M. R. Marshall (2005). Increasing the accuracy of productivity and survival estimates in assessing landbird population status. Conservation Biology $19: 66-74$.

Benton, T. G., and A. Grant (1999). Elasticity analysis as an important tool in evolutionary and population ecology. Trends in Ecology \& Evolution 14:467471.

Chu-Agor, M. L., R. Muñoz-Carpena, G. Kiker, A. Emanuelsson, and I. Linkov (2011). Exploring vulnerability of coastal habitats to sea level rise through global sensitivity and uncertainty analyses. Environmental Modelling \& Software 26:593-604.

Dinsmore, S. J., D. J. Lauten, K. A. Castelein, E. P. Gaines, and M. A. Stern (2014). Predator exclosures, predator removal, and habitat improvement increase nest success of Snowy Plovers in Oregon, USA. The Condor 116:619-628.

Dinsmore, S. J., E. P. Gaines, S. F. Pearson, D. J. Lauten, and K. A. Castelein (2017). Factors affecting Snowy Plover chick survival in a managed population. The Condor: $34-43$.

Fraga, R. M., and J.A. Amat (1996). Breeding biology of a Kentish Plover (Charadrius alexandrinus) population in an inland saline lake. Ardeola 43:69-85.

Galbraith, H., R. Jones, R. Park, J. Clough, S. Herrod-Julius, B. Harrington, and G. Page (2002). Global climate change and sea level rise: potential losses of intertidal habitat for shorebirds. Waterbirds 25:173. 
Heppell, S. S., L. B. Crowder, and D. T. Crouse (1996). Models to evaluate headstarting as a management tool for long-lived turtles. Ecological Applications 6:556-565.

ICF International (2010). Habitat Conservation Plan for the Western Snowy Plover. August. (ICF 06537.06.) Portland, OR. Prepared for Oregon Parks and Recreation Department.

Johnson, H. E., L. S. Mills, T. R. Stephenson, and J. D. Wehausen (2010). Populationspecific vital rate contributions influence management of an endangered ungulate. Ecological applications: a publication of the Ecological Society of America 20:1753-1765.

Lafferty, K. D., D. Goodman, and C. P. Sandoval (2006). Restoration of breeding by Snowy Plovers following protection from disturbance. Biodiversity \& Conservation 15:2217-2230.

Lavers, J. L., C. Wilcox, and C. J. Donlan (2010). Bird demographic responses to predator removal programs. Biological Invasions 12:3839-3859.

Lebreton, J.-D., K. P. Burnham, J. Clobert, and D. R. Anderson (1992). Modeling survival and testing biological hypotheses using marked animals: a unified approach with case studies. Ecological Monographs 62:67-118.

McNew, L. B., A. J. Gregory, S. M. Wisely, and B. K. Sandercock (2012). Demography of greater prairie- chickens: Regional variation in vital rates, sensitivity values, and population dynamics. The Journal of Wildlife Management 76:987-1000.

Muir, J. J., and M. A. Colwell (2010). Snowy Plovers select open habitats for courtship scrapes and nests. The Condor 112:507-510. 
Neuman, K. K., G. W. Page, L. E. Stenzel, J. C. Warriner, and J. S. Warriner (2004). Effect of mammalian predator management on Snowy Plover breeding success. Waterbirds 27:257-263.

Oregon Department of Fish and Wildlife (2009). Oregon Administrative Rules, Oregon Department of Fish and Wildlife, Division 100 Wildlife Diversity Plan. http://www.dfw.state.or.us/OARs/100.pdf

Page, G. W., and L. E. Stenzel (1981). The breeding status of the Snowy Plover in California. Western Birds 12:1-40.

Page, G. W., L. E. Stenzel, and C. A. Ribic (1985). Nest site selection and clutch predation in the Snowy Plover. Auk 102:347-353.

Page, G. W., M. A. Stern, and P. W. C. Paton (1995). Differences in wintering areas of Snowy Plovers from inland breeding sites in Western North America. The Condor 97:258-262.

Page, G. W., L. E. Stenzel, J. C. Warriner, J. S. Warriner, and P. W. Paton (2009). Snowy Plover (Charadrius alexandrinus). The Birds of North America Online. https://doi.org/10.2173/bna.154

Ruhlen, T. D., S. Abbott, L. E. Stenzel, and G. W. Page (2003). Evidence that human disturbance reduces Snowy Plover chick survival. Journal of Field Ornithology 74:300-304.

Sandercock, B. K. (2003). Estimation of survival rates for wader populations: a review of mark-recapture methods. Wader Study Group Bulletin 100:163-174. 
Sibly, R. M., and J. Hone (2002). Population growth rate and its determinants: an overview. Philosophical Transactions of the Royal Society of London. Series B: Biological Sciences 357:1153-1170.

Sillett, T. S., and R. T. Holmes (2002). Variation in survivorship of a migratory songbird throughout its annual cycle. Journal of Animal Ecology 71:296-308.

Smith, R. K., A. S. Pullin, G. B. Stewart, and W. J. Sutherland (2010). Effectiveness of predator removal for enhancing bird populations. Conservation Biology, 24: 820829. doi:10.1111/j.1523-1739.2009.01421.x

Stahl, J. T., and M. K. Oli (2006). Relative importance of avian life-history variables to population growth rate. Ecological Modelling 198:23-39.

Stenzel, L. E., G. W. Page, J. C. Warriner, J. S. Warriner, D. E. George, C. R. Eyster, B. A. Ramer, K. K. Neuman, and B. K. Sandercock (2007). Survival and natal dispersal of juvenile snowy plovers (Charadrius alexandrinus) in central coastal California. The Auk 124:1023-1036.

U.S. Department of Agriculture and U.S. Department of Interior (2002). Predator damage management to protect the federally threatened Pacific coast population of the Western Snowy Plover. Prepared by USDA, APHIS, Wildlife Services Program and the Siuslaw National Forest; USDI, Fish and Wildlife Service Region 1 and Bureau of Land Management Coos Bay District; and in cooperation with the Oregon Department of Fish and Wildlife, and Oregon Parks and Recreation Department. 
U. S. Fish and Wildlife Service (1993). Determination of Threatened Status for the Pacific Coast Population of the Western Snowy Plover. Federal Register $58: 12864-12874$.

U.S. Fish and Wildlife Service (2007). Recovery Plan for the Pacific Coast Population of the Western Snowy Plover (Charadrius alexandrinus nivosus). In 2 volumes.

Warriner, J. S., J. C. Warriner, G. W. Page, and L. E. Stenzel (1986). Mating system and reproductive success of a small population of polygamous Snowy Plovers. Wilson Bulletin 98:15-37.

Wiedemann, A. M. (1984). Ecology of Pacific Northwest coastal sand dunes: A community profile. Evergreen State Coll., Olympia, WA (USA).

Wiedemann, A. M. (1987). The ecology of European beachgrass (Ammophila arenaria [L.] Link). A review of the literature. Technical report 87-1-01. Nongame Wildlife Program, Oregon Department of Fish and Wildlife, Corvallis. Wilson, R. A. (1980). Snowy plover nesting ecology on the Oregon coast. [Online.] Available at http://ir.library.oregonstate.edu/xmlui/handle/1957/10543 


\title{
CHAPTER 2. SNOWY PLOVER CHICK SURVIVAL IN OREGON
}

Eleanor P. Gaines ${ }^{1}$, Stephen J. Dinsmore ${ }^{2}$, and Michael T. Murphy ${ }^{3}$

${ }^{1}$ Oregon Biodiversity Information Center - Institute for Natural Resources, Portland State University, PO Box 751, Portland, OR USA

${ }^{2}$ Department of Natural Resource Ecology and Management, 339 Science II, Iowa State University, Ames, IA USA

${ }^{3}$ Biology Department, Portland State University, PO Box 751, Portland, OR USA

\begin{abstract}
Effective management of sensitive species requires accurate estimation of vital rates and a thorough understanding of the processes that drive them. We examined Western Snowy Plover (Charadrius nivosus nivosus) chick survival from hatching to fledging along the Oregon Coast to better understand factors influencing productivity in this federally threatened species. The mean probability of surviving from hatching to fledging at 28 days was $0.61(\mathrm{SE}=0.01,95 \% \mathrm{CI}$ : $0.58,0.64)$. Chick survival improved with age, varied by site, and was higher in years with predator management. Survival was lowest in the chicks' first 5 days of life. We found a quadratic trend in chick survival over the long brood-rearing season; chicks hatched at the peak of the season had highest survival to fledging. Chicks that experienced colder-than-average weather during their pre-fledging period also had lower survival, particularly during their first 5 days, suggesting that effectiveness of management efforts in early spring may be limited by unpredictable spring weather near the northern end of the species' range.
\end{abstract}

Keywords: Charadrius nivosus, chick survival, environmental effects, predator management 


\section{INTRODUCTION}

Avian productivity of precocial species can be parsed into nest survival, chick survival to fledging, and juvenile recruitment into the breeding population. Nest and brood predation or losses to extreme weather are often high in ground nesting birds and are often the target of management for species of conservation concern. Effective management requires a thorough understanding of the life history parameters that influence population growth, but this information is often lacking for rare and uncommon species.

Furthermore, assessing survival of precocial young can be problematic because tracking mobile, often-cryptic offspring is difficult once they leave the nest. However, insight into the factors affecting survival from hatching to fledging (hereafter: fledging period) is critical to informing conservation decisions and discerning larger patterns of population growth.

The Western Snowy Plover (Charadrius nivosus nivosus) breeds along the Pacific Coast from Baja California Sur, Mexico to Washington, U.S.A. and at disjunct interior sites (Page et al. 2009). Populations within 80 kilometers of the coast are listed as Threatened by U. S. Fish and Wildlife Service because of poor recruitment and survival (U.S. Fish and Wildlife Service 1993, 2007, Thomas et al. 2012). Limiting factors include increasing predation from native and non-native predators (Neuman et al. 2004), human disturbance (Ruhlen et al. 2003, Lafferty et al. 2006), and habitat loss to development, exotic vegetation, and recreational use (Page and Stenzel 1981, Page et al. 2009, Muir and Colwell 2010). These factors are intertwined. For example, humanassociated trash attracts predators, and exotic vegetation provides cover for non-native and invasive native predators. In Oregon, intensive and coordinated management to 
benefit Snowy Plovers addresses all these limiting factors and has been ongoing since 1990. Management has been effective; Snowy Plover populations in Oregon have grown by nearly an order of magnitude during the last 25 years. Despite this success, managers need to know the effects of management actions on individual life stages to allow for effective decision-making as the Oregon population approaches recovery goals. Here, we examine temporal, environmental, and management factors influencing Snowy Plover chick survival to fledging using a well-studied, banded population and 25 years of data.

Snowy Plover nests are cryptic and adults depend on early detection of approaching threats to avoid predation (Muir and Colwell 2010). Clutch size is typically 3 eggs (range 1-6); single egg clutches are rarely incubated (Warriner et al. 1986). Incubation is shared by both parents, lasts 29 days, and begins when the clutch is complete (Page et al. 2009). Snowy Plovers have a sequentially polyandrous breeding system; males raise the precocial chicks for approximately 28 days to fledging. Females typically abandon broods shortly after hatching to attempt an additional nest with a new male. Broods remain with the tending parent until fledging. Occasionally - especially if it is late in the breeding season - females will stay with a brood. Chicks may succumb to exposure during inclement weather and a suite of predators including American Crows (Corvus brachyrhynchos), Common Ravens (Corvus corax), Great Horned Owl (Bubo virginianus), Northern Harrier (Circus hudsonius), Peregrine Falcon (Falco peregrinus), red fox (Vulpes vulpes), and coyote (Canis latrans). Snowy Plovers begin breeding at age 1, and most breed annually for the remainder of their life (Warriner et al. 1986, Sandercock et al. 2005). 
In Northern California, Colwell et al. (2007) found that Snowy Plover chick survival increased with age, varied by habitat and increased seasonally; chicks hatched later in the season were more likely to have fledged. In an analysis of the Oregon population between 1991 and 2011, Dinsmore et al. (2017) showed that chick survival in Oregon varied among sites and improved with chick age and predator management, but found no effect of season. Acknowledging these different findings, we were interested in further exploring the effect of season on chick survival in Oregon. We suspected that chick survival suffered during the frequent early spring storms along the Oregon Coast. Understanding seasonal effects on chick survival allows managers to effectively and efficiently time conservation actions to best benefit population growth.

Productivity increases with parent age or experience in many bird species, through variable fertility, nest survival, or chick survival to fledging (Sydeman et al. 1991, Martin 1995, Lepage et al. 1999, Sandercock et al. 1999, King et al. 2013). Snowy Plover broods are almost always raised by the male, thus we expected that older males would be associated with greater chick survival to fledging. Here we further expand on Dinsmore et al. (2017) by adding 4 years and 446 broods to the original analysis to test two hypotheses: 1) Snowy Plover chick survival in Oregon improves during the breeding season, and 2) male parent age has a positive effect on chick survival in this population.

\section{METHODS}

\section{Study Area}

We studied survival of Snowy Plover chicks from hatch to fledging at nine sites along the Oregon Coast (Figure 1) between 1990 and 2014. Occupied habitat covered approximately $17.7 \mathrm{~km}^{2}$ along a $137 \mathrm{~km}$ stretch of the Oregon coast near the northern 
limit of the species range, and included habitat typical of nesting Snowy Plovers: open ocean beaches, sand spits, ocean over-wash sites, sand dunes, and estuarine sand flats. Vegetation in these areas is sparse, but much of Oregon's dunes are dominated by nonnative, invasive European beachgrass (Ammophila arenaria), which over time has stabilized the naturally ephemeral dune system, resulting in densely vegetated, steep dunes that are unsuitable for plover use and provide cover for predators (Wiedemann 1984, 1987, Muir and Colwell 2010). Although plovers occasionally nested at other Oregon beaches (two known nests during the study period), these sites encompassed all regularly occupied coastal habitat in Oregon. Sites varied in ownership, management, and predation and recreation pressure. In 2002, land managers instituted an integrated predator management plan at Coos Bay North Spit, Bandon Beach, and New River that included lethal removal of plover predators (U.S. Department of Agriculture and U.S. Department of Interior 2002, Dinsmore et al. 2017). In 2004, lethal predator management was extended to all nine sites. Predator management was conducted by USDA APHISWildlife Services in coordination with the Recovery Unit 1 Snowy Plover Working Team, and primarily targeted American Crows, Common Ravens, and nonnative red fox. Predator management activities began before plover nesting (typically in February each year) and continued through August. See Dinsmore et al. (2017) for further details on the predator management program.

\section{Field methods}

We located plover nests by observing adult behavior and tracking, and estimated hatching date by counting 29 days from clutch completion (Warriner et al. 1986, Page et al 2009). When nests were found with complete clutches we estimated anticipated hatch date by 
floatation (Westerskov 1950, Rizzolo and Schmutz 2007). Chicks were banded at or soon after hatching with brood-specific combinations of one metal U. S. Geological Survey (USGS) band covered with plastic tape and one colored Darvic band (Avinet, Portland, ME, USA). Adults were captured on or near the nest using walk-in traps (Dietz et al. 1994) and noose carpets (Mehl et al. 2003), and were banded with unique four-band combinations, two on each tarsometatarsus.

Following hatching, we surveyed to resight broods at least weekly. Early in the brood-rearing period, plover chicks can be difficult to locate, and to minimize disturbance we often confirmed broods were active based on adult behavior. Males with active broods will feign injury, vocalize, and behave conspicuously to distract a potential threat to chicks. We increased efforts to relocate broods and count individual chicks as fledging age approached. All hatch-year birds seen at any point after 28 days old were considered fledged (Warriner et al. 1986, Page et al. 2009). Brood failure was rarely directly observed, but was inferred based on repeated sightings of adults without chicks and exhibiting no defensive behaviors prior to the brood's $28^{\text {th }}$ day. Likewise, we concluded broods failed if the tending parent was found with a new nest prior to the brood's $28^{\text {th }}$ day.

This work was permitted by Portland State University IACUC number PSU13.11.25.1, USFWS recovery permits TE839094 and TE39372B, U.S. Fish and Wildlife Service banding permits 21825 and 23854, and Oregon Department of Fish and Wildlife annual scientific take authorizations. 


\section{Survival Modeling}

Because individual chicks were not uniquely identifiable, but tending parents were, we used the young survival from marked adults model (Lukacs et al. 2004) implemented in Program MARK (version 8.2, White and Burnham 1999) to estimate chick survival and detection probability during the 28-day brood-rearing period, based on repeated brood counts associated with individually marked adults. This model is an extension of a Cormack-Jolly-Seber model (Cormack 1964, Jolly 1965, Seber 1965) and assumes that tending parents are uniquely identifiable and that marks are correctly read, the initial number of chicks in a brood (i.e., the number hatched) is known, chicks within a brood are interchangeable, and that there is no adoption of chicks from outside the brood (Lukacs et al. 2004). There is presently no goodness-of-fit test for this model in MARK.

We compiled 28-occasion encounter histories for broods hatched between 1990 and 2014 with a uniquely identifiable tending parent (usually the male). The number of broods increased throughout the study period (Table 1). Because we often did not count individual chicks, particularly early in the brood-rearing period, we had many adult resightings with no chick counts. Following Dinsmore et al. (2017) we chose to exclude these encounters, and only included encounters with known chick counts. To be included in the analysis, broods must have originated from nests found at or before hatching, must have known hatch date and known fate, and must have a uniquely identifiable tending parent. We did not include broods whose tending parent could not be identified. Most years, there were a handful of broods from nests that we did not locate during incubation. Because we did not know the complete brood size at time of hatching, we did not include those broods in this analysis. 
We used a hierarchical approach to model effects on detection probability first (no effect [.], linear [T], and quadratic [TT] trends on time), and used the best model from that analysis to model effects on survival. We included the following sources of variation in our models of survival.

- Year. We included annual effects (Yr) to account for among-year differences that may occur for a host of reasons, including weather, variation in predator populations, or other environmental factors.

- Predator management. Dinsmore et al. (2017) found a strong benefit of lethal predator management on this population and we were interested in documenting this effect in the larger data set. We included a categorical variable (PM) indicating whether a brood was reared at a site with or without lethal predator management. Predator management was strongly collinear with year, so we did not include these covariates in the same model.

- Site. The nine sites in our study area differed by ownership, management, predator composition and density, and recreation use so we included a site effect (Site) to account for these differences.

- Seasonal patterns. Snowy Plovers in Oregon breed over a long season; during this study the first nest hatched on 16 April, and the last brood fledged on 25 September. Colwell et al. (2007) found that chicks hatched later in the season were more likely to fledge in Humboldt County, California whereas a negative seasonal trend in chick survival has been documented in other shorebirds (Brudney et al. 2013, Koczur et al. 2014, 
Catlin et al. 2015). Dinsmore et al. (2017) did not find any effect of season in chick survival in Oregon, and we were interested in analyzing this apparent difference more thoroughly. Thus, in our larger data set we included linear (Hatch) and quadratic $\left(\mathrm{Hatch}^{2}\right)$ covariates for hatch date (day $1=16$ April).

- Brood age. Snowy Plover chicks show increasing survival with age (Colwell et al. 2007, Dinsmore 2017) so we included linear (Age) and quadratic $\left(\mathrm{Age}^{2}\right)$ age effects as days since hatching. Colwell et al. (2007) found rapid improvements in Snowy Plover chick survival after broods reached three days. Thus we also modeled age effects with one intercept for the brood's first 3, 5, 7, and 10 days, and another for the remaining 25, 23, 21, and 18 days (Age3, Age5, Age7, Age10).

- Male parent age. Parent age or experience can affect dependent chick survival (Sydeman et al. 1991, Saunders et al. 2012, King et al. 2013). Most Snowy Plover broods are reared by the male, and we expected that older, more experienced parents would have higher brood survival. Thus, we included a covariate for male parent age (MAge) to test this hypothesis. We also considered a quadratic effect of parent age (MAge ${ }^{2}$ ) to account for possible senescence. We knew the male parent age for 913 broods because those parents were originally banded in Oregon as chicks. We knew the minimum male parent age of an additional 509 broods because the males were originally banded in Oregon as adults. In these cases, we assumed birds banded as adults were one year old at time of 
capture. There were 181 broods (11\%) associated with unbanded males that were of unknown age. These adults were uniquely identifiable by association with their banded broods and because they were the only unbanded adults at a particular site. We assigned the mean male age of 2.86 years to these unknown birds.

- Weather. Results of the a priori survival analysis indicated poor chick survival in early spring, and prompted a post hoc analysis exploring the effects of cold and wet weather on chick survival. For each brood, we totaled the number of days in the 28-day fledging period that were colder (Cold) or wetter (Wet) than average. We retrieved daily total precipitation and minimum temperature data from the National Oceanic and Atmospheric Administration (Menne et al. 2012) collected at the North Bend Oregon Regional Airport (Station USW00024284, latitude 44.0931743, longitude -121.2005845) for the period of brood activity (4/16 to 9/25) for each year of the study. We identified cold weather during fledging periods by summing the number of days that fell below one standard deviation of the mean daily minimum temperature, as measured during the period of brood activity across all study years. Between 1990 and 2014, the mean minimum temperature between 16 April and 25 September was $10.18 \pm 2.68^{\circ} \mathrm{C}$. Thus, we counted the days in each brood's 28 -day fledging period that fell below $7.50^{\circ} \mathrm{C}$ (Cold). The number of colder-than-average days during each brood's fledging period ranged from 0 to 17 . Likewise, we identified wet weather during fledging 
periods by summing the number of days of more than one standard deviation above the mean daily precipitation, as measured during the period of brood activity across all study years. Between 1990 and 2014, the mean daily precipitation between 16 April and 25 September was 1.43 $\pm 4.72 \mathrm{~mm}$. Thus, we counted the days in each brood's 28-day fledging period with more than $6.15 \mathrm{~mm}$ precipitation (Wet). The number of wetter-than-average days during each fledging period ranged from 0 to 12 .

We modeled survival in four steps, advancing models within $2 \mathrm{AIC}_{\mathrm{c}}$ units to the next step. First, we compared models that described annual variation as a function of year and predator management. We advanced the most parsimonious model and added covariates for site and seasonal effects. In the third phase we explored effects of chick age and male parent age. Finally, we added weather covariates to top models. We built all models using the design matrix and a logit link function in Program MARK. We used an information-theoretic approach (Burnham and Anderson 2002) and model selection by Akaike's Information Criterion corrected for small sample size (AIC c $_{\text {; }}$ Akaike 1973) to evaluate competing models and their effects. The best-supported model was that with the lowest $\mathrm{AIC}_{\mathrm{c}}$ and highest model weight, but we considered models within $2 \mathrm{AIC}_{\mathrm{c}}$ units of the top model to have good support in the data (Burnham and Anderson 2002). We removed models within $2 \mathrm{AIC}_{\mathrm{c}}$ units that added a parameter without improving model deviance to ensure that $\Delta \mathrm{AIC}_{\mathrm{c}}$ values were not the result of uninformative parameters (Arnold 2010). We report beta parameters and 95\% confidence intervals for specific model covariates, and consider effects significant if their $95 \%$ confidence intervals do not 
include 0 . We report means \pm SE and $95 \%$ confidence intervals for survival estimates, except where otherwise noted.

\section{RESULTS}

Our data consisted of 4,058 chicks from 1,603 broods monitored between 1990 and 2014; brood size ranged from 1 to 3 chicks. We observed 1,773 chicks at or beyond age 28 days. The mean number of chicks fledged per brood was $1.11 \pm 0.02$ and the mean hatch date was 27 June \pm 0.67 days (range 16 April -29 August).

As in Dinsmore et al.'s previous analysis (2017), we found a single model with overwhelming support in the data (Table 2) and we use this model to make inference about effects on Snowy Plover chick survival. Our best model showed that chick survival increased significantly after chicks reached 5 days old, benefitted from lethal predator management, varied by site, showed a quadratic trend on hatch date, and declined with cold weather. We found no significant effect from year, male parent age, or wet weather during the fledging period. Detection probability was best explained by a quadratic trend on time. The only other model with any support in the data $\left(\Delta \mathrm{AIC}_{\mathrm{c}}=10.71\right)$ was identical except that it lacked an effect of cold weather. A model that substituted a linear trend on chick age for the Age5 covariate was not well-supported $\left(\Delta \mathrm{AIC}_{\mathrm{c}}=17.91\right)$, but we use it to graphically display improvement in survival with age (Figure 2).

Chick survival improved as broods aged and was best explained by constraining age effects to two levels before and after the chicks' fifth day $\left(\beta_{\text {Age } 5}=-2.36, \mathrm{SE}=0.20\right.$, 95\% CI: -2.75, -1.98). Survival varied by site and was greatest at Coos Bay North Spit, and lowest at Sutton, although individual site effects were not well estimated (Figure 3). As in Dinsmore's 2017 analysis, we saw a strong positive effect of predator management 
on chick survival $\left(\beta_{\mathrm{PM}}=0.33, \mathrm{SE}=0.07,95 \% \mathrm{CI}\right.$ : 0.19, 0.47). Our top model included a small but significant quadratic effect on hatch date $\left(\beta_{\text {Hatch }^{2}}{ }^{2}=-0.00019, \mathrm{SE}=0.000036\right.$, 95\% CI: $-0.00026,-0.00012)$; chicks hatched at the peak of the brood-rearing season had higher survival than those hatched at either end of the season. This effect mainly affected chicks in their first 5 days (Figure 4). We also found a negative effect of cold weather on chick survival $\left(\beta_{\text {Cold }}=-0.04, \mathrm{SE}=0.01,95 \% \mathrm{CI}:-0.06,-0.02\right)$. Chicks whose fledging periods coincided with periods of colder-than-average weather had lower survival, particularly during the first 5 days (Figure 5). Using our top model with mean covariate values, daily survival was $0.933(\mathrm{SE}=0.004, \mathrm{CI}=0.924,0.940)$ for chicks’ first 5 days, and $0.993(\mathrm{SE}=0.001, \mathrm{CI}=0.991,0.995)$ after 5 days. Based on mean hatch date, cumulative survival at individual sites ranged from 0.37 at Sutton to 0.69 at Coos Bay North Spit. Overall, the probability of a chick's survival to fledging was 0.61 ( $\mathrm{SE}=0.01$, $\mathrm{CI}=0.58,0.64)$

Detection probability showed a quadratic effect of age; it decreased through the middle of the fledging period before peaking towards the end of the fledging period. This pattern reflects increased effort to locate individual chicks at hatch (age 0) and as the broods approached fledging age, and decreased effort to make counts of individual chicks in broods during the middle of the fledging period.

\section{DISCUSSION}

Chick survival to fledging is an important contributor to productivity and overall population growth (Stahl and Oli 2006); a thorough understanding of this demographic parameter is fundamental to effective conservation. Chick survival estimates for this and other Charadrius species vary widely (Colwell et al. 2007, Catlin et al. 2011, DeRose- 
Wilson et al. 2013). In our previous analysis (Dinsmore et al. 2017), we estimated overall survival to 28 days as 0.57 (95\% CI: $0.50,0.63)$. Cumulative survival in the current analysis is slightly higher, but within the range of Dinsmore et al.’s 95\% CI (2017). Improved survival likely reflects additional years with predator management in this analysis. Colwell et al. (2007) reported cumulative fledging period survival in river habitat at 0.47 to 0.80 , and along beaches at 0.06 to 0.42 ; these estimates are mostly lower than ours, but the Northern California population did not receive predator management and has been identified as a population sink (Mullin et al. 2010). Our results reinforce earlier studies of Snowy Plover chick survival (Colwell et al. 2007, Dinsmore et al. 2017) and provide a deeper understanding of the factors influencing survival near the northern limits of the species' range. This work clarifies the effect of season on chick survival, and shows that extreme weather limits productivity. Our findings also have important management implications. Efforts to improve chick survival early in the breeding season may be a gamble as they will often be cancelled by unpredictable cold spring weather on the Oregon Coast. Actions focused during the peak of the broodrearing period (June to mid-July) are more likely to be effective.

Precocial chicks often have a period of higher mortality early in the fledging period as they develop thermoregulatory ability (Pienkowski 1984, Visser and Ricklefs 1993, Schekkermann and Visser 2001, Ruthrauff and McCaffery 2005), foraging skills (Marchetti and Price 1989), and learn to avoid predators (Powell 1992, Colwell et al. 2007, Catlin et al. 2011). Our best model suggested a significant increase in survival when chicks reached 5 days old (Figure 2), although without individually marked chicks we cannot distinguish increasing survival with age from heterogeneity in survival of 
individual chicks within a brood (Lukacs et al. 2004). Our findings are similar to the increase in survival after 3 days reported by Colwell et al. (2007). Their analysis linked improved survival with age-related behavioral changes, providing further support for increasing survival with age.

\section{Seasonal effects}

The role of seasonality on chick survival is important for managers; with limited resources, it is critical to target conservation actions where and when they will be most effective. Colwell et al. (2007) found that survival increased across the season, but most other shorebird studies documented declining chick survival as the breeding season progressed (Ruthrauff and McCaffery 2005, Brudney et al. 2013, Koczur et al. 2014). Dinsmore et al.'s (2017) finding of no significant effect of season on chick survival in Oregon thus warranted further exploration. Our re-analysis of the Oregon data, with a larger data set, found a quadratic effect of hatch date on chick survival - chicks hatched at the peak of the season had higher survival than chicks hatched early or late in the season. This effect was particularly pronounced in the chicks' first 5 days (Figure 4). Snowy Plovers in Oregon have a long breeding season; the first nest in this analysis hatched on 16 April, and the last brood fledged on 25 September. While coastal temperatures are generally mild, weather along the Oregon coast is cool and variable in spring, gradually improving by mid- to late June. Temperatures between 16 April and 25 September, $1990-2014$ ranged from 0.56 to $17.22^{\circ} \mathrm{C}$. Temperature affects rate of growth and survival to fledging in other precocial species (Schekkerman et al. 1998, Hötker and Segebade 2000, Pearce-Higgins and Yalden 2002). Although we cannot entirely rule out effects of predators, we suspect low survival early in the breeding season could be 
attributed to poor weather during the fledging period, particularly since Oregon is near the northern limit of the species' distribution. Young chicks unlucky enough to hatch during a period of prolonged cold weather would have to spend more time being brooded and have less opportunity for foraging, potentially slowing growth. Adding weather variables to our analyses post hoc improved the model and indicated that colder-thanaverage temperatures during the fledging period had a negative effect on survival for very young chicks (Figure 5). A similar effect of wetter-than-average weather was not supported.

Weather does not explain the decline in survival towards the end of the breeding season. Recreational use of Oregon's beaches is typically low until mid-June (Shelby and Tokarczyk 2002), thus human disturbance is not likely to affect survival of chicks that hatch early, but may affect survival of mid-to late-season broods. Seasonally variable predation may explain reduced chick survival at either end of the season, but we do not have quantitative data on predator numbers across the breeding season. In all years during which predator management was in effect, work began in late winter, well before the period of brood activity, but ended in late August, before late-hatching broods fledged, possibly explaining declining survival late in the brood-rearing season. These latehatching broods may be exposed to larger predator populations that include newlyindependent young predators. Extending predator management through the brood-rearing period could improve late-season chick survival. Alternatively, declining chick survival towards the end of the breeding season may have been the result of deteriorating foraging conditions or waning care as parents prepare for molt and wintering (Hemborg and Lundberg 1998, Lepage et al. 1999). 


\section{Effect of male parent age}

Chick survival increases with parent age, to a point, in many species (Pyle et al. 1991, Martin 1995, Blomqvist et al. 1997, Saunders et al. 2012, King et al. 2013). Fledging success can be influenced indirectly by earlier nesting by experienced birds (Saunders et al. 2012), or by age-related improvements in competence (Nur 1984, Forslund and Pärt 1995). In closely related Piping Plovers, Saunders et al. (2012) found that chick survival to fledging benefitted from female experience with the nesting area and earlier nesting by older parents. Because males rear most Snowy Plover broods, we expected male age to affect chick survival. Although we found no significant effect of male parent age on chick survival, broods tended by known-age males $\geq 2$ years old (ASY) hatched significantly earlier than those associated with known-age second year males $(t=4.55$, df $=912, p<0.001)$, suggesting an interaction between parent age and hatch date. Since Oregon broods hatched in early spring tend to have lower survival, it is possible that any benefit from older males is nullified by unpredictable spring weather. This potential interaction is an interesting avenue for further study.

\section{Summary}

Too often, information on vital rates is unavailable for species of conservation concern, yet this information is essential for effective management. Our analysis furthers understanding of Snowy Plover chick survival during the 28-day brood-rearing period. Our work shows that Snowy Plover chicks have significantly higher survival after their first 5 days, and that survival is greatest during the peak of the brood-rearing season. Colder-than-average weather limited chick survival, particularly during the chicks' first 5 days. We confirmed the importance of lethal predator management to Snowy Plover 
productivity; it is possible that extending predator control through the end of the broodrearing season could improve survival of chicks hatched late in the season.

\section{ACKNOWLEDGEMENTS}

Snowy Plover management in Oregon has been supported by Coos Bay District Bureau of Land Management (BLM), Siuslaw National Forest, U.S. Fish and Wildlife Service, Oregon Department of Fish and Wildlife, and Oregon Parks and Recreation Department. Mark Stern of The Nature Conservancy initiated consistent monitoring in Oregon. We thank the many field staff who have worked on plover monitoring crews over the years, particularly David J. Lauten, Kathleen A. Castelein, J. Daniel Farrar, and Adam Kotaich who collected much of the data reported here. We appreciate the support of the Recovery Unit 1 working team and the cooperation of USDA Wildlife Services. 


\section{TABLES AND FIGURES}

Table 1. Number of Snowy Plover broods in chick survival analysis by year (1990-2014) and site within Oregon. Sites are Sutton Beach (Sutt), Siltcoos River estuary (Silt), Dunes Overlook (Over), Tahkenitch Creek estuary (Tahk), Tenmile Creek estuary (Tenm), Coos Bay North Spit (CBNS), Bandon Beach (Band), New River (New R), and Floras Lake (Flor).

\begin{tabular}{rrrrrrrrrrr}
\hline Year & Sutt & Silt & Over & Tahk & Tenm & CBNS & Band & NewR & Flor & Total \\
\hline 1990 & & & & & & 6 & & & & 6 \\
1991 & & & & & & 5 & 2 & 3 & 2 & 12 \\
1992 & & & & & 7 & 8 & 3 & 2 & 4 & 24 \\
1993 & & & & & 7 & 8 & 4 & & 9 & 28 \\
1994 & & 2 & & 3 & 1 & 16 & 5 & 5 & 5 & 37 \\
1995 & & 2 & & 4 & 4 & 14 & 2 & 5 & 5 & 36 \\
1996 & & 1 & & 8 & 2 & 20 & 2 & 15 & 2 & 50 \\
1997 & 3 & 2 & & 4 & 2 & 14 & & 14 & 6 & 45 \\
1998 & 4 & 4 & & 4 & 3 & 8 & & 21 & & 44 \\
1999 & 1 & 8 & 2 & 1 & 3 & 13 & 1 & 15 & & 44 \\
2000 & 3 & 7 & 3 & 2 & 5 & 8 & & 6 & 4 & 38 \\
2001 & 1 & 1 & 4 & 8 & 5 & 9 & 2 & 9 & & 39 \\
2002 & & 4 & 5 & 7 & 6 & 8 & & 8 & 1 & 39 \\
2003 & 1 & 2 & 3 & 7 & 9 & 12 & 2 & 10 & & 46 \\
2004 & & 7 & 6 & 6 & 11 & 16 & 13 & 13 & & 72 \\
2005 & & 8 & 7 & 5 & 8 & 15 & 13 & 13 & & 69 \\
2006 & & 8 & 6 & 3 & 11 & 20 & 7 & 13 & & 68 \\
2007 & & 9 & 7 & 2 & 18 & 19 & 10 & 20 & & 85 \\
2008 & & 10 & 2 & & 10 & 27 & 3 & 15 & & 67 \\
2009 & & 11 & 5 & 2 & 12 & 23 & 5 & 20 & & 78 \\
2010 & & 13 & 16 & 3 & 18 & 16 & 11 & 15 & & 92 \\
2011 & & 16 & 32 & 14 & 7 & 47 & 13 & 15 & & 144 \\
2012 & & 17 & 28 & 21 & 6 & 53 & 8 & 7 & 1 & 141 \\
2013 & & 8 & 3 & 6 & 15 & 29 & 6 & 24 & & 91 \\
2014 & 1 & 8 & 34 & 16 & 41 & 64 & 36 & 7 & 1 & 208 \\
\hline & & & & & & & & & &
\end{tabular}


Table 2. Model selection results for daily survival of Snowy Plover chicks along the Oregon coast from 1990 to 2014. Model name shows effects on daily survival $(\varphi)$ and detection probability $(p)$. Models are ranked by descending $\Delta \mathrm{AIC}_{\mathrm{c}}$ values and are shown with model weight $\left(w_{i}\right)$, number of parameters $(K)$, and model deviance. Parameters on chick survival included chick age (t); a linear trend on chick age (Age); 3, 5, 7 and 10 day step functions of chick age (Age3, Age5, Age7, Age10); site; predator management (PM); linear (Hatch) and quadratic $\left(\mathrm{Hatch}^{2}\right)$ seasonal hatch date; male parent age (MAge); and number of colder-than-average (Cold) and wetter-than-average (Wet) days within fledging period on daily chick survival. Effects considered on detection probability included time (t), constant (.), and linear (T), and quadratic (TT) time trends.

\begin{tabular}{|c|c|c|c|c|}
\hline Model & $\Delta \mathrm{AIC}_{\mathrm{c}}{ }^{\mathrm{a}}$ & $w_{i}$ & $K$ & Deviance \\
\hline$\varphi\left(\mathrm{PM}+\right.$ Site + Hatch $^{2}+$ Age $5+$ Cold $) p(\mathrm{TT})$ & 0.00 & 0.99 & 17 & 7316.34 \\
\hline$\varphi\left(\mathrm{PM}+\right.$ Site+Hatch ${ }^{2}+$ Age5 $) p(\mathrm{TT})$ & 10.71 & 0.01 & 16 & 7329.08 \\
\hline$\varphi\left(\mathrm{PM}+\right.$ Site + Hatch $^{2}+$ Age $5+$ Wet $) p(\mathrm{TT})$ & 10.82 & 0.00 & 17 & 7327.16 \\
\hline$\varphi\left(\mathrm{PM}+\right.$ Site+Hatch ${ }^{2}+$ Age5+MAge $) p(\mathrm{TT})$ & 12.72 & 0.00 & 17 & 7329.07 \\
\hline$\varphi\left(\mathrm{PM}+\mathrm{Site}+\mathrm{Hatch}^{2}+\right.$ Age + Cold $) p(\mathrm{TT})$ & 17.91 & 0.00 & 17 & 7334.25 \\
\hline$\varphi\left(\mathrm{PM}+\right.$ Site Hatch $^{2}+$ Age $) p(\mathrm{TT})$ & 29.18 & 0.00 & 16 & 7347.54 \\
\hline$\varphi\left(\mathrm{PM}+\mathrm{Site}+\mathrm{Hatch}^{2}+\right.$ Age 7$) p(\mathrm{TT})$ & 30.43 & 0.00 & 16 & 7348.79 \\
\hline$\varphi\left(\mathrm{PM}+\mathrm{Site}+\mathrm{Hatch}^{2}+\right.$ Age3 $) p(\mathrm{TT})$ & 31.87 & 0.00 & 16 & 7350.23 \\
\hline$\varphi\left(\mathrm{PM}+\right.$ Site+Hatch ${ }^{2}+$ Age10) $p(\mathrm{TT})$ & 58.40 & 0.00 & 16 & 7376.76 \\
\hline$\varphi(\mathrm{t}) p(\mathrm{t})$ & 91.42 & 0.00 & 54 & 7332.19 \\
\hline$\varphi(\mathrm{t}) p(\mathrm{TT})$ & 104.80 & 0.00 & 30 & 7394.78 \\
\hline$\varphi\left(\mathrm{PM}+\right.$ Site $\left.+\mathrm{Hatch}^{2}\right) p(\mathrm{TT})$ & 149.04 & 0.00 & 15 & 7469.42 \\
\hline$\varphi(\mathrm{PM}+$ Site+Hatch $) p(\mathrm{TT})$ & 183.04 & 0.00 & 14 & 7505.44 \\
\hline$\varphi(\mathrm{PM}+$ Site $) p(\mathrm{TT})$ & 183.11 & 0.00 & 13 & 7507.52 \\
\hline$\varphi(\mathrm{PM}) p(\mathrm{TT})$ & 207.60 & 0.00 & 5 & 7548.11 \\
\hline$\varphi(\mathrm{Yr}) p(\mathrm{TT})$ & 219.02 & 0.00 & 29 & 7511.03 \\
\hline$\varphi(\mathrm{t}) p(\mathrm{~T})$ & 266.98 & 0.00 & 29 & 7558.99 \\
\hline
\end{tabular}

${ }^{\text {a }}$ The AICc value of the best model was 7350.52 . 


\section{LIST OF FIGURES}

Figure 1. Snowy Plover monitoring locations in coastal Oregon, 1990-2014.

Figure 2. Daily survival estimates (mean and 95\% CI) of Snowy Plover chicks during the 28-day fledging period based on model constraining age as a linear effect.

Figure 3. Probability of surviving to fledge at 28 days (95\% CI) for Snowy Plover chicks at 9 sites along the Oregon coast, 1990-2014.

Figure 4. Effect of age and hatch date (mean and 95\% CI) on Snowy Plover daily chick survival along the Oregon coast, 1990 - 2014.

Figure 5. Effect of age and colder-than-average weather during fledging period (mean and $95 \%$ CI) on daily survival of Snowy Plover chicks along the Oregon coast, 1990 2014. 


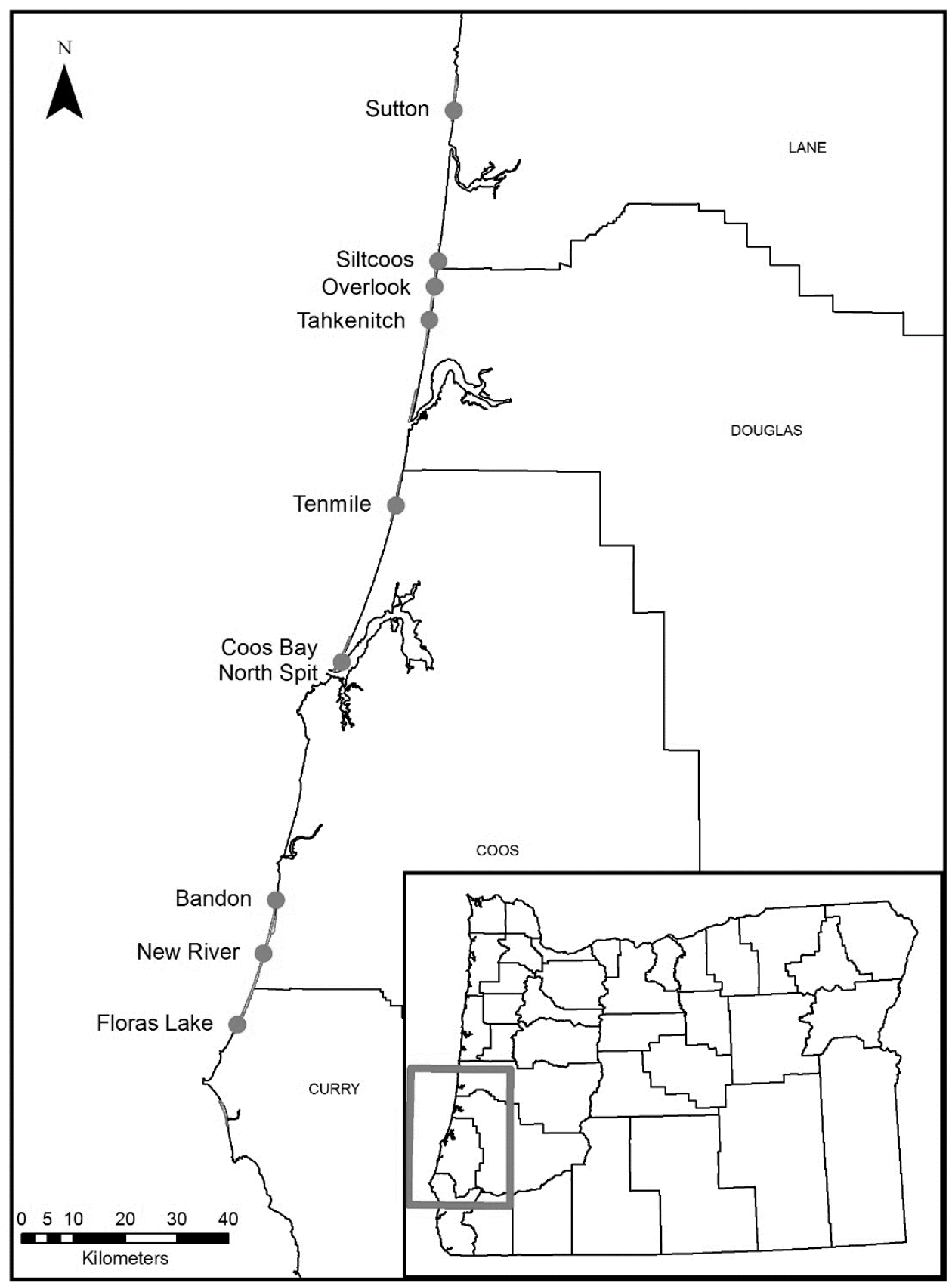

Figure 1. Snowy Plover monitoring locations in coastal Oregon, 1990-2014. 


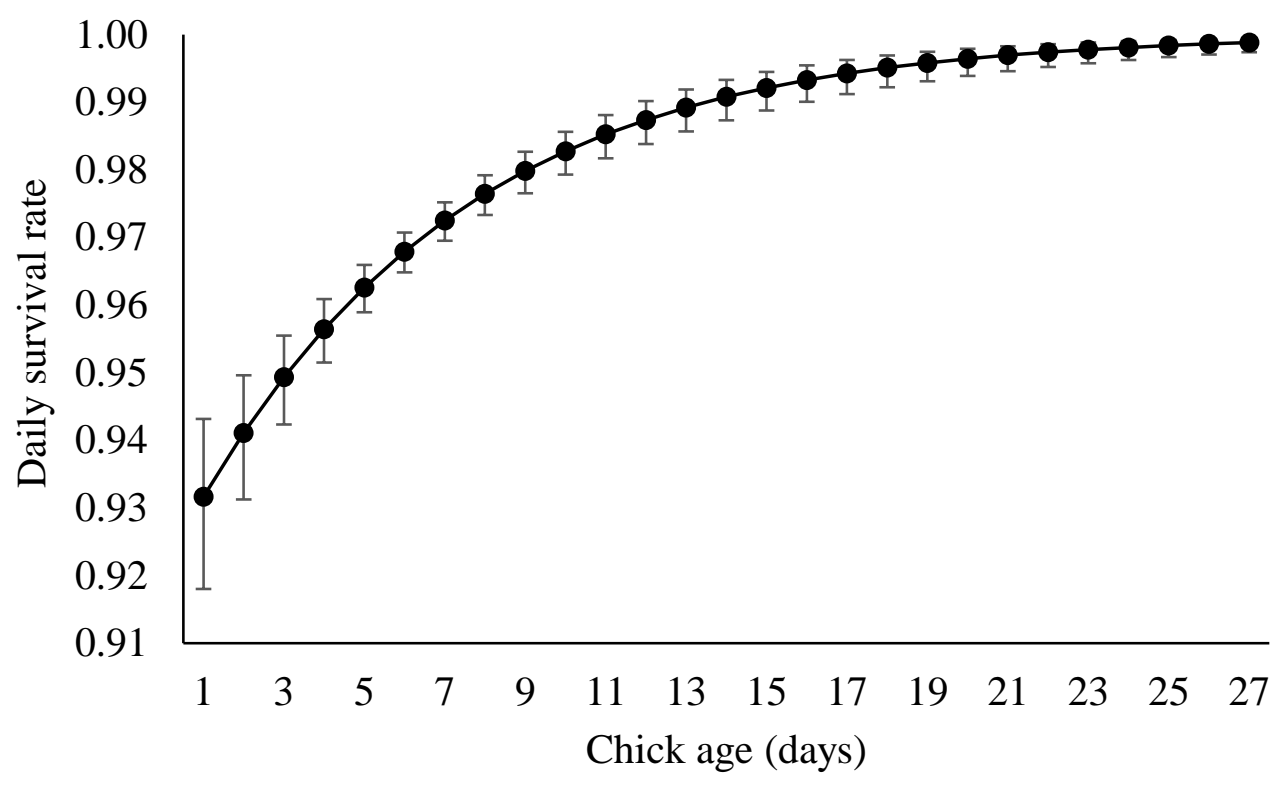

Figure 2. Daily survival estimates (mean and 95\% CI) of Snowy Plover chicks during the 28-day fledging period based on model constraining age as a linear effect. 


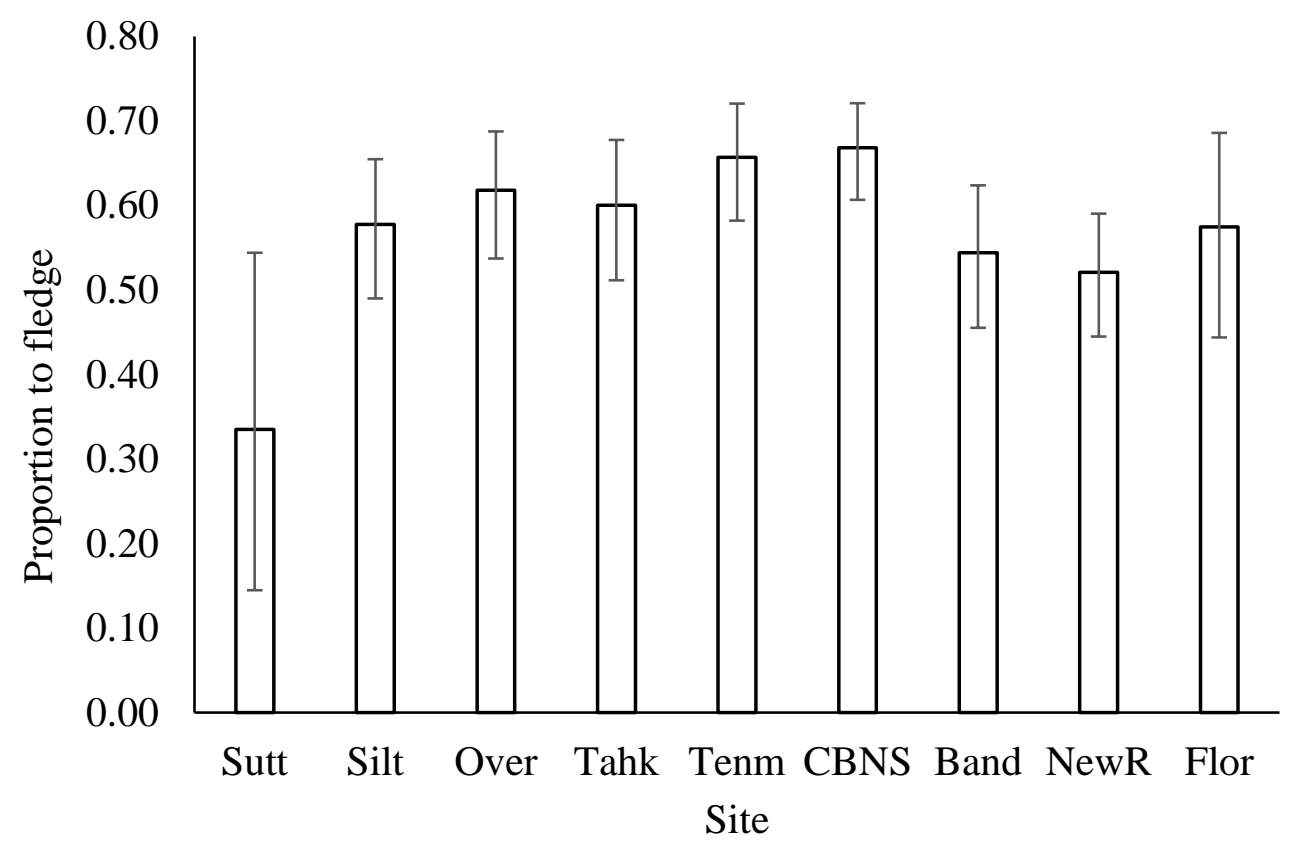

Figure 3. Probability of surviving to fledge at 28 days (95\% CI) for Snowy Plover chicks at 9 sites along the Oregon coast, 1990-2014. Sites are Sutton Beach (Sutt), Siltcoos River estuary (Silt), Dunes Overlook (Over), Tahkenitch Creek estuary (Tahk), Tenmile Creek estuary (Tenm), Coos Bay North Spit (CBNS), Bandon Beach (Band), New River (New R), and Floras Lake (Flor). 


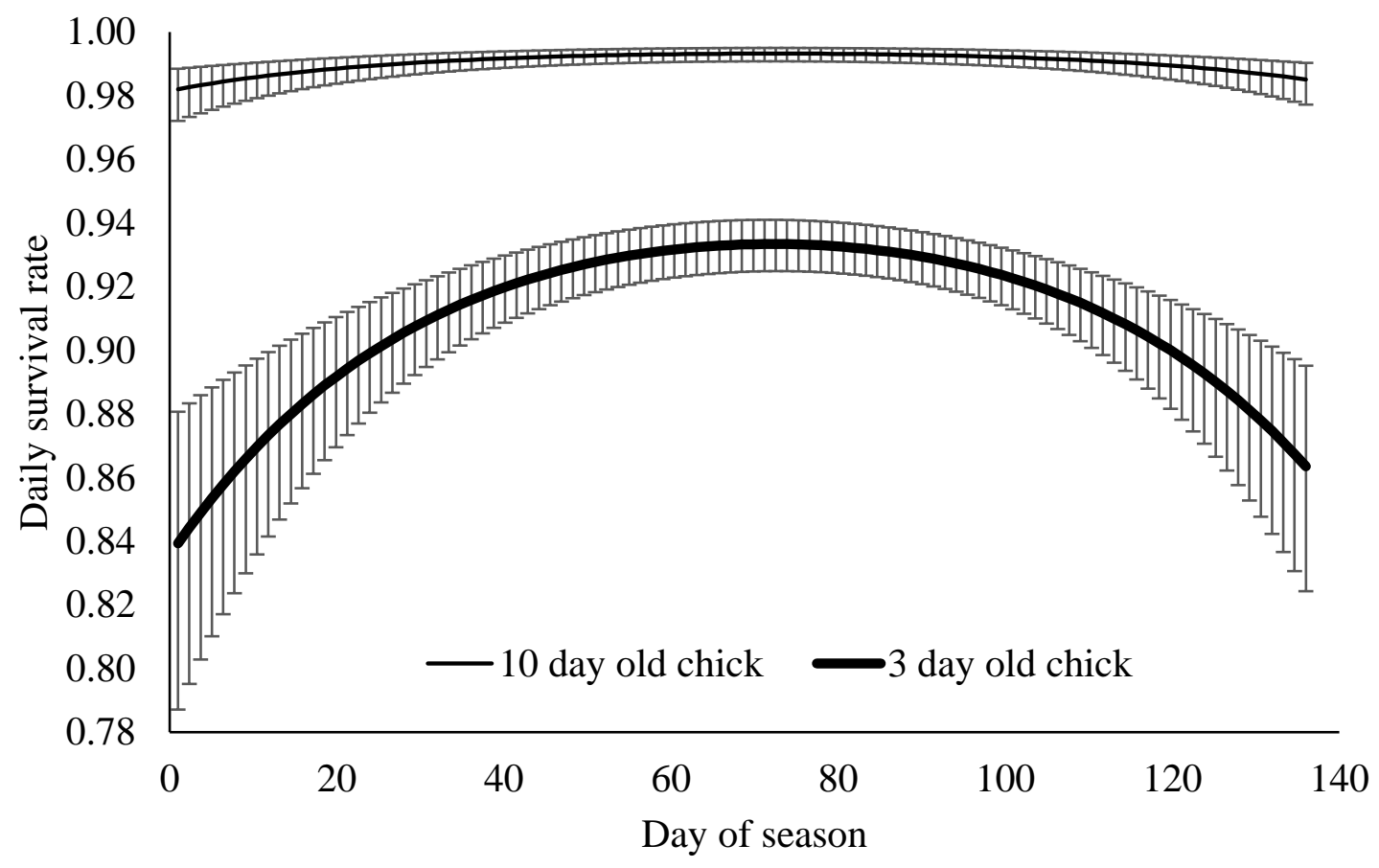

Figure 4. Effect of age and hatch date (mean and 95\% CI) on Snowy Plover daily chick survival along the Oregon coast, 1990 - 2014. Day 1 of season corresponds to 14 April, day 136 corresponds to 29 August. Mean hatch date $=27$ June. 


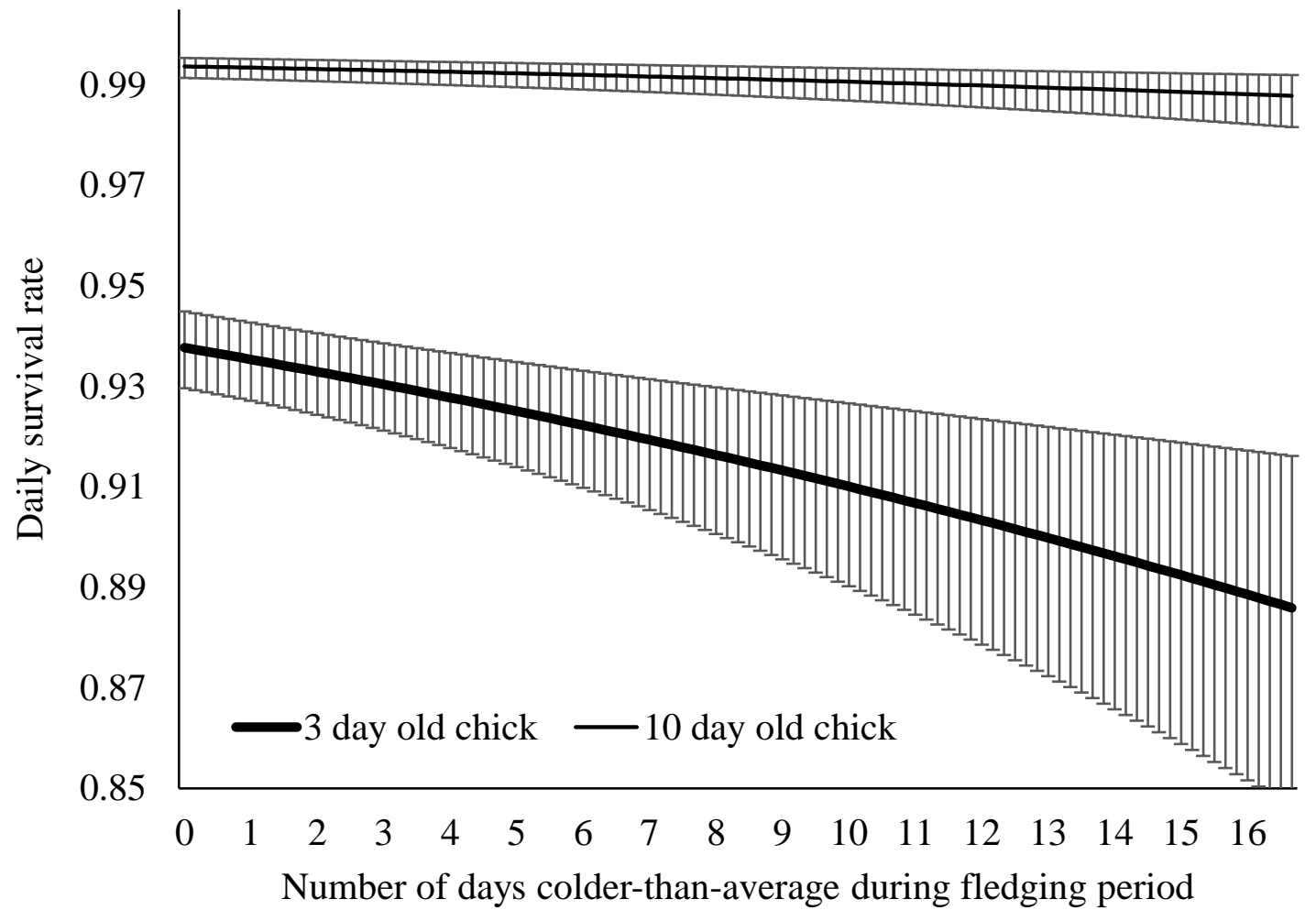

Figure 5. Effect of age and colder-than-average weather during fledging period (mean and 95\% CI) on daily survival of Snowy Plover chicks along the Oregon coast, 1990 2014. 


\section{LITERATURE CITED}

Akaike, H. (1973). Information theory and an extension of the maximum likelihood principle. In International Symposium on Information Theory, 2nd ed. (B. N. Petran and F. Csaki, Editors). Budapest, Hungary. pp. 267-281.

Arnold, T. W. (2010). Uninformative parameters and model selection using Akaike's Information Criterion. The Journal of Wildlife Management 74:1175-1178.

Blomqvist, D., O. C. Johansson, and F. Götmark (1997). Parental quality and egg size affect chick survival in a precocial bird, the lapwing (Vanellus vanellus). Oecologia 110:18-24.

Brudney, L. J., T. W. Arnold, S. P. Saunders, and F. J. Cuthbert (2013). Survival of Piping Plover (Charadrius melodus) chicks in the Great Lakes Region. The Auk 130:150-160.

Burnham, K. P., and D. R. Anderson (2002). Model Selection and Multi-model Inference. 2nd Edition. Springer-Verlag.

Catlin, D. H., J. H. Felio, and J. D. Fraser (2011). Effect of great-horned owl trapping on chick survival in piping plovers. The Journal of Wildlife Management 75:458462.

Catlin, D. H., J. D. Fraser, and J. H. Felio (2015). Demographic responses of piping plovers to habitat creation on the Missouri river. Wildlife Monographs 192:1-42.

Colwell, M. A., S. J. Hurley, J. N. Hall, and S. J. Dinsmore (2007). Age-related survival and behavior of Snowy Plover chicks. The Condor 109:638-647.

Cormack, R. M. (1964). Estimates of survival from the sighting of marked animals. Biometrics 51:429-438. 
DeRose-Wilson, A., J. D. Fraser, S. M. Karpanty, and D. H. Catlin (2013). Nest-site selection and demography of Wilson's Plovers on a North Carolina barrier island. Journal of Field Ornithology 84:329-344.

Dietz, N. J., P. J. Bergmann, and L. D. Flake (1994). A walk-in trap for nesting ducks. Wildlife Society Bulletin 22:19-22.

Dinsmore, S. J., E. P. Gaines, S. F. Pearson, D. J. Lauten, and K. A. Castelein (2017). Factors affecting Snowy Plover chick survival in a managed population. The Condor:34-43.

Forslund, P., and T. Pärt (1995). Age and reproduction in birds — hypotheses and tests. Trends in Ecology \& Evolution 10:374-378.

Hemborg, C., and A. Lundberg (1998). Costs of overlapping reproduction and moult in passerine birds: an experiment with the pied flycatcher. Behavioral Ecology and Sociobiology 43:19-23.

Hötker, H., and A. Segebade (2000). Effects of predation and weather on the breeding success of Avocets (Recurvirostra avosetta). Bird Study 47:91-101.

Jolly, G. M. (1965). Explicit estimates from capture-recapture data with both death and immigration-stochastic models. Biometrika 64:225-247.

King, R. S., J. L. Espenshade, S. K. Kirkpatrick-Wahl, M. K. Lapinski, I. Malekan, and J. M. Ricket (2013). Whooping crane (Grus americana) chick mortality and management intervention. Wildlife Biology 19:420-428.

Koczur, L. M., A. E. Munters, S. A. Heath, B. M. Ballard, M. C. Green, S. J. Dinsmore, and F. Hernández (2014). Reproductive success of the American Oystercatcher (Haematopus palliatus) in Texas. Waterbirds 37:371-380. 
Lafferty, K. D., D. Goodman, and C. P. Sandoval (2006). Restoration of breeding by Snowy Plovers following protection from disturbance. Biodiversity \& Conservation 15:2217-2230.

Lepage, D., A. Desrochers, and G. Gauthier (1999). Seasonal decline of growth and fledging success in Snow Geese (Anser caerulescens): an effect of date or parental quality? Journal of Avian Biology 30:72-78.

Lukacs, P. M., V. J. Dreitz, F. L. Knopf, and K. P. Burnham (2004). Estimating survival probabilities of unmarked dependent young when detection is imperfect. The Condor 106:926-931.

Marchetti, K., and T. Price (1989). Differences in the foraging of juvenile and adult birds: the importance of developmental constraints. Biological Reviews 64:51-70.

Martin, K. (1995). Patterns and mechanisms for age-dependent reproduction and survival in birds. Integrative and Comparative Biology 35:340-348.

Mehl, K. R., K. L. Drake, G. W. Page, P. M. Sanzenbacher, S. M. Haig, and J. E. Thompson (2003). Capture of breeding and wintering shorebirds with leg-hold noose-mats. Journal of Field Ornithology 74:401-405.

Menne, M.J., I. Durre, B. Korzeniewski, S. McNeal, K. Thomas, X. Yin, S. Anthony, R. Ray, R.S. Vose, B.E.Gleason, and T.G. Houston (2012). Global Historical Climatology Network - Daily (GHCN-Daily), Version 3.24. NOAA National Climatic Data Center. http://doi.org/10.7289/V5D21VHZ 6 June 2018].

Muir, J. J., and M. A. Colwell (2010). Snowy Plovers select open habitats for courtship scrapes and nests. The Condor 112:507-510. 
Mullin, S. M., M. A. Colwell, S. E. McAllister, and S. J. Dinsmore (2010). Apparent survival and population growth of Snowy Plovers in coastal Northern California. Journal of Wildlife Management 74:1792-1798.

Neuman, K. K., G. W. Page, L. E. Stenzel, J. C. Warriner, and J. S. Warriner (2004). Effect of mammalian predator management on Snowy Plover breeding success. Waterbirds 27:257-263.

Nur, N. (1984). Increased reproductive success with age in the California Gull: due to increased effort or improvement of skill? Oikos 43:407-408.

Page, G. W., and L. E. Stenzel (1981). The breeding status of the Snowy Plover in California. Western Birds 12:1-40.

Page, G. W., L. E. Stenzel, J. C. Warriner, J. S. Warriner, and P. W. Paton (2009). Snowy Plover (Charadrius alexandrinus). The Birds of North America Online.

Pearce-Higgins, J. W., and D. W. Yalden (2002). Variation in the growth and survival of Golden Plover (Pluvialis apricaria) chicks. Ibis 144:200-209.

Pienkowski, M. M. (1984). Behaviour of young Ringed Plovers (Charadrius hiaticula) and its relationship to growth and survival to reproductive age. The Ibis 126:133155.

Powell, A. N. (1992). The effects of early experience on the development, behavior, and survival of shorebirds. Ph.D. dissertation, University of Minnesota, St. Paul, MN, USA.

Pyle, P., L. B. Spear, W. J. Sydeman, and D. G. Ainley (1991). The effects of experience and age on the breeding peformance of Western Gulls. The Auk 108:25-33. 
Rizzolo, D. J., and J. A. Schmutz (2007). Egg flotation estimates Nest Age for Pacific and Red-throated Loons. Waterbirds 30:207-213.

Ruhlen, T. D., S. Abbott, L. E. Stenzel, and G. W. Page (2003). Evidence that human disturbance reduces Snowy Plover chick survival. Journal of Field Ornithology 74:300-304.

Ruthrauff, D. R., and B. J. McCaffery (2005). Survival of Western Sandpiper broods on the Yukon-Kuskokwim Delta, Alaska. The Condor 107:597-604.

Sandercock, B. K., D. B. Lank, and F. Cooke (1999). Seasonal declines in the fecundity of Arctic-breeding sandpipers: different tactics in two species with an invariant clutch size. Journal of Avian Biology 30:460-468.

Sandercock, B. K., T. Székely, and A. Kosztolányi (2005). The effects of age and sex on the apparent survival of Kentish Plovers breeding in southern Turkey. The Condor 107:583-596.

Saunders, S. P., E. A. Roche, T. W. Arnold, and F. J. Cuthbert (2012). Female site familiarity increases fledging success in Piping Plovers (Charadrius melodus). The Auk 129:329-337.

Schekkerman, H., M. W. J. Van Roomen, and L. G. Underhill (1998). Growth, behaviour of broods and weather-related variation in breeding productivity of Curlew Sandpipers (Calidris ferruginea). Ardea:153-168.

Schekkerman, H., and G. H. Visser (2001). Prefledging energy requirements in shorebirds: energetic implications of self-feeding precocial development. The Auk 118:944-957.

Seber, G. A. F. (1965). A note on the multiple recapture census. Biometrika 52:249-259. 
Shelby, B., and J. Tokarczyk (2002). Oregon shore recreational use study. Oregon Parks and Recreation Department. https://digital.osl.state.or.us/islandora/object/osl:11696

Stahl, J. T., and M. K. Oli (2006). Relative importance of avian life-history variables to population growth rate. Ecological Modelling 198:23-39.

Sydeman, W. J., J. F. Penniman, T. M. Penniman, P. Pyle, and D. G. Ainley (1991). Breeding performance in the Western Gull: effects of parental age, timing of breeding and year in relation to food availability. Journal of Animal Ecology 60:135-149.

Thomas, S. M., J. E. Lyons, B. A. Andres, E. E. T-Smith, E. Palacios, J. F. Cavitt, J. Andrew Royle, S. D. Fellows, K. Maty, W. H. Howe, E. Mellink, et al. (2012). Population size of Snowy Plovers breeding in North America. Waterbirds 35:114.

U.S. Department of Agriculture and U.S. Department of Interior (2002). Predator damage management to protect the federally threatened Pacific coast population of the Western Snowy Plover. Prepared by USDA, APHIS, Wildlife Services Program and the Siuslaw National Forest; USDI, Fish and Wildlife Service Region 1 and Bureau of Land Management Coos Bay District; and in cooperation with the Oregon Department of Fish and Wildlife, and Oregon Parks and Recreation Department. Portland, OR.

U. S. Fish and Wildlife Service (1993). Determination of Threatened Status for the Pacific Coast Population of the Western Snowy Plover. Federal Register $58: 12864-12874$. 
U.S. Fish and Wildlife Service (2007). Recovery Plan for the Pacific Coast Population of the Western Snowy Plover (Charadrius alexandrinus nivosus). In 2 volumes. [Online.] Available at http://www.fws.gov/arcata/es/birds/WSP/documents/RecoveryPlanWebRelease_0 9242007/WSP\%20Final\%20RP\%2010-1-07.pdf.

Visser, G. H., and R. E. Ricklefs (1993). Temperature regulation in neonates of shorebirds. The Auk 110:445-457.

Warriner, J. S., J. C. Warriner, G. W. Page, and L. E. Stenzel (1986). Mating system and reproductive success of a small population of polygamous Snowy Plovers. The Wilson Bulletin 98:15-37.

Westerskov, K. (1950). Methods for Determining the Age of Game Bird Eggs. The Journal of Wildlife Management 14:56-67.

White, G. C., and K. P. Burnham (1999). Program MARK: survival estimation from populations of marked animals. Bird Study 46:S120-S139.

Wiedemann, A. M. (1984). Ecology of Pacific Northwest Coastal Sand Dunes: A Community Profile. [Online.] Available at http://www.osti.gov/scitech/biblio/6685464.

Wiedemann, A. M. (1987). The ecology of European beachgrass. Oregon Department of Fish and Wildlife. $15 \mathrm{pp}$. 


\title{
CHAPTER 3. SNOWY PLOVER JUVENILE SURVIVAL IN OREGON
}

Eleanor P. Gaines ${ }^{1}$, Stephen J. Dinsmore ${ }^{2}$, and Michael T. Murphy ${ }^{3}$

${ }^{1}$ Oregon Biodiversity Information Center - Institute for Natural Resources, Portland State University, PO Box 751, Portland, OR USA

${ }^{2}$ Department of Natural Resource Ecology and Management, 339 Science II, Iowa State University, Ames, IA USA

${ }^{3}$ Biology Department, Portland State University, PO Box 751, Portland, OR USA

\begin{abstract}
Effective conservation of threatened species relies on accurate estimation of vital rates and a thorough understanding of the processes that drive them. We estimated age-specific survival of Western Snowy Plovers (Charadrius nivosus nivosus) over 25 years (19902014) along the Oregon Coast, near the northern end of the species' range. The mean probability of surviving from fledging to year one was $0.53 \pm 0.02$ (mean $\pm \mathrm{SE}$ ). Combined with previously estimated survival from hatching to fledging, survival probability from hatching to reproduction in year one was 0.32 . Survival for adults after the first year was significantly higher $(0.73 \pm 0.01)$. Juvenile survival followed a negative trend over the early years of our study, before rebounding slightly after implementation of predator management across the study area, though this improvement did not outweigh the overall negative trend. We found no sex differences in juvenile survival or detection probability, and no support for variation in juvenile survival based on other temporal and individual covariates.
\end{abstract}

Keywords: Charadrius nivosus, age-specific survival, predator management 


\section{INTRODUCTION}

Survival and recruitment of young are important contributors to population growth, and understanding the relative importance of these life history variables is key to effective conservation of threatened populations (Crouse et al. 1987, Stahl and Oli 2006, Maness and Anderson 2013). Although accurate estimates of juvenile survival are an important prerequisite to evaluating a population's viability (Sandercock 2003), this vital rate is notoriously difficult to document in all birds, but especially precocial species, because of the difficulty of following young after they leave the nest, higher dispersal, and lower return rates of young birds relative to adults (Pulliam et al. 1992, Lukacs et al. 2004, Sandercock et al. 2005).

Shorebird populations are experiencing alarming declines in the US and globally (Brown et al. 2001, International Wader Study Group 2003). The Pacific Coast population of the Western Snowy Plover (Charadrius nivosus nivosus), for instance, occurs within 80 kilometers of the Pacific Coast from Baja California Sur, Mexico, to Washington, U.S.A. (Page et al. 2009), and is listed as threatened by the U. S. Fish and Wildlife Service because of poor productivity and survival (U. S. Fish and Wildlife Service 1993, U. S. Fish and Wildlife Service 2007, Thomas et al. 2012). Limiting factors include increasing predation from synanthropic predators (Neuman et al. 2004), human disturbance (Ruhlen et al. 2003, Lafferty et al. 2006), and habitat loss to development, exotic vegetation, and recreational use (Page and Stenzel 1981, U. S. Fish and Wildlife Service 1993, 2007, Page et al. 2009, Galbraith et al. 2002, Muir and Colwell 2010). These factors are intertwined. For example, human-associated trash attracts predators, and exotic vegetation provides cover for non-native and invasive native predators. Along 
the Oregon coast, intensive and coordinated management to benefit Snowy Plovers addresses all these limiting factors and has been ongoing since 1990. Management has been effective; Snowy Plover populations in Oregon have grown almost an order of magnitude over the last 25 years (Table 1). Despite this success, managers need to know how their actions affect individual life stages to allow for effective decision-making as populations approach recovery goals.

Snowy Plovers are well-studied along the Pacific Coast, and juvenile survival has been estimated for populations outside of Oregon. Stenzel et al. (2007) used a Barker model to account for permanent emigration in their estimate of juvenile survival along the central California coast between 1984 and 1999. Mullin et al. (2010) estimated juvenile apparent survival for the small population of Snowy Plovers in Northern California, and classified this population as a sink. Although their estimates are roughly similar, vital rates often vary spatially and temporally, and effective conservation requires a thorough understanding of local population dynamics (Anders and Marshall 2005, McNew et al. 2012, Eberhart-Phillips and Colwell 2013). We thus felt it important, because environmental and management conditions in Oregon are quite different from those in California, to provide an independent estimate of juvenile survival for the Oregon population. The Oregon population is the largest north of the central California coast, and is at the northern end of the species' range (Figure 1; a small population occurs farther north, along the Long Beach peninsula in Washington). This population has been color banded since 1990 and individuals exhibit high levels of site fidelity, providing an excellent opportunity to explore age-specific survival. Although the Oregon population has been intensively managed since 1990, no estimates of juvenile survival have been 
reported. Here, we examine temporal, environmental, and management factors influencing Snowy Plover age-specific survival and detection probability using a large, well-studied, banded population and 25 years of data, and compare our findings to existing estimates of juvenile survival. Although we also report an estimate of adult survival, our primary interest here is to document juvenile survival during the postfledging period, from fledging at 28 days to the following spring, and to explore factors that may predict survival during this period. We investigate adult survival more fully in a separate analysis.

\section{METHODS}

\section{Study Area}

As part of a long-term monitoring project, we studied juvenile Snowy Plovers (defined as birds between fledging age, or 28 days after hatching, and 1 April of the following spring) from 1990 to 2014 at nine sites along the Oregon coast. The Oregon population is geographically isolated; the nearest nesting sites in California and Washington are over $220 \mathrm{~km}$ away. Occupied habitat covered approximately $17.7 \mathrm{~km}^{2}$ along a $137 \mathrm{~km}$ stretch of the Oregon coast, and included habitat typical of nesting Snowy Plovers: open ocean beaches, sand spits, ocean over-wash sites, sand dunes, and estuarine sand flats. Vegetation in these areas is sparse, but much of Oregon's dunes are dominated by nonnative, invasive European beachgrass (Ammophila arenaria) which over time has stabilized the naturally ephemeral dune system, resulting in densely vegetated, steep dunes that are unsuitable for plover use and provide cover for predators (Wiedemann 1984, 1987, Muir and Colwell 2010). Although plovers occasionally nested at other Oregon beaches (two of 3,639 known nests during the study period), these sites 
encompassed all regularly occupied coastal habitat in Oregon. Sites varied in ownership, management, and predation and recreation pressure.

Breeding season management for the Snowy Plover in Oregon is intensive and includes habitat restoration and maintenance, recreation restrictions, and an integrated predator management plan that incorporates both lethal and non-lethal actions. Initial management to counter high levels of predation included trash and carcass removal from nesting beaches, harassment of individual predators, and installation of protective exclosures over plover nests (Dinsmore et al. 2014). In 2002, land managers instituted an integrated predator management plan at Coos Bay North Spit, Bandon Beach, and New River that included lethal removal of plover predators (U.S. Department of Agriculture and U.S. Department of Interior 2002, Dinsmore et al. 2017). In 2004, lethal predator management was extended to all nine sites and continued for the duration of the study. Predator management was conducted by USDA APHIS-Wildlife Services in coordination with the Recovery Unit 1 Snowy Plover Working Team, and primarily targeted American Crows (Corvus brachyrhynchos), Common Ravens (Corvus corax), and nonnative red fox (Vulpes vulpes). Predator management activities began before plover nesting (typically in February each year) and continued through August. See Dinsmore et al. (2017) for further details on the predator management program.

\section{Field Methods}

We began marking chicks and adults in 1990 and continued through 2014. See Dinsmore et al. (2014) for nest location and monitoring methods. Chicks were captured by hand and marked at or near the nest, usually within 24 hours of hatching. We banded chicks with brood-specific two band color combinations consisting of a U. S. Geological Survey 
(USGS) metal band covered with plastic tape on one leg, and a Darvic (Avinet, Portland, ME, USA) color band on the other (Dinsmore et al. 2017). Chicks were pursued for no more than two minutes and no further than 90 feet, and were released at the nest site after banding. Chicks that returned in subsequent seasons were recaptured, individually identified by the USGS band, and given unique adult combinations. Adults were captured on or near the nest using walk-in traps (Dietz et al. 1994) and noose carpets (Mehl et al. 2003). Adults were marked with unique four band combinations consisting of a USGS band covered with plastic tape and three Darvic bands, two on each tarsometatarsus. Trapping efforts were limited to 20 minute at each nest and adults and chicks were released within 20 minutes of capture. We did not attempt to capture adults or chicks during inclement weather (including high wind, excessive heat, or cold). All banding operations followed standard bird banding techniques (Gustafson et al. 1997) and the Bander's Code of Ethics (U. S. Geologic Survey Bird Banding Laboratory 2011). Most chicks in the study area were banded $(85 \% \pm 0.02)$, but each year a small number were not (Table 2) either because the last egg in a clutch had not yet hatched at the time of banding, or because the nest was not detected before hatching. Unbanded individuals were not included in our analysis.

After banding, we surveyed for broods approximately weekly throughout the remaining nesting season to document the number of chicks fledged from each brood. Hatch-year birds seen any point after 28 days were considered fledged, and were included in our analysis. Subsequently, individuals were resighted annually from April through July. We considered fledglings to have survived to adulthood if they were observed in the study area at least once between April and July after their hatch year. We recorded sex of 
individuals that returned to Oregon in subsequent years based on plumage and behavior characteristics; sex was not identifiable in the birds' first year.

This work was permitted by Portland State University IACUC number

PSU13.11.25.1, USFWS recovery permits TE839094 and TE39372B, U.S. Fish and Wildlife Service banding permits 21825 and 23854, and Oregon Department of Fish and Wildlife annual scientific take authorizations.

\section{Age-specific Survival Modeling}

We compiled 25-occasion (1990 - 2014) encounter histories for 1,522 individuals banded as chicks in Oregon that survived to fledge (at 28 days) between 1990 and 2013. We used a live-recaptures Cormack-Jolly-Seber (CJS; Cormack 1964, Jolly 1965, Seber 1965) model in Program MARK ver. 8.2 (White and Burnham 1999) to generate maximum likelihood estimates of apparent survival $(\varphi)$ and detection probability $(p)$. We estimate apparent survival here because limitations on existing data did not support an analysis of true survival. Apparent survival underestimates true survival because it confounds permanent emigration with death. In our study, this bias is mitigated to some extent by Snowy Plovers' relatively high natal philopatry and breeding site fidelity, high encounter probability, and our large study area (Sandercock et al. 2005, Maness and Anderson 2013). Regardless, survival estimates from this analysis should be considered a minimum. Despite the bias, we maintain that local (apparent) survival provides valuable information for managers (Méndez et al. 2018). We used a two age-class structure (juveniles and adults) because we expected juvenile survival and detection probability to be lower than that of adults (Sandercock 2003, Stenzel et al. 2007, Mullin et al. 2010). Earlier analysis of our data did not support three age classes. First-year birds were treated 
as juveniles and all birds older than 1 year were considered adults because Snowy Plovers breed as 1 year olds (Warriner et al. 1986, Sandercock et al. 2005). We tested a fully time dependent model with age structure $(\varphi[\mathrm{Age} \mathrm{yr} / \mathrm{yr}] p[\mathrm{Age} \mathrm{yr} / \mathrm{yr}])$ for goodness of fit using the median $\hat{c}$ procedure in MARK. The median $\hat{c}$ procedure indicated the data were slightly overdispersed, so we adjusted the variance inflation factor $(\hat{c})$ for all models to 1.0259304 .

In this analysis, we were interested in juvenile survival, so we held adult survival and detection probability constant in all models (.). We used a hierarchical approach to model effects on detection probability of juveniles first (no effect [.], year [Yr], age [Age], sex [Sex], and linear [T] and quadratic [TT] time trends across years) using a biologically plausible standard model for survival $(\varphi[$ Age $\mathrm{Yr} /]$.$) . We used the most$ parsimonious model for detection probability to model effects on annual apparent survival (no effect [.], year [Yr], age [Age], and linear [T] and quadratic [TT] time trends across years). After selecting a base survival model, we substituted annual covariates (annual number of chicks fledged [FlPop], adult population size [AdPop], predator management [PM], winter weather conditions [Wet], [Cold], and large scale climate patterns $[\mathrm{MEI}]$ ) for time to see if these covariates better explained annual variation in juvenile survival. To avoid misleading results due to parameter collinearity we did not include multiple time-related covariates in the same model (Manness and Anderson 2013). Finally we added individual covariates (sex [Sex], hatch date [Hatch], [Hatch $\left.{ }^{2}\right]$, and site [Site]) from the pre-fledging period to serve as predictors of post-fledging survival. The rationale for including each covariate is articulated below. 
Population size - The Oregon Snowy Plover population grew over the course of the study. To identify possible density dependent effects on juvenile survival, we included annual covariates for the total number of chicks fledged (FIPop) and adult population size (AdPop) during the individual's hatch year. The number of chicks fledged was the total number of banded and unbanded chicks surviving at least 28 days as reported by field crews each year. Adult population size was determined by weekly surveys of banded adults observed between early May and early July (the peak nesting period) each year. We estimated the number of unbanded adults present during the nesting season by counting all unbanded birds observed during 10-day intervals from early May to early July, subtracting the number of adults subsequently banded that year, and selected the 10-day interval with the highest number of unbanded adults. This estimate of unbanded adults was added to the count of banded birds for an estimate of total adult population during each breeding season.

Predator management - We previously documented positive effects of predator management on nest survival (Dinsmore et al. 2014) and chick survival to fledging (Dinsmore et al. 2017), and here test if a similar benefit might extend to the juvenile survival period. Although predator management activities were limited to the breeding season (and thus mainly occurred outside the juvenile survival period), and focused primarily on nest and chick predators, we hypothesized that they may provide recently fledged juveniles with a reduced predator environment. Additionally, we expected that juveniles fledged in years with predator management would be able to spend more time foraging and less time avoiding predators, both before and after fledging, and hence might be in better condition to survive their first winter (Saunders et al. 2014). Thus, we 
predicted that birds fledged in years with predator management might have higher survival. Predator management was initiated in Oregon at 3 sites in 2002, and in 2004 it was extended to all sites for the duration of the study. We coded an individual covariate (PM) indicating whether or not a bird fledged in a year with or without predator management. All individuals fledged from 1990 through 2001 did not receive predator management, and all birds fledged from 2004 to 2014 did. For birds fledged in 2002 and 2003, we coded PM based on natal site. In these years, only birds originating from Coos Bay North Spit, Bandon, and New River were coded as having received predator management.

Climate and weather - We expected that climatic conditions over an individual's first winter may affect survival. Oregon juveniles may winter locally or migrate to Washington or as far south as Baja California (Oregon Biodiversity Information Center, unpublished data, Page et al. 2009). Thus, we included an annual covariate to reflect broad scale climate conditions over the winter months along the Pacific Coast. We used the sum of the monthly multivariate El Niño-Southern Oscillation indices (MEI) for September-March, 1990-2014 (available from the National Oceanographic and Atmospheric Administration [NOAA] Earth System Research Laboratory Physical Sciences Division, https://www.esrl.noaa.gov/psd/enso/mei/) as a proxy for broad scale regional winter climate conditions (Stenzel et al 2007, Wolter and Timlin 2011).

We also explored local winter weather conditions by averaging the number of colder-than-average (Cold) and wetter-than average (Wet) days each winter at three sites across the plover's winter range. We retrieved daily total precipitation and minimum temperature data from the NOAA (Menne et al. 2012) collected between October and 
February each winter (winters of 1990-91 to 2013-14) near three Snowy Plover wintering sites. Data collection sites were North Bend Oregon Regional Airport (Station USW00024284), Eureka Weather Forecast Office Woodley Island California (Station USW00024213), and San Francisco International Airport California (Station USW00023234) and were chosen based on proximity to known wintering sites used by Oregon birds and completeness of data during our study period. We identified cold winter weather by summing the number of days each winter that fell below one standard deviation of the mean daily minimum winter temperature across the three sites. Between 1990 and 2014, the mean minimum temperature between 1 October and 28 February was $6.71 \pm 3.01^{\circ} \mathrm{C}($ mean $\pm \mathrm{SD})$. Thus we counted the days each winter with minimum daily temperature that fell below $3.70^{\circ} \mathrm{C}$ (Cold). The number of colder-than-average days each winter ranged from 8 to 39. Likewise, we identified wet winter weather by summing the number of days each winter with precipitation more than one standard deviation above the mean daily precipitation across the three sites. Between 1990 and 2014, the mean daily precipitation between 1 October and 28 February was $0.46 \pm 0.75 \mathrm{~cm}$. Thus we counted the number of days each winter with total precipitation greater than $1.21 \mathrm{~cm}$ (Wet). The number of wetter-than-average days each winter ranged from 4 to 32 .

Sex - Most Snowy Plover populations exhibit a male-biased adult sex ratio (ASR; Wilson and Hardy 2002, Page et al. 2009). Eberhart-Phillips et al. (2017) found the strongly male-biased ASR observed in a Snowy Plover population in Mexico was largely driven by variations in sex-specific survival of juveniles, though the cause of this variation was not clear. Similarly, Sandercock et al. (2005) found a male skewed ASR largely caused by differential juvenile survival of closely related Kentish Plovers 
(Charadrius alexandrinus). In central California, Stenzel et al. (2007) documented the sex ratio of adults entering their first breeding season at 0.5 . Coupled with the assumption of an even sex ratio at hatch (Székely et al. 2004), this suggested no evidence for variable juvenile survival by sex. Instead, they attributed the observed male-skewed ASR to sex differences in true survival at the adult stage, likely because of longer breeding dispersal distances by females (Stenzel et al. 2011). Although we had no data on the sex of birds that did not return as adults to our study area, we included sex as a covariate on juvenile survival for the birds that were resighted as adults in an attempt to identify potential variation in juvenile apparent survival by sex.

Hatch date -Snowy Plovers fledge chicks over a long, five month breeding season. We suspected that survival over the juvenile period would vary by fledge date. Chicks fledged early in the season would have to survive longer to return the following spring than their late-fledging counterparts (Stenzel et al. 2007). Alternatively, chicks fledged early in the season would have more time to develop foraging skills, fat stores, and experience that could result in higher overwinter survival (Naef- Daenzer et al. 2001, Maness and Anderson 2013, Saunders et al. 2014). We considered all chicks observed after 28 days to have fledged. However, we did not always observe chicks on the fledge date, thus we included an individual covariate for hatch date (Hatch) as a proxy for fledge date (day 1 = April 22). We also included a quadratic effect of hatch date (Hatch2) to capture possible non-linear survival of individuals hatched mid-season.

Site - We found that chick survival in Oregon varied by nesting site (Dinsmore et al. 2017), and we postulated that this effect may extend to juveniles, with some sites 
producing higher quality individuals. We assigned covariates for site based on the individual's natal nest location using the nine sites in Figure 1.

We built all models using the design matrix and used the logit link function in Program MARK. We used an information-theoretic approach (Burnham and Anderson 2002) and model selection by Akaike's information criterion (Akaike 1992) corrected for small sample size and overdispersion $\left(\mathrm{QAIC}_{c}\right)$ to identify the most parsimonious model among the suite of candidate models. We used the model with the lowest $\mathrm{QAIC}_{c}$ for inference and parameter estimation (Burnham and Anderson 2002), but also report on competitive models that were within $7 \Delta \mathrm{QAIC}_{c}$ units. We removed models within 2 $\mathrm{QAIC}_{c}$ units that added a parameter without improving model deviance to ensure that $\Delta \mathrm{QAIC}_{c}$ values were not the result of uninformative parameters (Arnold 2010). We report beta parameters and $95 \%$ confidence intervals for specific model covariates, and consider effects significant if their $95 \%$ confidence intervals do not include 0 . We report means \pm SE and 95\% confidence intervals for survival estimates, except where otherwise noted.

\section{RESULTS}

We banded 3,697 chicks between 1990 and 2014, and of these, 1,772 (48\%) survived to fledge. The numbers of banded fledglings generally increased as the Oregon population grew (Table 2). Juvenile Snowy Plovers exhibited high natal site fidelity in our study. During our first 24 years (excluding 2014 because those birds did not have the opportunity to return before the study ended), 1,522 juveniles fledged and could be used to estimate juvenile survival. Of these, $786(52 \%)$ were resighted in Oregon in subsequent years. Of these, 752 were initially resighted at the first opportunity, during their second year. Our encounter history consisted of 3,730 live encounters (newly 
banded individuals plus resightings of previously banded birds; counting only one sighting per individual per year). Birds returning to Oregon included 394 males, 382 females, and 10 birds of unknown sex. Because the sex of juvenile birds cannot be determined by plumage or behavior, we could not identify sex of the 736 individuals that were never resighted.

The best-supported model for juvenile detection probability indicated a strong age effect $\left(\beta_{\mathrm{Ad}}=2.00 \pm 0.42, \mathrm{CI} 1.12,2.81\right)$ with a positive time trend. Detection probability for juveniles ranged from $0.83 \pm 0.05$ to $0.97 \pm 0.01$, and improved over the course of the study. Detection probability for adults was $0.97 \pm 0.01$. This model had $98 \%$ support in the data, so we used this best model for detection probability ( $p[$ Age T/.]) going forward to model survival.

As expected, all survival models showed strong support for a difference in apparent survival by age; adult plovers had higher survival than juvenile plovers. The best-supported model showed a quadratic time effect on juvenile survival (Table 3). A model that substituted predator management for time was equally well supported, but surprisingly, the effect of predator management on juvenile survival was negative $\left(\beta_{\mathrm{PM}}=\right.$ $-0.27 \pm 0.12$, CI $-0.50,-0.03)$. Based on the top model, juvenile survival declined from 1990 to 2004 before rebounding slightly in the later years of the study (Figure 2), ranging from $0.49 \pm 0.02$ to $0.67 \pm 0.05$, and adult survival was estimated at $0.73 \pm 0.01$. Based on the variance components procedure in Program MARK, the best overall estimate for juvenile survival was $0.53 \pm 0.02$. The second model, which was equally well supported, replaced the time effect with predator management. Under this model, juvenile survival of birds hatched at sites with predator management was significantly lower $(0.51 \pm 0.02)$ 
than that of birds without predator management $(0.57 \pm 0.02)$. There was no evidence of effects based on number of chicks fledged annually, adult population size, climate, weather, sex, hatch date, or site on juvenile survival, and there was no evidence for differences in adult survival or encounter probability based on sex.

\section{DISCUSSION}

A thorough understanding of demographic parameters from across the range is fundamental to effective conservation of small populations, but rarely do data on juvenile survival exist for more than one population (Méndez et al. 2018). Our analysis allows comparison across the species' range. Our overall estimate of juvenile survival $(0.53 \pm$ 0.02, CI 0.50, 0.56) was moderately higher than estimates from central and Northern California (Stenzel et al. 2007, $0.46 \pm 0.02$ CI 0.43, 0.50; Mullin et al. 2010, $0.40 \pm 0.06$ CI $0.28,0.52)$, substantially higher than that from northwestern Mexico $(0.22 \pm 0.02$, CI 0.18, 0.27 for males and 0.15 \pm 0.02 , CI 0.11, 0.19 for females, Eberhart-Phillips et al. 2017). The Northern California Snowy Plover population is small, receives limited management, and has been identified as a sink (Mullin et al. 2010). Some of the difference in apparent juvenile survival between Oregon and Northern California may be attributed to higher philopatry in Oregon and greater natal dispersal from Northern California (Mullin et al. 2010). However, the central California population at Monterey Bay is roughly similar to our study population - large, intensively managed, and monitored. Stenzel et al. (2007) estimated true survival, which avoids negative bias due to permanent emigration, making our higher apparent survival estimate more notable. Although the two analyses cover different time periods (Stenzel et al. 2007, $1984-1999$ 
versus this study, 1990 - 2014), annual estimates from this study were still higher than those reported by Stenzel et al (2007) for the period of overlap.

Our best-fitting models expressed juvenile survival as a function of time, or with almost equal strength, the presence of lethal predator management. Collectively, these two models had 86\% support in the data (Table 3). In Monterey Bay, Stenzel et al. (2007) found no time trend in juvenile survival between 1984 and 1999. Mullin et al. (2010) reported constant juvenile survival between 2001 and 2007. By contrast, our data showed a strong negative trend from 1990 - 2004, followed by a modest improvement in survival after full implementation of lethal predator management. Despite the overall decline in juvenile survival, the Oregon population grew over the study period, suggesting that other life stages are contributing to population growth.

Lethal predator management began at a subset of sites on our study area in 2002, and at all sites in 2004, and targeted common nest and chick predators - primarily American Crows (Corvus brachyrhynchos), Common Ravens (Corvus corax), and red fox (Vulpes vulpes). Stenzel et al. (2007) found no effect of mammalian predator management on juvenile survival. In previous analyses, we found significant positive effects of predator management on nest survival (Dinsmore et al. 2014) and chick survival to fledging (Gaines et al. in prep, Chapter 2), but in this analysis, predator management had a negative effect on juvenile survival. The different effects of predator management on nest, chick, and juvenile survival suggest that causes of mortality are different for juveniles than earlier life stages. Corvids are a primary nest predator (Dinsmore et al. 2014), and take young chicks as well. Juveniles are likely exposed to a different suite of predators post-fledging, particularly as young birds disperse during their 
first winter. Additionally, a negative effect of predator management could indicate density-dependent mortality (Côté and Sutherland 1997, Stenzel et al. 2007); as more fledglings are produced, predation increases on that life stage. In Oregon, the positive effect of predator management on nest and chick survival has resulted in higher numbers of fledglings (Table 2). However, we found no effect from measures of density dependence (AdPop or FlPop) on juvenile survival. Finally, it is possible that a small positive effect of predator management was masked by the larger overall negative time trend, as is indicated by the modest increase in juvenile survival after 2004 (Figure 2). Indeed, we suspect that predator management mitigated further declines in juvenile survival. Future analysis of additional years' data are needed to confirm this.

We found no significant effects of winter weather on survival during the juvenile period. Juveniles spend the winter anywhere from Washington to Baja California, Mexico. MEI captures broad scale oceanic and atmospheric weather conditions (Wolter and Timlin 2011), and unfortunately, effects of El Nino events are not constant over this range. The opposing El Nino effects of dry conditions in the Pacific Northwest and wet weather in Southern California may have cancelled each other out. We also explored effects of cold and wet weather in the vicinity of three known wintering sites. Because we did not have data on wintering locations of individual juveniles, we were not able to identify effects of local winter weather on juvenile survival. An analysis that includes weather conditions at individual's specific wintering locations may reveal patterns of survival based on winter storms.

We found a quadratic effect of hatch date on chick survival to fledging in this population; chicks hatched at the peak of the nesting season were more likely to survive 
to fledging age (Gaines et al. in prep, Chapter 2). However, like Stenzel et al. (2007), we found no seasonal linear or quadratic effect on juvenile survival; birds hatched (and fledged) early in the season had equal survival to those hatched later. Snowy Plovers have a long breeding season, and young that fledge early have more time to build fat stores and develop predator avoidance skills before winter than their late-fledging counterparts (Spear and Nur 1994, Dawson and Clark 2000, Maness and Anderson 2013). However these same individuals have a much longer first survival interval. Additionally, Colwell et al. (2007) suggested that late-hatching plovers in Northern California were more likely to become winter residents, while early-hatching plovers were more likely to migrate out of the area for winter. Anecdotal evidence suggests this pattern holds true in Oregon. Greater dispersal may lead to higher over-winter mortality or permanent emigration of early-hatching individuals. Saunders et al. (2014) found that Piping Plovers (Charadrius melodus) hatched earlier in the season had higher juvenile survival, though their breeding season is shorter than that of Snowy Plovers (approximately 3 versus5 months). In Snowy Plovers, it is possible that any benefit associated with early fledging was masked by a longer survival interval and greater dispersal (Stenzel et al. 2007).

Although we had no data on the sex of the juveniles that did not return as adults, we found no bias in the sex ratio of returning birds, and no difference in detection probability based on sex. Assuming an equal sex ratio at hatch (Székely et al. 2004, Stenzel et al. 2007, Eberhart-Phillips et al. 2017), we found no evidence of variable survival by sex during the first year. Our results are similar to those of Stenzel et al. (2007), but in northwestern Mexico, Eberhart-Phillips et al. (2017) found that a strongly male-skewed ASR was largely due to variation in juvenile survival by sex. The ASR in 
Oregon is much closer to parity, and sometimes even female-skewed, supporting a lack of a difference in survival by sex (Table 1).

Chick survival to fledging varied by site in this population (Gaines et al. in prep, Chapter 2), but we found no significant site effect on juvenile survival. This is perhaps unsurprising, as juveniles frequently disperse from natal sites for the majority of the survival interval.

Our previous analysis of survival from hatching to fledging for the same time period in this population (Gaines et al. in prep, Chapter 2) yielded an average chick survival rate of $0.61( \pm 0.01, \mathrm{CI} 0.58,0.64)$. Combined with results here, first year survival of Snowy Plovers in Oregon from hatching to year one was approximately 0.32, much higher than first year survival rates reported by Stenzel et al. $(0.18,2007)$ or Eberhart-Phillips et al. (0.22 male and 0.15 female, 2017), but consistent with the strong recovery observed in this population.

Our focus in this analysis was to document juvenile survival for a population near the northern end of its distribution, and to identify factors that affected it. We are conducting a larger analysis of factors affecting adult survival, but the adult apparent survival estimate provided here $(0.73 \pm 0.01, \mathrm{CI} 0.71,0.75)$ is slightly higher than the true survival estimate for Monterey Bay $(0.69 \pm 0.03$, Stenzel et al. 2007) and the apparent survival estimate for northwestern Mexico $(0.69 \pm 0.03$, CI $0.63,0.74$ for males and $0.68 \pm 0.03$, CI 0.62, 0.74 for females, Eberhart-Phillips et al. 2017). Our estimate of adult survival is much higher than apparent survival estimates for Northern California ( $0.61 \pm 0.11$ for males and $0.50 \pm 0.11$ for females, Mullin et al. 2010), but Northern 
California estimates may be low because of emigration after reproductive failures (Colwell et al. 2007, Mullin et al. 2010).

The CJS model provides an estimate of $\varphi$ that is a function of true survival and permanent emigration (Sandercock et al. 2005). Thus, apparent survival likely underestimates true survival because it confounds dispersal with mortality, but the estimates can be useful at a local level. However, our high estimates for juvenile survival, compared to Stenzel et al.'s (2007) estimate of true survival, suggest that this population exhibits relatively low permanent emigration. Intensive monitoring of Snowy Plovers along the Pacific Coast provides the opportunity for future collaborations across recovery units to further refine survival estimates by accounting for dispersal.

\section{ACKNOWLEDGEMENTS}

Snowy Plover monitoring and management in Oregon has been a cooperative effort funded by Coos Bay District Bureau of Land Management, Siuslaw National Forest, U.S. Fish and Wildlife Service, Oregon Department of Fish and Wildlife, and Oregon Parks and Recreation Department. USDA Wildlife Services conducted predator management activities. Monitoring work was initiated by Mark Stern of The Nature Conservancy of

Oregon and continued by the Institute for Natural Resources at Portland State University and Oregon State University. This work would not have been possible without the dedication of numerous field staff, particularly long term plover biologists David Lauten, Kathleen Castelein, Daniel Farrar, and Adam Kotaich. We also appreciate the support of the Recovery Unit 1 Snowy Plover working team. 


\section{TABLES AND FIGURES}

Table 1. Adult sex ratio (ASR) and total population estimate of Snowy Plovers along the Oregon Coast, 1993 - 2014. In some years, total population includes a small number of birds of unknown sex. From 1990 - 1992 field crews did not report individuals observed by sex.

\begin{tabular}{lrrrr}
\hline & & & $\begin{array}{r}\text { Total adult } \\
\text { population } \\
\text { estimate }\end{array}$ & ASR \\
Year & Male & Female & 75 & \\
\hline 1990 & & & 44 & \\
1991 & & & 50 & \\
1992 & & & 72 & 0.50 \\
1993 & 36 & 36 & 83 & 0.51 \\
1994 & 42 & 41 & 120 & 0.50 \\
1995 & 60 & 60 & 134 & 0.51 \\
1996 & 69 & 65 & 141 & 0.49 \\
1997 & 68 & 72 & 97 & 0.57 \\
1998 & 55 & 41 & 95 & 0.47 \\
1999 & 45 & 50 & 109 & 0.46 \\
2000 & 50 & 59 & 111 & 0.49 \\
2001 & 54 & 57 & 99 & 0.48 \\
2002 & 46 & 50 & 102 & 0.49 \\
2003 & 50 & 52 & 136 & 0.50 \\
2004 & 68 & 68 & 153 & 0.48 \\
2005 & 73 & 80 & 178 & 0.47 \\
2006 & 83 & 95 & 181 & 0.46 \\
2007 & 84 & 97 & 187 & 0.47 \\
2008 & 87 & 100 & 199 & 0.49 \\
2009 & 98 & 101 & 232 & 0.47 \\
2010 & 110 & 122 & 247 & 0.51 \\
2011 & 125 & 122 & 290 & 0.50 \\
2012 & 145 & 145 & 304 & 0.54 \\
2013 & 164 & 140 & 338 & 0.56 \\
2014 & 188 & 150 & &
\end{tabular}


Table 2. Number of Snowy Plover chicks banded and fledged annually in Oregon, 19902014.

\begin{tabular}{lrrr}
\hline Year & $\begin{array}{r}\text { Chicks } \\
\text { banded }\end{array}$ & $\begin{array}{r}\text { \% Chicks } \\
\text { banded }\end{array}$ & $\begin{array}{r}\text { Banded chicks } \\
\text { fledged }\end{array}$ \\
\hline 1990 & 9 & 0.38 & 1 \\
1991 & 29 & 0.91 & 15 \\
1992 & 69 & 0.92 & 33 \\
1993 & 70 & 0.88 & 35 \\
1994 & 103 & 0.90 & 57 \\
1995 & 103 & 0.94 & 44 \\
1996 & 142 & 0.95 & 44 \\
1997 & 115 & 0.91 & 38 \\
1998 & 102 & 0.87 & 30 \\
1999 & 113 & 0.94 & 52 \\
2000 & 102 & 0.96 & 43 \\
2001 & 90 & 0.96 & 32 \\
2002 & 82 & 0.84 & 29 \\
2003 & 108 & 0.89 & 52 \\
2004 & 170 & 0.89 & 102 \\
2005 & 152 & 0.83 & 64 \\
2006 & 132 & 0.62 & 72 \\
2007 & 169 & 0.79 & 111 \\
2008 & 125 & 0.80 & 66 \\
2009 & 181 & 0.87 & 103 \\
2010 & 204 & 0.87 & 84 \\
2011 & 312 & 0.87 & 158 \\
2012 & 334 & 0.87 & 161 \\
2013 & 194 & 0.80 & 96 \\
2014 & 487 & 0.87 & 250 \\
\hline & & & \\
Total & 3697 & & 1772 \\
Mean \pm SE & & $0.85 \pm 0.02$ &
\end{tabular}


Table 3. Model selection results for age specific survival $(\varphi)$ and detection probability $(p)$ of Snowy Plovers along the Oregon coast, 1990 - 2014. Models are ranked by ascending $\Delta$ QAIC $_{\mathrm{c}}$ values and shown with the model weight $\left(w_{i}\right)$, number of parameters $(K)$, and model deviance corrected for overdispersion $(\hat{c}=1.03)$. The $\mathrm{QAIC}_{\mathrm{c}}$ of the best model was 4874.19. Final parameters included age (juvenile/adult), lethal predator management (PM), linear (T) and quadratic (TT) time trends, year (yr), and constant effects over time (.). Only models with $\triangle \mathrm{QAIC}_{\mathrm{c}}$ less than 7 are shown.

\begin{tabular}{lrrrr}
\hline Model & $\Delta$ QAICc & wi & K & QDeviance \\
\hline$\varphi($ Age TT/.) $p($ Age T/.) & 0.00 & 0.43 & 7 & 4860.16 \\
$\varphi($ Age PM/.) $p($ Age T/.) & 0.04 & 0.43 & 6 & 4862.21 \\
$\varphi($ Age ./.) $p($ Age T/.) & 3.14 & 0.09 & 5 & 4867.32 \\
$\varphi($ Age T/.) $p($ Age T/.) & 4.39 & 0.05 & 6 & 4866.56 \\
\hline
\end{tabular}




\section{LIST OF FIGURES}

Figure 1. Snowy Plover breeding sites along Oregon coast, 1990 - 2014.

Figure 2. Snowy Plover juvenile survival with 95\% CI, 1990- 2014, based on model $\varphi($ AgeTT/.) $p($ AgeT/.).

Figure 3. Apparent survival estimates with process variance only (sampling variation removed) and 95\% CI, for adult and juvenile Snowy Plovers along the Oregon coast, $1990-2014$ 


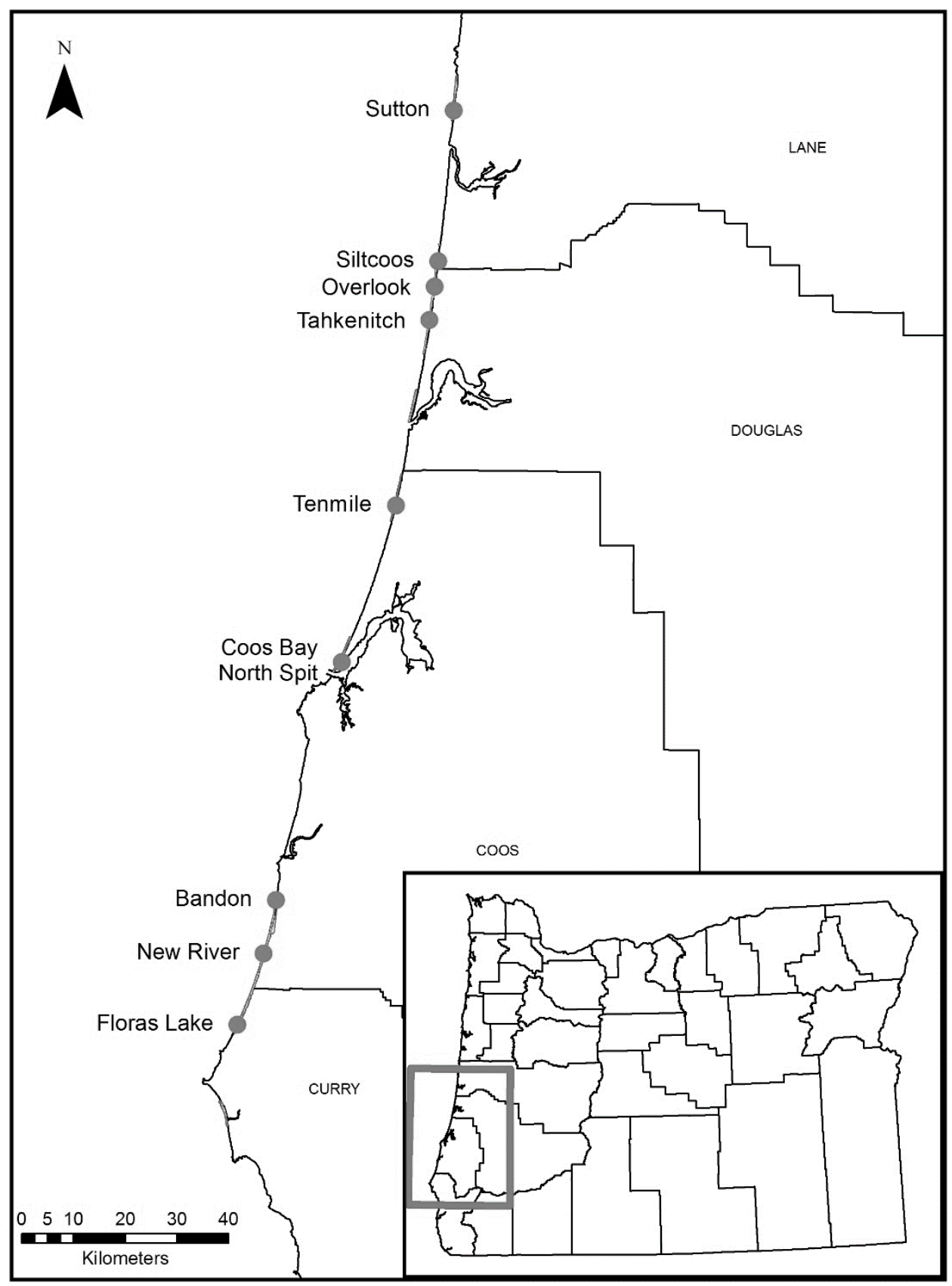

Figure 1. Snowy Plover breeding sites along Oregon coast, 1990 - 2014. 


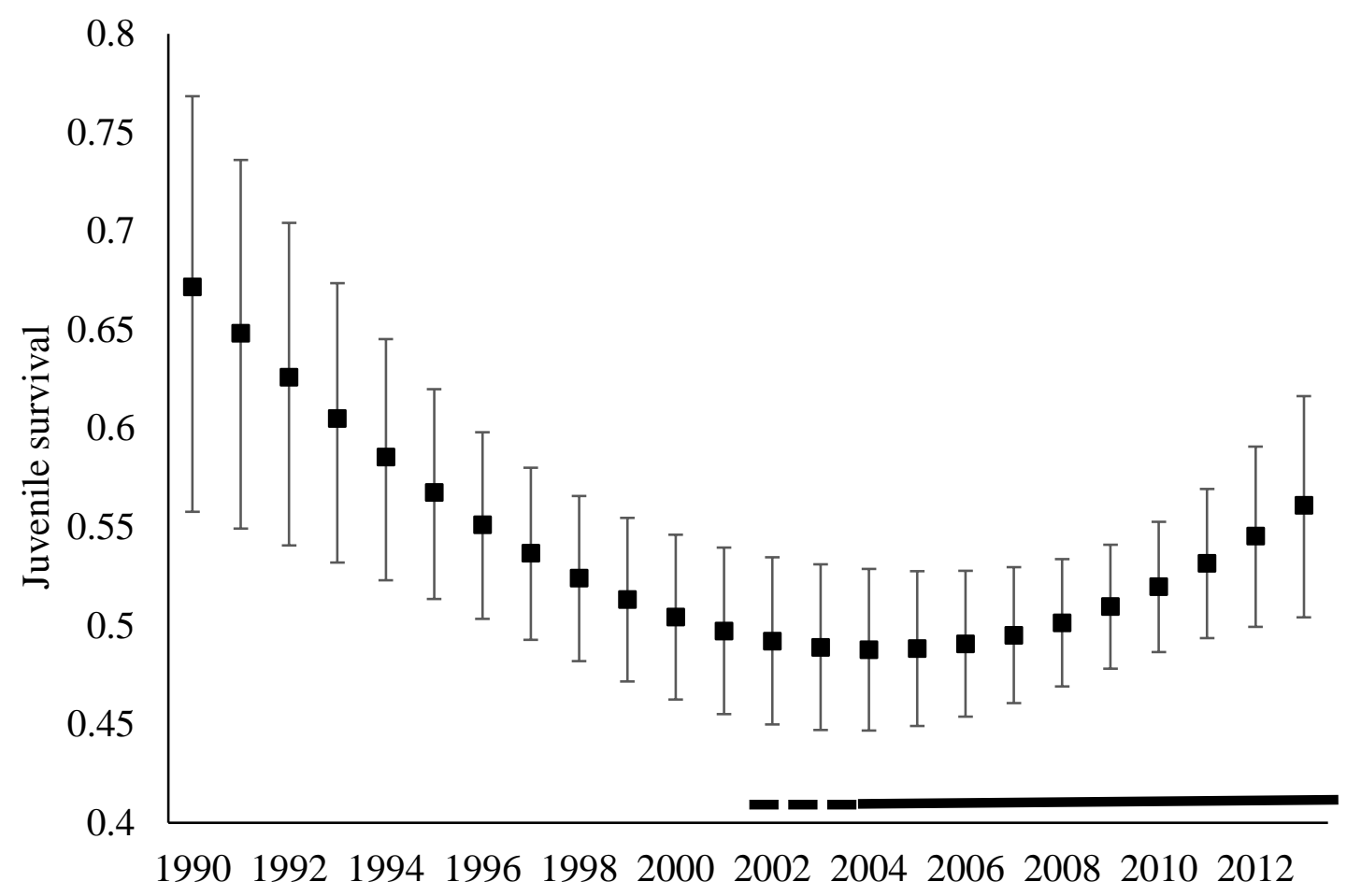

Figure 2. Snowy Plover juvenile survival with 95\% CI, 1990- 2014, based on model $\varphi($ AgeTT/.) $p($ AgeT/.). Dashed line indicates years with predator management at Coos Bay North Spit, Bandon, and New River. Solid line indicates years with predator management at all sites. 


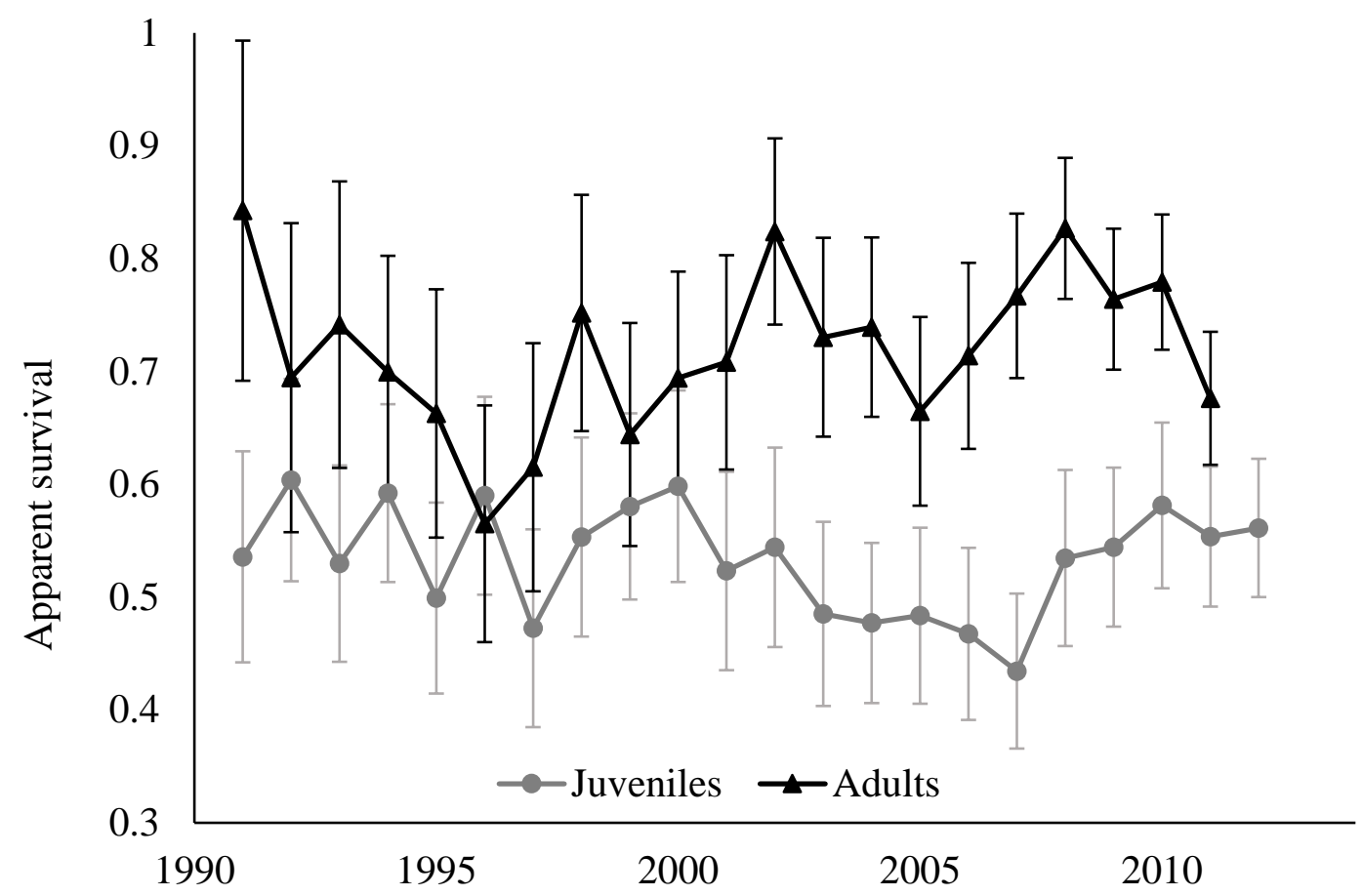

Figure 3. Apparent survival estimates with process variance only (sampling variation removed) and 95\% CI, for adult and juvenile Snowy Plovers along the Oregon coast, 1990 - 2014. Based on global model, $\varphi($ Age $\mathrm{Yr} / \mathrm{Yr}) p($ AgeYr/Yr). 


\section{LITERATURE CITED}

Akaike, H. (1992). Information theory and an extension of the maximum likelihood principle. Breakthroughs in statistics. Samuel Kotz, Norman L. Johnson, editors.

Anders, A. D., and M. R. Marshall (2005). Increasing the accuracy of productivity and survival Estimates in Assessing Landbird Population Status. Conservation Biology 19:66-74.

Arnold, T.W. (2010). Uninformative parameters and model selection using Akaike's Information Criterion. Journal of Wildlife Management 74:1175-1178.

Brown, S. C., C. M. Hickey, B. Harrington, and R. Gill (2001). United States shorebird conservation plan. Manomet Center for Conservation Sciences.

Burnham, K. P., and D. R. Anderson (2002). Model Selection and Multi-model Inference. 2nd Edition. Springer-Verlag.

Colwell, M. A., S. E. McAllister, C. B. Millett, A. N. Transou, S. M. Mullin, Z. J. Nelson, C. A. Wilson, and R. R. LeValley (2007). Philopatry and natal dispersal of the western snowy plover. The Wilson Journal of Ornithology 119:378-385.

Cormack, R. M. (1964). Estimates of survival from the sighting of marked animals. Biometrika 51:429-438.

Côté, I. M., and W. J. Sutherland (1997). The effectiveness of removing predators to protect bird populations. Conservation Biology 11:395-405.

Crouse, D. T., L. B. Crowder, and H. Caswell (1987). A stage-based population model for Loggerhead sea turtles and implications for conservation. Ecology 68:14121423. 
Dawson, R. D., and R. G. Clark (2000). Effects of hatching date and egg size on growth, recruitment, and adult size of lesser scaup. The Condor 102:930-935.

Dietz, N. J., P. J. Bergmann, and L. D. Flake (1994). A walk-in trap for nesting ducks. Wildlife Society Bulletin 22:19-22.

Dinsmore, S. J., D. J. Lauten, K. A. Castelein, E. P. Gaines, and M. A. Stern (2014). Predator exclosures, predator removal, and habitat improvement increase nest success of Snowy Plovers in Oregon, USA. The Condor 116:619-628.

Dinsmore, S. J., E. P. Gaines, S. F. Pearson, D. J. Lauten, and K. A. Castelein (2017). Factors affecting Snowy Plover chick survival in a managed population. The Condor:34-43.

Eberhart-Phillips, L. J., and M. A. Colwell (2013). Conservation challenges of a sink: the viability of an isolated population of the Snowy Plover. Bird Conservation International:1-15.

Eberhart-Phillips, L. J., C. Küpper, T. E. X. Miller, M. Cruz-López, K. H. Maher, N. dos Remedios, M. A. Stoffel, J. I. Hoffman, O. Krüger, and T. Székely (2017). Sexspecific early survival drives adult sex ratio bias in snowy plovers and impacts mating system and population growth. Proceedings of the National Academy of Sciences:201620043.

Galbraith, H., R. Jones, R. Park, J. Clough, S. Herrod-Julius, B. Harrington, and G. Page (2002). Global climate change and sea level rise: potential losses of intertidal habitat for shorebirds. Waterbirds 25:173. 
Gustafson, M. E., J. Hildenbrand, and L. Metras (1997). Bird Banding Laboratory. North American bird banding manual. [Online.] Available at http://www.pwrc.usgs.gov/BBL/manual/.

International Wader Study Group (2003). Waders are declining worldwide. Conclusions from the 2003 International Wader Study Group Conference, Cádiz, Spain. Wader Study Group Bulletin 101/102:8-12.

Jolly, G. M. (1965). Explicit estimates from capture-recapture data with both death and immigration-stochastic model. Biometrika 52:225-247.

Lafferty, K. D., D. Goodman, and C. P. Sandoval (2006). Restoration of breeding by Snowy Plovers following protection from disturbance. Biodiversity \& Conservation 15:2217-2230.

Lukacs, P. M., V. J. Dreitz, F. L. Knopf, and K. P. Burnham (2004). Estimating survival probabilities of unmarked dependent young when detection is imperfect. The Condor 106:926-931.

Maness, T. J., and D. J. Anderson (2013). Predictors of Juvenile Survival in Birds. Ornithological Monographs 78:1-55.

McNew Lance B., Gregory Andrew J., Wisely Samantha M., and Sandercock Brett K. (2012). Demography of greater prairie-chickens: Regional variation in vital rates, sensitivity values, and population dynamics. The Journal of Wildlife Management 76:987-1000.

Mehl, K. R., K. L. Drake, G. W. Page, P. M. Sanzenbacher, S. M. Haig, and J. E. Thompson (2003). Capture of breeding and wintering shorebirds with leg-hold noose-mats. Journal of Field Ornithology 74:401-405. 
Méndez, V., J. A. Alves, J. A. Gill, and T. G. Gunnarsson (2018). Patterns and processes in shorebird survival rates: a global review. Ibis: 10.1111/ibi.12586.

Menne, M. J., I. Durre, R. S. Vose, B. E. Gleason, and T. G. Houston (2012). An overview of the Global Historical Climatology Network-Daily Database. Journal of Atmospheric and Oceanic Technology 29:897-910.

Muir, J. J., and M. A. Colwell (2010). Snowy Plovers select open habitats for courtship scrapes and nests. The Condor 112:507-510.

Mullin, S. M., M. A. Colwell, S. E. McAllister, and S. J. Dinsmore (2010). Apparent survival and population growth of Snowy Plovers in coastal Northern California. Journal of Wildlife Management 74:1792-1798.

Naef-Daenzer, B., F. Widmer, and M. Nuber (2001). Differential post-fledging survival of great and coal tits in relation to their condition and fledging date. Journal of Animal Ecology 70:730-738.

Neuman, K. K., G. W. Page, L. E. Stenzel, J. C. Warriner, and J. S. Warriner (2004). Effect of mammalian predator management on Snowy Plover breeding success. Waterbirds 27:257-263.

Page, G. W., and L. E. Stenzel (1981). The breeding status of the Snowy Plover in California. Western Birds 12:1-40.

Page, G. W., L. E. Stenzel, J. C. Warriner, J. S. Warriner, and P. W. Paton (2009). Snowy Plover (Charadrius alexandrinus). The Birds of North America Online. https://doi.org/10.2173/bna.154

Pulliam, H. R., J. B. Dunning, and J. Liu (1992). Population dynamics in complex landscapes: a case study. Ecological Applications 2:165-177. 
Ruhlen, T. D., S. Abbott, L. E. Stenzel, and G. W. Page (2003). Evidence that human disturbance reduces Snowy Plover chick survival. Journal of Field Ornithology $74: 300-304$.

Sandercock, B. K. (2003). Estimation of survival rates for wader populations: a review of mark-recapture methods. Wader Study Group Bulletin 100:163-174.

Sandercock, B. K., T. Székely, and A. Kosztolányi (2005). The effects of age and sex on the apparent survival of Kentish Plovers breeding in southern Turkey. The Condor 107:583-596.

Saunders, S. P., T. W. Arnold, E. A. Roche, and F. J. Cuthbert (2014). Age-specific survival and recruitment of piping plovers Charadrius melodus in the Great Lakes region. Journal of Avian Biology:437-449.

Seber, G. A. F. (1965). A note on the multiple-recapture census. Biometrika 52:249-259.

Spear, L., and N. Nur (1994). Brood size, hatching order and hatching date: effects on four life-history stages from hatching to recruitment in Western Gulls. Journal of Animal Ecology 63:283-298.

Stahl, J. T., and M. K. Oli (2006). Relative importance of avian life-history variables to population growth rate. Ecological Modelling 198:23-39.

Stenzel, L. E., G. W. Page, J. C. Warriner, J. S. Warriner, D. E. George, C. R. Eyster, B. A. Ramer, K. K. Neuman, and B. K. Sandercock (2007). Survival and natal dispersal of juvenile snowy plovers (Charadrius alexandrinus) in central coastal California. The Auk 124:1023-1036.

Stenzel, L. E., G. W. Page, J. C. Warriner, J. S. Warriner, K. K. Neuman, D. E. George, C. R. Eyster, and F. C. Bidstrup (2011). Male-skewed adult sex ratio, survival, 
mating opportunity and annual productivity in the Snowy Plover Charadrius alexandrinus. Ibis 153:312-322.

Székely, T., I. C. Cuthill, S. Yezerinac, R. Griffiths, and J. Kis (2004). Brood sex ratio in the Kentish plover. Behavioral Ecology 15:58-62.

Thomas, S. M., J. E. Lyons, B. A. Andres, E. E. T-Smith, E. Palacios, J. F. Cavitt, J. Andrew Royle, S. D. Fellows, K. Maty, W. H. Howe, E. Mellink, et al. (2012). Population size of Snowy Plovers breeding in North America. Waterbirds 35:114.

U.S. Department of Agriculture and U.S. Department of Interior (2002). Predator damage management to protect the federally threatened Pacific coast population of the Western Snowy Plover. Prepared by USDA, APHIS, Wildlife Services Program and the Siuslaw National Forest; USDI, Fish and Wildlife Service Region 1 and Bureau of Land Management Coos Bay District; and in cooperation with the Oregon Department of Fish and Wildlife, and Oregon Parks and Recreation Department.

U. S. Fish and Wildlife Service (1993). Determination of Threatened Status for the Pacific Coast Population of the Western Snowy Plover. Federal Register $58: 12864-12874$.

U.S. Fish and Wildlife Service (2007). Recovery Plan for the Pacific Coast Population of the Western Snowy Plover (Charadrius alexandrinus nivosus). In 2 volumes.

U. S. Geologic Survey Bird Banding Laboratory (2011). Banders' code of ethics. Ethics and responsibility of bird banders. [Online.] Available at http://www.pwrc.usgs.gov/BBl/resources/ethics.cfm. 
Warriner, J. S., J. C. Warriner, G. W. Page, and L. E. Stenzel (1986). Mating system and reproductive success of a small population of polygamous Snowy Plovers. The Wilson Bulletin 98:15-37.

White, G. C., and K. P. Burnham (1999). Program MARK: survival estimation from populations of marked animals. Bird Study 46:S120-S139.

Wiedemann, A. M. (1984). Ecology of Pacific Northwest Coastal Sand Dunes: A Community Profile. Evergreen State Coll., Olympia, WA (USA) FWS/OBS$84 / 04$.

Wiedemann, A. M. (1987). The ecology of European beachgrass. Oregon Department of Fish and Wildlife 87.

Wilson, K., and I. C. Hardy (2002). Statistical analysis of sex ratios: an introduction. In Sex ratios: concepts and research methods. Cambridge University Press, pp. 4892.

Wolter, K., and M. S. Timlin (2011). El Niño/Southern Oscillation behaviour since 1871 as diagnosed in an extended multivariate ENSO index (MEI.ext). International Journal of Climatology 31:1074-1087. 
CHAPTER 4. THE EFFECT OF MANAGEMENT ON SNOWY PLOVER ADULT

\section{SURVIVAL}

Eleanor P. Gaines ${ }^{1}$, Stephen J. Dinsmore ${ }^{2}$, and Michael T. Murphy ${ }^{3}$

${ }^{1}$ Oregon Biodiversity Information Center - Institute for Natural Resources, Portland State University, PO Box 751, Portland, OR USA

${ }^{2}$ Department of Natural Resource Ecology and Management, 339 Science II, Iowa State University, Ames, IA USA

${ }^{3}$ Biology Department, Portland State University, PO Box 751, Portland, OR USA

\section{ABSTRACT}

Conservation of threatened species requires accurate estimates of vital rates. Among shorebirds, population growth is generally most sensitive to changes in adult survival, thus it is important to understand factors affecting this demographic rate. We examined the effect of management actions, initiated to improve productivity, on adult survival of a threatened population of Snowy Plovers in Oregon, USA. During the course of our study we saw increasing apparent adult survival that averaged $0.71 \pm 0.01$ (mean $\pm \mathrm{SE}$ ) between 1990 and 2014. This increase was concomitant with implementation of lethal predator management and a decline in the use of nest exclosures. We also saw evidence that wetter-than-average winter weather depressed adult survival. This 25 -year analysis adds to our knowledge of an intensively managed, threatened species at the northern limit of its range.

Key words: Charadrius nivosus, nest exclosures, predator management, adult apparent survival 


\section{INTRODUCTION}

Understanding how life history parameters influence population growth is crucial to effective conservation, but this information is often lacking for declining species. Among birds generally (Sæther and Bakke 2000), and shorebirds in particular, population growth is most sensitive to adult survival (Hitchcock and Gratto-Trevor 1997, Sandercock 2003, Calvert et al. 2006, Stahl and Oli 2006, Dinsmore et al. 2010), and thus understanding how management affects this vital rate is key to effective stewardship of threatened populations. However, management actions are frequently directed towards improving life history parameters such as productivity that are more tractable but which may have negligible effects on population growth (Heppell et al. 1996, Johnson et al. 2010). Given limited resources available, it is important that efforts be directed where they will be most effective, and certainly not where they will be counterproductive. An important unanswered question is how do management actions intended to benefit productivity affect adult survival. Might, as theory predicts (Williams 1966, Stearns 1976), increased production of young entail a cost such that, that either through diminution of somatic reserves or increased exposure to predators, brings about a reduction in adult survival? Shorebird populations are experiencing alarming declines in the US and globally (Brown et al. 2001, International Wader Study Group 2003), and management for these populations often aims to improve nest success and survival to fledging. Protective nest exclosures are widely used tools to improve productivity in ground-nesting shorebirds (Deblinger et al. 1992, Estelle et al. 1996, English et al. 2017), though there are concerns that the benefit of increased productivity is offset by an increase in adult predation around exclosures (Hardy and Colwell 2008, Barber et al. 2010, Burns et al. 2013, Dinsmore et 
al. 2014). Additionally, human-altered habitats often result in an increase in synanthropic native and non-native predators, and these human-subsidized predators can have an outsized effect on small prey populations. Lethal predator management has been used to improve productivity in a variety of shorebird species (Pauliny et al. 2008, Fletcher et al. 2010, Catlin et al. 2011), though it does not always promote population growth (Neuman et al. 2004). Information on the effect of these management actions on adult survivalthe life stage that most affects population growth—is fundamental to conservation.

The Pacific Coast population of the Western Snowy Plover (Charadrius nivosus nivosus) occurs within $80 \mathrm{~km}$ of the Pacific Coast from Damon Point, Washington, USA to Bahia Magdalena, Baja California, Mexico (U. S. Fish and Wildlife Service 2007, Page et al. 2009), and is listed as threatened by the U. S. Fish and Wildlife Service because of poor productivity and survival (U. S. Fish and Wildlife Service 1993, U. S. Fish and Wildlife Service 2007, Thomas et al. 2012). Limiting factors include increasing predation from synanthropic predators (Neuman et al. 2004), human disturbance (Ruhlen et al. 2003, Lafferty et al. 2006), and habitat loss to development, exotic vegetation, and recreational use (Page and Stenzel 1981, U. S. Fish and Wildlife Service 1993, 2007, Page et al. 2009, Galbraith et al. 2002, Muir and Colwell 2010). These factors are intertwined. For example, human-associated trash attracts predators (Rees et al. 2014) and exotic vegetation provides cover for non-native and invasive native predators. Along the Oregon coast, intensive and coordinated management to benefit Snowy Plovers addresses all these limiting factors and has been ongoing since 1990. Management has been effective; Snowy Plover populations in Oregon have grown by nearly an order of magnitude during the last 25 years (Table 1). Despite this success, managers need to 
know how their actions affect individual life stages to allow for effective decisionmaking as populations approach recovery goals.

Snowy Plovers are well-studied along the Pacific Coast, and adult survival has been estimated for populations outside of Oregon. To date, no estimates of adult survival have been published for the large, well-studied Oregon population. Stenzel et al. (2007) used a Barker model (1999) to account for permanent emigration in their estimate of adult survival along the central California coast between 1984 and 1999, while Colwell et al. (2013) estimated adult apparent survival for the small population of Snowy Plovers in Northern California. Environmental and management conditions in Oregon are quite different from those in California. Furthermore, vital rates often vary spatially and temporally, and effective conservation requires a thorough understanding of local population dynamics (Anders and Marshall 2005, McNew et al. 2012, Eberhart-Phillips and Colwell 2013). The Oregon population is the largest north of the central California coast, and is at the northern end of the species' range (a small population occurs farther north, along the Long Beach peninsula in Washington). This population has been colorbanded since 1990 and individuals exhibit high levels of site fidelity. Here, we examine temporal, environmental, and management factors influencing Snowy Plover adult apparent survival and detection probability. Our results from this long-term analysis will help inform management of this threatened species in Oregon and beyond.

\section{METHODS}

\section{Study Area}

As part of a long-term monitoring project, we studied breeding Snowy Plovers from 1990 to 2014 at nine sites along the Oregon coast (Figure 1). Although plovers rarely nested at 
other Oregon beaches (two of 3,639 known nests during the study period), these sites encompassed all regularly occupied coastal habitat in Oregon. The sites varied in ownership, management, and predation and recreation pressures. Although some dispersal occurs between states, the Oregon population is geographically remote; the nearest nesting sites in California and Washington are $>220 \mathrm{~km}$ away. Occupied habitat covered approximately $17.7 \mathrm{~km}^{2}$ along a $137 \mathrm{~km}$ stretch of the Oregon coast, and included habitat typical of nesting Snowy Plovers: open ocean beaches, sand spits, ocean over-wash sites, sand dunes, and estuarine sand flats. Dunes are dominated by non-native, invasive European beachgrass (Ammophila arenaria), which over time has stabilized the naturally ephemeral dune system, resulting in densely vegetated, steep dunes that are unsuitable for plover nesting and provide cover for predators (Wiedemann 1984, 1987, Muir and Colwell 2010). Breeding season management for the Snowy Plovers in Oregon is intensive and includes habitat restoration and maintenance, recreation restrictions, and an integrated predator management plan that incorporates both lethal and non-lethal actions.

\section{Field Methods}

We began color banding adults and chicks in 1990 and in most years at least $80 \%$ of the adult population was banded (Dinsmore et al. 2017; Table 1). We observed banded adults and located nests at all sites during at least weekly surveys from early April until all broods fledged, typically mid-September (Dinsmore et al. 2014). We recorded sex of adults based on plumage and behavior (Page et al. 2009). We surveyed at least weekly, recording banded individuals seen, from April through September each year. 
Initial management to counter high levels of predation included trash and carcass removal from nesting beaches, harassment of individual predators, and beginning in 1990, installation of exclosures around some nests $(n=1204)($ Dinsmore et al. 2014). Most exclosures were $5 \times 10 \mathrm{~cm}$ wire mesh cages with a wire top and blueberry netting false top to protect plovers from hitting the top of the exclosure. Exclosures have repeatedly been shown to improve nest success (Hardy and Colwell 2008, Dinsmore et al. 2014). However, we have documented predation of adults incubating in exclosures, and it is unclear whether adult survival differs at exclosed and unexclosed nests (Murphy et al. 2003, Watts et al. 2012, Colwell et al. 2013).

Further steps to reduce predation began in 2002 with the initiation of an integrated predator management plan at Coos Bay North Spit, Bandon Beach, and New River that included lethal removal of plover predators (U.S. Department of Agriculture and U.S. Department of Interior 2002, Dinsmore et al. 2017). In 2004, lethal predator management was extended to all nine sites and continued for the duration of the study. Predator management was conducted by USDA APHIS-Wildlife Services in coordination with the Recovery Unit 1 Snowy Plover Working Team, and primarily targeted nest and chick predators, including American Crows (Corvus brachyrhynchos), Common Ravens (Corvus corax), nonnative red fox (Vulpes vulpes), and striped skunks (Mephitis mephitis). Other non-target predators, including Great Horned Owls (Bubo virginianus), Northern Harriers (Circus hudsonius), coyotes (Canis latrans), raccoons (Procyon lotor), and feral cats (Felis catus), were removed when they exhibited focused attention on plover nests through regular presence or hunting on a nesting area, and non-lethal control measures proved ineffective. Corvids comprised 90\%, red fox accounted for 5\%, and 
striped skunk made up 2\% of the predators removed between 2002 and 2014. All other predator species accounted for less than $1 \%$ of the total removals (Table 2). Predator management activities began before plover nesting (typically in February each year) and continued through August. See Dinsmore et al. (2017) for further details on the predator management program.

This work was permitted by Portland State University IACUC number PSU13.11.25.1, USFWS recovery permits TE839094 and TE39372B, U.S. Fish and Wildlife Service banding permits 21825 and 23854, and Oregon Department of Fish and Wildlife annual scientific take authorizations.

\section{Adult Survival Modeling}

We compiled 25-occasion encounter histories for 1,069 banded birds observed in Oregon as adults between 1990 and 2014 with a resighting period of 1 April to 31 July each year. This resighting period helps ensure closure by limiting resightings to a period of peak breeding and minimal movement in or out of the population. We used a live recaptures Cormack-Jolly-Seber (CJS; Cormack 1964, Jolly 1965, Seber 1965) model in Program MARK (White and Burnham 1999) to generate maximum likelihood estimates of apparent annual survival $(\varphi)$ and detection probability $(p)$. We estimate apparent survival here because limitations on existing data did not support an analysis of true survival. Apparent survival confounds permanent emigration with death and thus our survival estimates should be considered minimums. However, our large resight area and the high site fidelity exhibited by the Oregon population partially mitigates this problem (Nur et al. 1999, Sandercock et al. 2005, Maness and Anderson 2013) and we maintain that our 
estimates of local (apparent) survival closely approximate true survival (Méndez et al. 2018).

We tested a fully time-dependent model $(\varphi[\mathrm{yr}] p[\mathrm{yr}])$ for goodness-of-fit using the median $\hat{c}$ procedure in MARK. The median $\hat{c}$ procedure indicated the data were slightly overdispersed, so we adjusted the variance inflation factor $(\hat{c})$ for all models to 1.21 . We used a hierarchical approach to model effects on detection probability first (no effect [.], year [yr], sex [sex], and linear [T] and quadratic [TT] time trends across years) with full year effects on survival. We used the most parsimonious model for detection probability to model effects on annual apparent survival (no effect [.], year [Yr], linear [T] and quadratic [TT] time trends across years, and sex [Sex]). After selecting a base survival model, we substituted annual covariates for winter weather conditions and management to see if these covariates better explained annual variation in adult survival. To avoid misleading results due to parameter collinearity we did not include multiple time-related covariates in the same model (Maness and Anderson 2013). We included 3 potential sources of variation in adult survival in our models: winter weather, predator management, and exclosure use.

Winter weather - In a previous analysis we found no effect of winter weather on juvenile survival, but Colwell et al. (2013) demonstrated that poor winter weather adversely affected annual adult survival in Northern California. We thus hypothesized that poor winter weather would negatively affect adult survival and included three covariates to explore aspects of weather at multiple scales. Some plovers migrate to Washington or as far south as Baja California (Oregon Biodiversity Information Center, unpublished data, Page et al. 2009) during the non-breeding season. Thus, we included an 
annual covariate to reflect broad-scale climate conditions over the winter months along the Pacific Coast. We used the sum of the monthly multivariate El Niño-Southern Oscillation indices (MEI) for September-March, 1990-2014 (available from the National Oceanographic and Atmospheric Administration [NOAA] Earth System Research Laboratory Physical Sciences Division, https://www.esrl.noaa.gov/psd/enso/mei/) as a proxy for broad-scale regional winter climate conditions (Stenzel et al 2007, Wolter and Timlin 2011).

Because many individuals remain in Oregon for the winter, we also explored local winter weather conditions by summing the number of colder-than-average (Cold) and wetter-than-average (Wet) days each winter along the Oregon coast. We retrieved daily total precipitation and minimum temperature data from NOAA (Menne et al. 2012) collected between October and February each winter (winters of 1990-91 to 2013-14) at North Bend, Oregon Regional Airport (Station USW00024284, Figure 1). This site was chosen based on its central location in our study area and completeness of data during our study period. We identified cold winter weather by summing the number of days each winter that fell more than one standard deviation below the mean daily minimum winter temperature. Between 1990 and 2014, the mean minimum daily temperature between 1 October and 28 February was $5.48 \pm 3.54^{\circ} \mathrm{C}$ (mean $\pm \mathrm{SD}$ ). Thus we counted the days each winter with minimum daily temperature that fell below $1.94^{\circ} \mathrm{C}(\mathrm{Cold})$. The number of colder-than-average days each winter ranged from 7 to 38 . Likewise, we identified wet winter weather by summing the number of days each winter with precipitation more than one standard deviation above the mean daily precipitation. Between 1990 and 2014, the mean daily precipitation between 1 October and 28 February was $0.66 \pm 1.17 \mathrm{~cm}$. Thus 
we counted the number of days each winter with total precipitation greater than $1.83 \mathrm{~cm}$ (Wet). The number of wetter-than-average days each winter ranged from 5 to 30 .

Predator management - Lethal predator management improved nest and chick survival to fledging in this population (Dinsmore et al. 2014, 2017). Although predator management primarily targeted nest and chick predators, we were interested in seeing if this survival benefit extended to adults. We explored the effect of years with and without lethal predator management on adult survival. There was no lethal predator management from 1990 - 2001. In 2002 and 2003 Coos Bay, Bandon, and New River received predator management, and from 2004 - 2014 all sites had predator management. We tested the predator management effect using two covariates for years with partial (2002 and 2003) and complete (2004 and later) predator management versus using a single covariate for years with any predator management (complete or partial). Results were similar, so we used only one covariate (PM) to code for any predator management from $2002-2014$ as this was more parsimonious.

Nest exclosures - Nest exclosures improved hatching success (Dinsmore et al. 2014), but we documented predation of multiple adults associated with exclosed nests and were concerned that birds nesting in exclosures may be subject to greater mortality. To identify a potential effect on adults from nesting in exclosures we included a covariate for the percent of known nests exclosed each year (EX). We hypothesized that years with a high percentage of exclosure use would have lower adult survival.

We built all models using the design matrix and used the logit link function in Program MARK. We used an information-theoretic approach (Burnham and Anderson 2002) and model selection by Akaike's Information Criterion (Akaike 1992) corrected 
for small sample size and overdispersion $(\mathrm{QAIC})$ ) to identify the most parsimonious model among the suite of candidate models. We report on all competitive models within $7 \Delta \mathrm{QAIC}_{c}$ units of the model with the lowest $\mathrm{QAIC}_{c}$ (Burnham and Anderson 2002). We removed models within $2 \mathrm{QAIC}_{c}$ units that added a parameter without improving model deviance to ensure that $\Delta \mathrm{QAIC}_{c}$ values were not the result of uninformative parameters (Arnold 2010). We used the variance components procedure in Program MARK to calculate an overall estimate of survival including process variance but not sampling variance. We report beta parameters and $95 \%$ confidence intervals for specific model covariates, and consider effects significant if their $95 \%$ confidence intervals do not include zero. We report means \pm SE and $95 \%$ confidence intervals for survival estimates, except where otherwise noted.

\section{RESULTS}

We monitored a total of 1,069 color-banded adults between 1990 and 2014. The number of birds present and the percent banded generally increased during the course of the study (Table 1). Forty-two birds were initially banded in California or Washington (as adults or chicks) before immigrating to Oregon; the remaining 1027 birds (96\%) were initially banded in Oregon as chicks $(n=786)$ or adults $(n=241)$. Our banded population included 571 males, 482 females, and 16 birds of unknown sex. We observed 3,006 live encounters (counting one resighting per individual per year) during a resight period that ran from 1 April to 31 July each year.

Detection probability was best explained by a linear time trend and sex $(p(\mathrm{~T}+\mathrm{Sex}))$. Detection probability improved over time, and was greater for males $\left(\beta_{\text {Male }}=\right.$ $0.33 \pm 0.16$, CI $0.02,0.63)$ than females. This is unsurprising - because males rear 
broods, they were more likely to be detected, and as the project progressed we became more skilled at resighting individuals. This model for detection probability $\left(\mathrm{w}_{\mathrm{i}}=0.67\right)$ was more than three times as likely as the next best-supported model $\left(\mathrm{w}_{\mathrm{i}}=0.20\right)$, and we used it going forward for all survival models.

Our modeling results yielded four competitive models that we used to make inference about Snowy Plover survival in Oregon. Collectively, these four models had all support in the model set (Table 3). The best-supported model showed a positive linear trend in adult survival over the course of the study $\left(\beta_{\mathrm{T}}=0.03 \pm 0.01, \mathrm{CI} 0.02,0.05, \mathrm{w}_{\mathrm{i}}=\right.$ 0.48). Using this model, adult survival ranged from $0.61 \pm 0.03$ to $0.77 \pm 0.01$, and detection probability ranged from $0.89 \pm 0.03$ to $0.98 \pm 0.01$. Our best overall estimate of adult survival from 1990 to 2014 was $0.71 \pm 0.01$, calculated using the fully time dependent model and the variance components procedure in Program MARK. Models that substituted management effects for time were also well supported. Lethal predator management had a significant positive effect on adult survival $\left(\beta_{\mathrm{PM}}=0.40 \pm 0.10, \mathrm{CI}\right.$ $0.21,0.60)$. Under this model, adult apparent survival was $0.66 \pm 0.02$ in years without lethal predator management, and $0.74 \pm 0.01$ in years with lethal predator management. Years in which more nests were exclosed had lower adult survival to the following year $\left(\beta_{\mathrm{EX}}=-0.69 \pm 0.17, \mathrm{CI}-1.03,-0.35 ;\right.$ Figure 2$)$. Under this model, adult survival ranged from $0.65 \pm 0.02$ in 1999 , a year when $87 \%$ of all known nests were exclosed, to $0.77 \pm$ 0.01 in 2013, when we exclosed only $5 \%$ of all known nests. We also found a small but significant negative effect of wetter-than-average winter weather on adult survival $\left(\beta_{\text {Wet }}=\right.$ $-0.02 \pm 0.01, \mathrm{CI}-0.04,-0.01)$. We found no effect from colder-than-average winter 
weather or from broad scale climate conditions along the Pacific Coast. Although males had slightly better survival than females, this effect was not significant (Figure 3).

\section{DISCUSSION}

Because population growth of long-lived bird species is most sensitive to changes in adult survival (Sæther and Bakke 2000, Sandercock 2003, Stahl and Oli 2006), accurate estimates of this vital rate and the factors affecting it are crucial to effective conservation. However, vital rates may also vary across a species' range (Hernández-Camacho et al. 2015, Méndez et al. 2018) making it important for managers to have local estimates available. Because of the difficulty associated with monitoring adult survival and dispersal, conservation efforts often focus on improving more tractable nest or fledging success (Lebreton et al.1992, Sillett and Holmes 2002). However, without a clear understanding of these efforts' effects on other vital rates and overall population growth, management directed at one vital rate may have unintended negative consequences at other life stages that can negate the efforts' benefits. On the basis of our analysis, management intended to improve nesting productivity had apparent negative consequences for adult survival of Western Snowy Plovers, a threatened shorebird.

By contrast, and surprisingly given the results of others (Stenzel et al. 2011, Colwell et al. 2013), survival appeared to be only minimally influenced by annual differences in winter weather. Some adults that breed in Oregon are resident, but others winter from Washington to Baja California, Mexico and it may be difficult to identify effects from poor weather when birds winter over a broad geographic range. Like Stenzel et al. (2007), we saw no effect of broad-scale Pacific climate conditions as measured by MEI. The MEI captures oceanic and atmospheric weather conditions across the Pacific 
(Wolter and Timlin 2011), but El Niño events bring dry conditions to the Pacific Northwest and increased rainfall to Southern California. With Oregon birds wintering along much of the Pacific Coast, these opposing effects at opposite ends of their winter range may have cancelled each other out. Analyses that include weather conditions at individuals' specific wintering locations may reveal effects of winter weather on adult survival, but our data are not well-enough defined to permit such an analysis.

Our overall estimate of adult apparent survival $(0.71 \pm 0.01)$ is similar to those reported from other Pacific Coast populations (0.69 \pm 0.03, Stenzel et al. 2007; $0.50 \pm$ 0.11 for females and $0.61 \pm 0.08$ for males, Mullin et al. 2010; $0.69 \pm 0.03$ for females and $0.73 \pm 0.03$ for males, Stenzel et al. 2011; Colwell et al. 2013; $0.68 \pm 0.03$ for females and $0.69 \pm 0.03$ for males, Eberhart-Phillips et al. 2017). Stenzel et al. (2011) estimated true survival, and while their overall estimates were similar to ours, they were driven by particularly low survival in 1998/1999. Excluding estimates for that cold winter, their adult true survival estimates were slightly higher $(0.72 \pm 0.01$ for females and $0.76 \pm 0.01$ for males), but still statistically similar to ours. Unlike others (Stenzel et al. 2007, Colwell et al. 2013), our best-supported model showed a linear trend in adult survival during the course of our study. The observed improvement in adult survival in the Oregon population was likely due to management; adult survival benefited from implementation of a lethal predator management program and a reduction in use of exclosures.

When human-subsidized predators use the same habitats as rare species, management must often control the subsidized species to maintain viable populations of the rare species (Boarman 2003, Martin et al. 2010). Lethal predator management is 
expensive, often controversial, and results are temporary without continued investment, but management can help improve productivity and persistence of small populations threatened by predators (Fletcher et al. 2010, Lavers et al. 2010, but see Côté and Sutherland 1997) or brood parasites (Kirtland's Warbler [Setophaga kirtlandii], Blackcapped Vireo [Vireo atricapilla], Wilsey et al. 2014; Southwestern Willow Flycatcher [Empidonax traillii extimus] and Least Bell's Vireo [V. bellii pusillus], Kus and Whitfield 2005). Thus managers need information assessing the effectiveness of such programs and identifying the vital rates affected. Lethal predator management has been shown to improve Snowy Plover nest and chick survival (Neuman et al. 2004, Dinsmore et al. 2014, 2017), and the Oregon program was initiated to improve these life stages, focusing on corvid and fox removal. Fox, and many of the non-target species removed, are documented adult predators in Oregon (e.g., Great Horned Owl, Northern Harrier, and feral cat; Table 2). These non-target predators were taken only after non-lethal methods failed to eliminate focused hunting activity on nesting areas. Combined with our analyses of previous life stages, predator management benefits survival across the life cycle (Dinsmore et al. 2014, 2017, Gaines et al. in prep, Chapters 2 and 3). Although we think it unlikely, we nonetheless acknowledge the possibility that the observed increase in adult survival after implementation of predator management was the result of lower permanent emigration, falsely suggesting improved adult survival in the later years of our study. High predation pressure early in the study may have encouraged individuals to disperse outside of Oregon. Indeed, plovers will disperse when repeated nesting attempts are unsuccessful. However, our large study area and the bird's demonstrated high breeding 
site fidelity argue against such an effect. And even if true, predator management allowed birds to remain in Oregon, resulting in a growing local population.

Many researchers have highlighted the need to weigh the benefit of increased productivity provided by exclosures against the potential cost of increased adult mortality because of the importance of adult survival for population growth in long-lived birds (Hitchcock and Gratto-Trevor 1997, Sæther and Bakke 2000, Murphy et al. 2003, Neuman et al. 2004, Dinsmore et al. 2010, Calvert and Taylor 2011; but see Sim et al. 2011, Cohen et al. 2016). However, documenting the effect of exclosure use on adult survival can be difficult because adult mortality is rarely observed. Early in the study, a majority of nests were exclosed in an effort to improve nest success (Figure 2, Dinsmore et al. 2014). However, we found 18 adults associated with exclosed nests depredated based on feathers or body parts in or near the exclosures. Roche et al. (2010) found that most apparent nest abandonment in Piping Plovers (C. melodus) was actually due to death of an adult, and in our study, an additional 27 exclosed nests were abandoned during incubation or hatching and adults were never resighted; we assume they were depredated. Although exclosed nests were monitored more closely, the fact that no adults associated with unexclosed nests were confirmed or suspected of being depredated suggests a potential serious threat to adults from exclosing nests. As predator management resulted in improved nest success, we reduced exclosure use and the suspicion of negative effects of nest exclosure on adult survival was confirmed by our analysis (Table 3, Figure 2).

The effect of exclosure use on adults has been intensively studied in Piping Plovers. Barber et al. (2010) documented significantly higher rates of adult predation and 
abandonment at exclosed Piping Plover nests in Atlantic Canada as compared to unexclosed nests. Calvert and Taylor (2011) included these findings in a matrix model that showed improved productivity from exclosure use at best compensated for increased adult predation, and at worst exacerbated a population decline. However, in an analysis of the entire Atlantic Coast population, Cohen et al. (2016) found that improvements in productivity were enough to offset decreases in adult survival. Stringham and Robinson (2015) used a coupled predator-prey model to rank effectiveness of predator management and exclosure use on Piping Plovers. Although all scenarios predicted a declining population, a combination of predator control and exclosure use predicted the highest final plover abundance. However, when reduced adult survival associated with exclosure use was included, the model predicted the lowest final plover abundance of all options. In Oregon, exclosures have a strong positive benefit on productivity (Dinsmore et al 2014), but given the importance of adult survival to overall population growth, it is doubtful that the benefits of exclosures outweigh the costs.

We did not look for a direct negative effect of nesting in an exclosure on individual adult survival. Rather, we compared effects of exclosure use over years and found that adult survival was higher in years with lower exclosure use. It is possible that selective, low levels of exclosure use may benefit population growth. Snowy Plovers exhibit high fidelity to sites where they have successfully hatched a nest, though not necessarily to sites where they have fledged young. Thus by increasing the likelihood of nests hatching, exclosures can help establish regular use of new sites. However, this is a double-edged sword. Exclosures may create an ecological trap if their use subjects adults 
to lower survival and encourages adults to repeatedly expend resources incubating nests at sites with high predation, where they are unlikely to fledge young.

The Snowy Plover is a heavily managed, federally threatened species, and effects of management on population growth are of immediate concern to conservation biologists in Oregon and beyond. Without intensive management, the plover population is likely to decline to an unsustainable size (U. S. Fish and Wildlife Service 2007), suffer local extirpations, or require captive breeding programs to remain viable. Adult survival is a key component of population growth, and insight into the effect of management actions on this vital rate will allow more informed management. We demonstrated that lethal predator management, while initiated to benefit productivity, resulted in improved adult survival whereas exclosure use had a negative effect. In addition, this study provides previously unavailable measures of adult survival from the northern edge of this species' distribution to help hone range-wide estimates of population viability. A future analysis, based on all locally generated vital rate estimates, will explore the effects of exclosure use and predator management on overall population growth and viability.

\section{ACKNOWLEDGEMENTS}

Snowy Plover monitoring and management in Oregon has been a cooperative effort funded by Coos Bay District Bureau of Land Management, Siuslaw National Forest, U.S. Fish and Wildlife Service, Oregon Department of Fish and Wildlife, and Oregon Parks and Recreation Department. USDA Wildlife Services conducted predator management activities. Monitoring work was initiated by Mark Stern of The Nature Conservancy of Oregon and continued by the Institute for Natural Resources at Portland State University and Oregon State University. This work would not have been possible without the 
dedication of numerous field staff, particularly long-term plover biologists David Lauten, Kathleen Castelein, Daniel Farrar, and Adam Kotaich. We also appreciate the support of the Recovery Unit 1 Snowy Plover working team. 


\section{TABLES AND FIGURES}

Table 1. Snowy Plover adult population estimates, percent of adult population banded, and percent of males in adult population along the Oregon Coast, 1990 - 2014. In some years, total population includes a small number of birds of unknown sex. From 1990 1992 field crews did not report individuals observed by sex.

\begin{tabular}{lrrrrr} 
& & & $\begin{array}{r}\text { Total adult } \\
\text { population } \\
\text { estimate }\end{array}$ & $\begin{array}{r}\text { \% Adults } \\
\text { banded }\end{array}$ & \% Males \\
\hline 1990 & Male & Female & 75 & 0.16 & \\
1991 & & & 44 & 0.36 & \\
1992 & & & 50 & 0.78 & \\
1993 & 36 & 36 & 72 & 0.68 & 0.50 \\
1994 & 42 & 41 & 83 & 0.75 & 0.51 \\
1995 & 60 & 60 & 120 & 0.83 & 0.50 \\
1996 & 69 & 65 & 134 & 0.74 & 0.51 \\
1997 & 68 & 72 & 141 & 0.65 & 0.49 \\
1998 & 55 & 41 & 97 & 0.74 & 0.57 \\
1999 & 45 & 50 & 95 & 0.85 & 0.47 \\
2000 & 50 & 59 & 109 & 0.87 & 0.46 \\
2001 & 54 & 57 & 111 & 0.86 & 0.49 \\
2002 & 46 & 50 & 99 & 0.88 & 0.48 \\
2003 & 50 & 52 & 102 & 0.93 & 0.49 \\
2004 & 68 & 68 & 136 & 0.89 & 0.50 \\
2005 & 73 & 80 & 153 & 0.90 & 0.48 \\
2006 & 83 & 95 & 178 & 0.79 & 0.47 \\
2007 & 84 & 97 & 181 & 0.71 & 0.46 \\
2008 & 87 & 100 & 187 & 0.73 & 0.47 \\
2009 & 98 & 101 & 199 & 0.78 & 0.49 \\
2010 & 110 & 122 & 232 & 0.82 & 0.47 \\
2011 & 125 & 122 & 247 & 0.84 & 0.51 \\
2012 & 145 & 145 & 290 & 0.88 & 0.50 \\
2013 & 164 & 140 & 304 & 0.88 & 0.54 \\
2014 & 188 & 150 & 338 & 0.80 & 0.56 \\
\hline & & & & &
\end{tabular}


Table 2. Number of predators removed at Snowy Plover nesting sites, 2002 - 2014.

\begin{tabular}{|c|c|c|c|c|c|c|c|c|c|c|}
\hline & Raven & Crow & $\begin{array}{r}\text { Red } \\
\text { fox }\end{array}$ & $\begin{array}{r}\text { Gray } \\
\text { fox } \\
\end{array}$ & Raccoon & $\begin{array}{r}\text { Striped } \\
\text { skunk }\end{array}$ & $\begin{array}{r}\text { Feral } \\
\text { cat }\end{array}$ & $\begin{array}{l}\text { Virginia } \\
\text { opossum }\end{array}$ & Coyote & $\begin{array}{r}\text { Great } \\
\text { Horned } \\
\text { Owl } \\
\end{array}$ \\
\hline $2002^{\mathrm{a}}$ & 12 & 14 & 6 & 2 & 12 & 5 & 1 & 1 & 0 & 0 \\
\hline $2003^{\mathrm{a}}$ & 150 & 38 & 12 & 2 & 8 & 6 & 1 & 1 & 0 & 0 \\
\hline 2004 & 150 & 101 & 27 & 3 & 19 & 13 & 4 & 17 & 0 & 0 \\
\hline 2005 & 82 & 132 & 15 & 0 & 0 & 3 & 2 & 3 & 0 & 0 \\
\hline 2006 & 145 & 89 & 17 & 0 & 0 & 8 & 1 & 0 & 4 & 0 \\
\hline 2007 & 65 & 144 & 13 & 3 & 2 & 7 & 0 & 0 & 0 & 1 \\
\hline 2008 & 219 & 122 & 15 & 0 & 3 & 2 & 1 & 0 & 2 & 0 \\
\hline 2009 & 151 & 169 & 10 & 2 & 3 & 4 & 4 & 0 & 2 & 0 \\
\hline 2010 & 81 & 168 & 7 & 0 & 1 & 3 & 0 & 0 & 1 & 0 \\
\hline 2011 & 95 & 178 & 15 & 0 & 0 & 6 & 0 & 0 & 0 & 1 \\
\hline 2012 & 225 & 50 & 13 & 0 & 0 & 3 & 0 & 0 & 2 & 0 \\
\hline 2013 & 213 & 123 & 20 & 0 & 0 & 0 & 0 & 0 & 0 & 0 \\
\hline 2014 & 185 & 130 & 6 & 0 & 0 & 0 & 0 & 0 & 0 & 0 \\
\hline Total & 1773 & 1458 & 176 & 12 & 48 & 60 & 14 & 22 & 11 & 2 \\
\hline
\end{tabular}

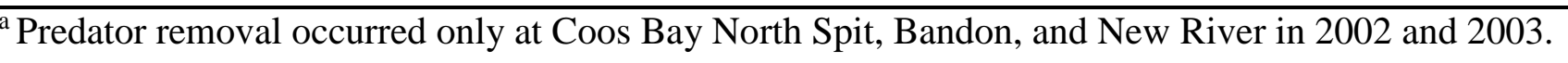


Table 3. Model selection results for apparent survival $(\varphi)$ and detection probability $(p)$ of adult Snowy Plovers along the Oregon coast, 1990 - 2014. Models are ranked by ascending $\triangle \mathrm{QAIC}$ values and shown with the model weight $\left(w_{i}\right)$, number of parameters $(K)$, and model deviance corrected for overdispersion $(\hat{c}=1.21)$. The $\mathrm{QAIC}_{\mathrm{c}}$ of the best model was 3099.65. Final parameters included sex (Sex), lethal predator management (PM), \% exclosure use (EX), wetter-than-average winter weather (Wet), and linear (T) and quadratic (TT) time trends. Only models with $\Delta \mathrm{QAIC}_{\mathrm{c}}$ less than 7 are shown.

\begin{tabular}{lrccr}
\hline Model & $\Delta$ QAICc & $w_{i}$ & $K$ & QDeviance \\
\hline$\varphi(\mathrm{T}) p(\mathrm{~T}+\mathrm{Sex})$ & 0.00 & 0.48 & 5 & 3089.63 \\
$\varphi(\mathrm{PM}) p(\mathrm{~T}+\mathrm{Sex})$ & 1.02 & 0.29 & 5 & 3090.65 \\
$\varphi(\mathrm{EX}) p(\mathrm{~T}+\mathrm{Sex})$ & 1.68 & 0.21 & 5 & 3091.31 \\
$\varphi(\mathrm{Wet}) p(\mathrm{~T}+\mathrm{Sex})$ & 6.03 & 0.02 & 5 & 3095.66 \\
\hline
\end{tabular}




\section{LIST OF FIGURES}

Figure 1. Snowy Plover breeding sites along Oregon coast, 1990 - 2014, and location of North Bend weather station used for weather data.

Figure 2. Effect of exclosure use on adult apparent survival, as estimated by model $\varphi(\mathrm{EX}) p(\mathrm{~T}+\mathrm{Sex})$ in Oregon, $1990-2014$.

Figure 3. Adult male and female Snowy Plover apparent survival with 95\% confidence intervals, in Oregon, $1990-2014$, based on model $\varphi(\mathrm{T}+\operatorname{Sex}) p(\mathrm{~T}+\mathrm{Sex})$. 


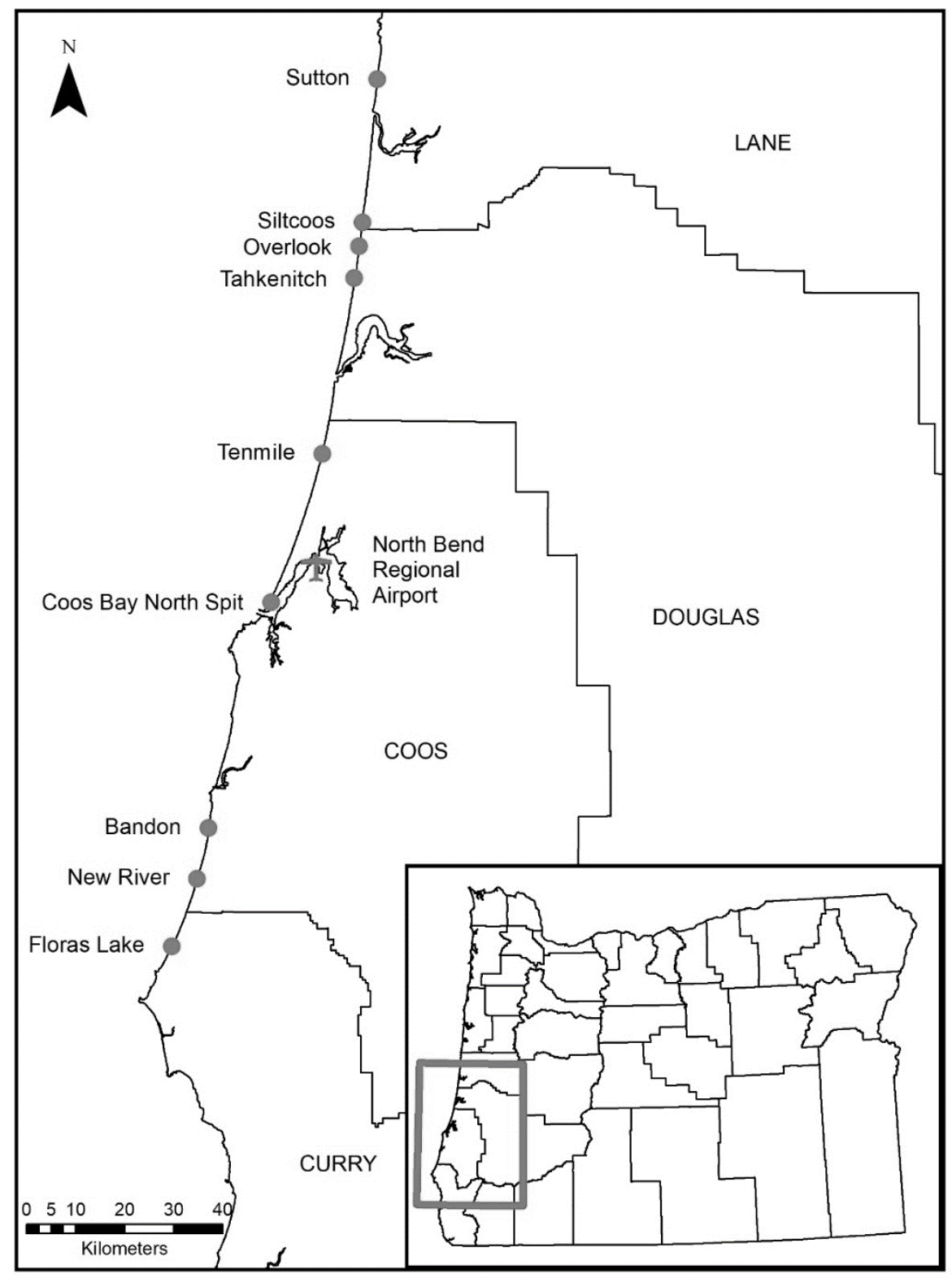

Figure 1. Snowy Plover breeding sites along Oregon coast, 1990 - 2014, and location of North Bend weather station used for weather data. 


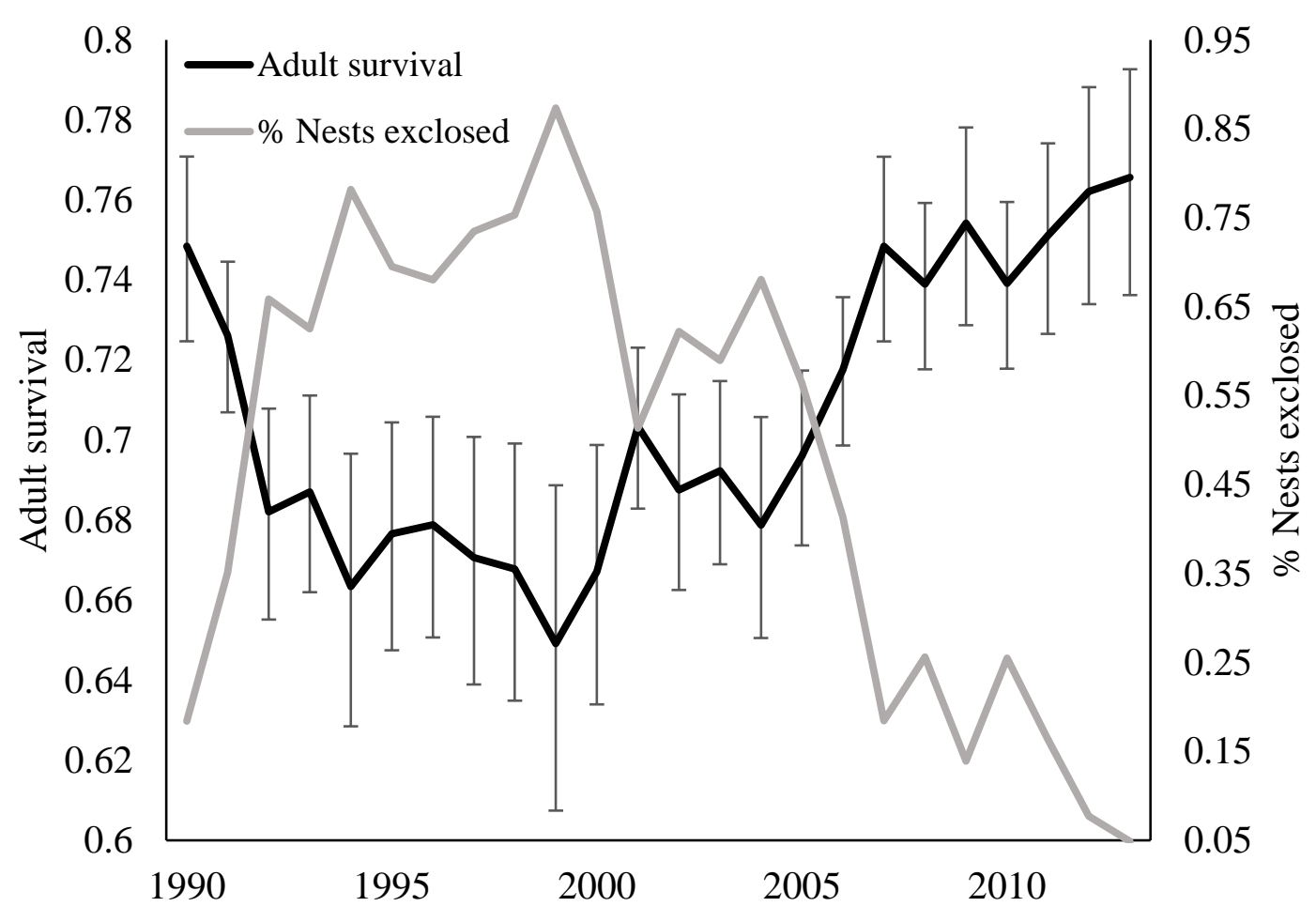

Figure 2. Effect of exclosure use on adult apparent survival, as estimated by model $\varphi(\mathrm{EX}) p(\mathrm{~T}+\mathrm{Sex})$ in Oregon, $1990-2014$. 


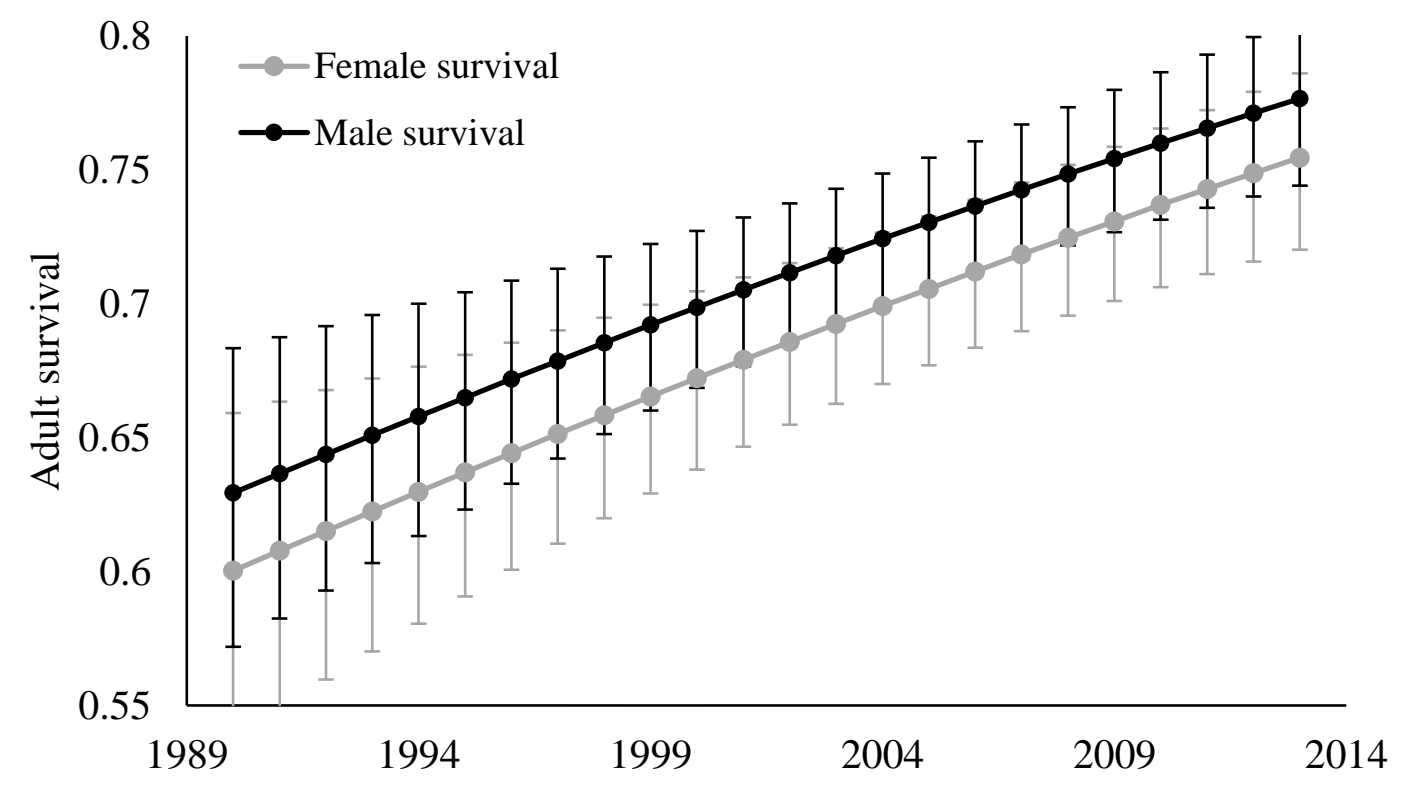

Figure 3. Adult male and female Snowy Plover apparent survival with $95 \%$ confidence intervals, in Oregon, $1990-2014$, based on model $\varphi(\mathrm{T}+\mathrm{Sex}) p(\mathrm{~T}+\mathrm{Sex})$. Although male survival was slightly higher than female survival, the difference was not significant. 


\section{LITERATURE CITED}

Akaike, H. (1992). Information theory and an extension of the maximum likelihood principle. Breakthroughs in statistics / Samuel Kotz, Norman L. Johnson editors.

Anders, A. D., and M. R. Marshall (2005). Increasing the accuracy of productivity and survival estimates in assessing landbird population status. Conservation Biology $19: 66-74$.

Arnold, T. W. (2010). Uninformative parameters and model selection using Akaike's Information Criterion. The Journal of Wildlife Management 74:1175-1178.

Barber, C., A. Nowak, K. Tulk, and L. Thomas (2010). Predator exclosures enhance reproductive success but increase adult mortality of Piping Plovers (Charadrius melodus). Avian Conservation and Ecology 5:6.

Barker, R. J. (1999). Joint analysis of mark-recapture, resighting and ring-recovery data with age-dependence and marking-effect. Bird Study 46:S82-S91.

Boarman, W. I. (2003). Managing a subsidized predator population: reducing Common Raven predation on desert tortoises. Environmental Management 32:205-217.

Brown, S. C., C. M. Hickey, B. Harrington, and R. Gill (2001). United States shorebird conservation plan. Manomet Center for Conservation Sciences.

Burnham, K. P., and D. R. Anderson (2002). Model Selection and Multi-model Inference. 2nd Edition. Springer-Verlag.

Burns, F., N. McCulloch, T. Szekely, and M. Bolton (2013). No overall benefit of predator exclosure cages for the endangered St. Helena Plover Charadrius sanctaehelenae. Ibis 155:397-401. 
Calvert, A. M., D. L. Amirault, F. Shaffer, R. Elliot, A. Hanson, J. McKnight, and P. D. Taylor (2006). Population assessment of an endangered shorebird: the Piping Plover. Avian Conservation and Ecology-Écologie et conservation des oiseaux 1:4.

Calvert, A. M., and P. D. Taylor (2011). Measuring conservation trade-offs: demographic models provide critical context to empirical studies. Avian Conservation and Ecology 6.

Catlin, D. H., J. H. Felio, and J. D. Fraser (2011). Effect of great-horned owl trapping on chick survival in piping plovers. The Journal of Wildlife Management 75:458462.

Cohen, J. B., A. Hecht, K. F. Robinson, E. E. Osnas, A. J. Tyre, C. Davis, A. Kocek, B. Maslo, and S. M. Melvin (2016). To exclose nests or not: structured decision making for the conservation of a threatened species. Ecosphere 7:e10499

Colwell, M. A., W. J. Pearson, L. J. Eberhart-Phillips, and S. J. Dinsmore (2013). Apparent survival of Snowy Plovers (Charadrius nivosus) varies with reproductive effort and year between sexes. The Auk 130:725-732.

Cormack, R. M. (1964). Estimates of survival from the sighting of marked animals. Biometrika 51:429-438.

Côté, I. M., and W. J. Sutherland (1997). The effectiveness of removing predators to protect bird populations. Conservation Biology 11:395-405. 
Deblinger, R. D., J. J. Vaske, and D. W. Rimmer (1992). An evaluation of different predator exclosures used to protect Atlantic coast Piping Plover nests. Wildlife Society Bulletin 20:274-279.

Dinsmore, S. J., M. B. Wunder, V. J. Dreitz, and F. L. Knopf (2010). An assessment of factors affecting population growth of the Mountain Plover. Avian Conservation and Ecology 5.

Dinsmore, S. J., D. J. Lauten, K. A. Castelein, E. P. Gaines, and M. A. Stern (2014). Predator exclosures, predator removal, and habitat improvement increase nest success of Snowy Plovers in Oregon, USA. The Condor 116:619-628.

Dinsmore, S. J., E. P. Gaines, S. F. Pearson, D. J. Lauten, and K. A. Castelein (2017). Factors affecting Snowy Plover chick survival in a managed population. The Condor: $34-43$.

Eberhart-Phillips, L. J., and M. A. Colwell (2013). Conservation challenges of a sink: the viability of an isolated population of the Snowy Plover. Bird Conservation International: $1-15$.

Eberhart-Phillips, L. J., C. Küpper, T. E. X. Miller, M. Cruz-López, K. H. Maher, N. dos Remedios, M. A. Stoffel, J. I. Hoffman, O. Krüger, and T. Székely (2017). Sexspecific early survival drives adult sex ratio bias in snowy plovers and impacts mating system and population growth. Proceedings of the National Academy of Sciences: 201620043.

English, W. B., E. Kwon, B. K. Sandercock, and D. B. Lank (2017). Effects of predator exclosures on nest survival of Red-necked Phalaropes. Wader Study 124:26-32. 
Estelle, V. B., T. J. Mabee, and A. H. Farmer (1996). Effectiveness of predator exclosures for Pectoral Sandpiper nests in Alaska. Journal of Field Ornithology $67: 447-452$.

Fletcher, K., N. J. Aebischer, D. Baines, R. Foster, and A. N. Hoodless (2010). Changes in breeding success and abundance of ground-nesting moorland birds in relation to the experimental deployment of legal predator control. Journal of Applied Ecology 47:263-272.

Galbraith, H., R. Jones, R. Park, J. Clough, S. Herrod-Julius, B. Harrington, and G. Page (2002). Global climate change and sea level rise: potential losses of intertidal habitat for shorebirds. Waterbirds 25:173.

Hardy, M. A., and M. A. Colwell (2008). The impact of predator exclosures on Snowy Plover nesting success: a seven-year study. Wader Study Group Bulletin 115:161-166.

Hernández-Camacho, C. J., V. J. Bakker, D. Aurioles-Gamboa, J. Laake, and L. R. Gerber (2015). The use of surrogate data in demographic population viability analysis: a case study of California sea lions. PLOS ONE 10:e0139158.

Heppell, S. S., L. B. Crowder, and D. T. Crouse (1996). Models to evaluate headstarting as a management tool for long-lived turtles. Ecological Applications 6:556-565.

Hitchcock, C. L., and C. Gratto-Trevor (1997). Diagnosing a shorebird local population decline with a stage-structured population model. Ecology 78:522-534. 
International Wader Study Group (2003). Waders are declining worldwide. Conclusions from the 2003 International Wader Study Group Conference, Cádiz, Spain. Wader Study Group Bulletin 101:8-12.

Johnson, H. E., L. S. Mills, T. R. Stephenson, and J. D. Wehausen (2010). Populationspecific vital rate contributions influence management of an endangered ungulate. Ecological applications: a publication of the Ecological Society of America 20:1753-1765.

Jolly, G. M. (1965). Explicit estimates from capture-recapture data with both death and immigration-stochastic model. Biometrika 52:225-247.

Kus, B. E, and M. J. Whitfield (2005). Parasitism, productivity, and population growth: Response of Least Bell's Vireo (Vireo bellii pusillus) and Southwestern Willow Flycatchrs (Empidonax traillii extimus) to cowbird (Molothrus spp.) control. Ornithological Monographs 57:16-27.

Lafferty, K. D., D. Goodman, and C. P. Sandoval (2006). Restoration of breeding by Snowy Plovers following protection from disturbance. Biodiversity \& Conservation 15:2217-2230.

Lavers, J. L., C. Wilcox, and C. J. Donlan (2010). Bird demographic responses to predator removal programs. Biological Invasions 12:3839-3859.

Lebreton, J.-D., K. P. Burnham, J. Clobert, and D. R. Anderson (1992). Modeling survival and testing biological hypotheses using marked animals: a unified approach with case studies. Ecological Monographs 62:67-118. 
Maness, T. J., and D. J. Anderson (2013). Predictors of juvenile survival in birds. Ornithological Monographs 78:1-55.

Martin, J., A. F. O’Connell Jr., W. L. Kendall, M. C. Runge, T. R. Simons, A. H. Waldstein, S. A. Schulte, S. J. Converse, G. W. Smith, T. Pinion, M. Rikard, and E. F. Zipkin (2010). Optimal control of native predators. Biological Conservation $143: 1751-1758$.

McNew L. B., A. J. Gregory, S. M. Wisely, and B. K. Sandercock (2012). Demography of greater prairie-chickens: Regional variation in vital rates, sensitivity values, and population dynamics. The Journal of Wildlife Management 76:987-1000.

Méndez, V., J. A. Alves, J. A. Gill, and T. G. Gunnarsson (2018). Patterns and processes in shorebird survival rates: a global review. Ibis: in press. doi: 10.1111/ibi.12586

Menne, M. J., I. Durre, R. S. Vose, B. E. Gleason, and T. G. Houston (2012). An overview of the Global Historical Climatology Network-Daily Database. Journal of Atmospheric and Oceanic Technology 29:897-910.

Muir, J. J., and M. A. Colwell (2010). Snowy Plovers select open habitats for courtship scrapes and nests. The Condor 112:507-510.

Mullin, S. M., M. A. Colwell, S. E. McAllister, and S. J. Dinsmore (2010). Apparent survival and population growth of Snowy Plovers in coastal Northern California. Journal of Wildlife Management 74:1792-1798.

Murphy, R. K., I. M. G. Michaud, D. R. C. Prescott, J. S. Ivan, B. J. Anderson, and M. L. French-Pombier (2003). Predation on Adult Piping Plovers at predator exclosure cages. Waterbirds 26:150-155. 
Neuman, K. K., G. W. Page, L. E. Stenzel, J. C. Warriner, and J. S. Warriner (2004). Effect of mammalian predator management on Snowy Plover breeding success. Waterbirds 27:257-263.

Nur, N., G. W. Page, and Stenzel, Lynne E. (1999). Population viability analysis for Pacific Coast Snowy Plovers. [Online.] Available at http://www.fws.gov/pacific/ecoservices/endangered/recovery/snowyplover/Appen dix_D.pdf.

Page, G. W., and L. E. Stenzel (1981). The breeding status of the Snowy Plover in California. Western Birds 12:1-40.

Page, G. W., L. E. Stenzel, J. C. Warriner, J. S. Warriner, and P. W. Paton (2009). Snowy Plover (Charadrius alexandrinus). The Birds of North America Online. https://doi.org/10.2173/bna.154

Pauliny, A., M. Larsson, and D. Blomqvist (2008). Nest predation management: effects on reproductive success in endangered shorebirds. The Journal of Wildlife Management 72:1579-1583.

Rees, J. D., J. K. Webb, M. S. Crowther, and M. Letnic (2014). Carrion subsidies provided by fishermen increase predation of beach-nesting bird nests by facultative scavengers. Animal Conservation 18:44-49.

Roche, E. A., T. W. Arnold, and F. J. Cuthbert (2010). Apparent nest abandonment as evidence of breeding-season mortality in Great Lakes Piping Plovers (Charadrius melodus). The Auk 127:402-410. 
Ruhlen, T. D., S. Abbott, L. E. Stenzel, and G. W. Page (2003). Evidence that human disturbance reduces Snowy Plover chick survival. Journal of Field Ornithology $74: 300-304$.

Sæther, B.-E., and Ø. Bakke (2000). Avian life history variation and contribution of demographic traits to the population growth rate. Ecology 81:642-653.

Sandercock, B. K. (2003). Estimation of survival rates for wader populations: a review of mark-recapture methods. Wader Study Group Bulletin 100:163-174.

Sandercock, B. K., T. Székely, and A. Kosztolányi (2005). The effects of age and sex on the apparent survival of Kentish Plovers breeding in southern Turkey. The Condor 107:583-596.

Seber, G. A. F. (1965). A note on the multiple-recapture census. Biometrika 52:249-259.

Sillett, T. S., and R. T. Holmes (2002). Variation in survivorship of a migratory songbird throughout its annual cycle. Journal of Animal Ecology 71:296-308.

Sim, I. M. W., G. W. Rebecca, S. C. Ludwig, M. C. Grant, and J. M. Reid (2011). Characterizing demographic variation and contributions to population growth rate in a declining population. Journal of Animal Ecology 80:159-170.

Stahl, J. T., and M. K. Oli (2006). Relative importance of avian life-history variables to population growth rate. Ecological Modelling 198:23-39.

Stearns, S. C. (1976). Life history tactics: a review of the ideas. The Quarterly Review of Biology 51:3-47.

Stenzel, L. E., G. W. Page, J. C. Warriner, J. S. Warriner, D. E. George, C. R. Eyster, B. A. Ramer, K. K. Neuman, and B. K. Sandercock (2007). Survival and natal 
dispersal of juvenile snowy plovers (Charadrius alexandrinus) in central coastal California. The Auk 124:1023-1036.

Stenzel, L. E., G. W. Page, J. C. Warriner, J. S. Warriner, K. K. Neuman, D. E. George, C. R. Eyster, and F. C. Bidstrup (2011). Male-skewed adult sex ratio, survival, mating opportunity and annual productivity in the Snowy Plover Charadrius alexandrinus. Ibis 153:312-322.

Stringham, O. C., and O. J. Robinson (2015). A modeling methodology to evaluate the efficacy of predator exclosures versus predator control. Animal Conservation 18:451-460.

Thomas, S. M., J. E. Lyons, B. A. Andres, E. E. T-Smith, E. Palacios, J. F. Cavitt, J. Andrew Royle, S. D. Fellows, K. Maty, W. H. Howe, E. Mellink, et al. (2012). Population size of Snowy Plovers breeding in North America. Waterbirds 35:114.

U.S. Department of Agriculture and U.S. Department of Interior (2002). Predator damage management to protect the federally threatened Pacific coast population of the Western Snowy Plover. Prepared by USDA, APHIS, Wildlife Services Program and the Siuslaw National Forest; USDI, Fish and Wildlife Service Region 1 and Bureau of Land Management Coos Bay District; and in cooperation with the Oregon Department of Fish and Wildlife, and Oregon Parks and Recreation Department. 
U. S. Fish and Wildlife Service (1993). Determination of Threatened Status for the Pacific Coast Population of the Western Snowy Plover. Federal Register 58:12864-12874.

U.S. Fish and Wildlife Service (2007). Recovery Plan for the Pacific Coast Population of the Western Snowy Plover (Charadrius alexandrinus nivosus). In 2 volumes.

Watts, C. M., J. Cao, C. Panza, C. Dugaw, M. Colwell, and E. A. Burroughs (2012). Modeling the effects of predator exclosures on a Western Snowy Plover population. Natural Resource Modeling 25:529-547.

White, G. C., and K. P. Burnham (1999). Program MARK: survival estimation from populations of marked animals. Bird Study 46:S120-S139.

Wiedemann, A. M. (1984). Ecology of Pacific Northwest Coastal Sand Dunes: A Community Profile. Evergreen State Coll., Olympia, WA (USA) FWS/OBS$84 / 04$.

Wiedemann, A. M. (1987). The ecology of European beachgrass. Oregon Department of Fish and Wildlife 87.

Williams, G. C. (1966). Natural selection, the costs of reproduction, and a refinement of Lack’s principle. American Naturalist 100:687-690.

Wilsey, C. B., J. J. Lawler, D. Cimprich, and N. H. Schumaker (2014). Dependence of the endangered Black-capped Vireo on sustained cowbird management. Conservation Biology 28:561-571. 
Wolter, K., and M. S. Timlin (2011). El Niño/Southern Oscillation behaviour since 1871 as diagnosed in an extended multivariate ENSO index (MEI.ext). International Journal of Climatology 31:1074-1087. 


\section{CHAPTER 5. A MATRIX MODEL TO COMPARE EFFECTS OF LETHAL PREDATOR MANAGEMENT ON SNOWY PLOVER POPULATION GROWTH IN OREGON}

Eleanor P. Gaines ${ }^{1}$, Stephen J. Dinsmore ${ }^{2}$, and Michael T. Murphy ${ }^{3}$

${ }^{1}$ Oregon Biodiversity Information Center - Institute for Natural Resources, Portland State University, PO Box 751, Portland, OR USA

${ }^{2}$ Department of Natural Resource Ecology and Management, 339 Science II, Iowa State University, Ames, IA USA

${ }^{3}$ Biology Department, Portland State University, PO Box 751, Portland, OR USA ABSTRACT

We modeled the population dynamics of the federally threatened Western Snowy Plover (Charadrius nivosus nivosus) along the Oregon coast in an effort to better understand local population dynamics and associated uncertainty. Our goals were to 1) assess relative contribution of demographic rates on population growth, 2) project population growth and viability 15 years into the future, and 3) compare expected population growth under varying levels of predator management. Elasticity analysis showed that population growth is most sensitive to changes in adult survival, followed by first year survival and adult productivity. Our model predictions tracked observed population growth through 2018 and forecasted an adult male population of 473 in 2029 under current management conditions - nearly doubling the population in 10 years. Current management resulted in continued positive population growth, but a reduced management scenario that included lethal predator removal on only $50 \%$ of the current population was predicted to maintain 
the population above recovery levels for at least the next 15 years. Alternative scenarios for population management should thus remain flexible and responsive to future trends in plover numbers.

Key words: adult survival, Charadrius nivosus, matrix population model, population viability analysis, predator management

\section{INTRODUCTION}

Population growth is a function of recruitment, survival, emigration, and immigration. A thorough understanding of these population parameters is crucial to effective conservation (Sibly and Hone 2002, Sandercock 2003, Anders and Marshall 2005, Stahl and Oli 2006), but this information is often lacking for threatened species - the very populations that need it most. Without such knowledge, management actions can be directed towards improving life history parameters that may have negligible effects on population growth (Crouse et al. 1987, Heppell et al. 1996, Dinsmore et al. 2010, Johnson et al. 2010). Further, management directed at one vital rate may have unintended consequences at other life stages that can negate the efforts' benefits. Given the limited resources available for recovery of declining species, especially when populations approach recovery goals, managers need information on how best to maintain populations so that efforts and resources can be directed where and when they will be most effective. For conservation-reliant species, removal of management is likely to result in population decline but for species with sufficient demographic data, population viability analysis (PVA) offers the opportunity to use quantitative measures to assess extinction risk, document progress towards recovery, identify relative importance of specific vital rates, 
and predict expected response to changing management scenarios (Beissinger and Westphal 1998, Nur et al. 1999, White 2000, Morris and Doak 2002, Armstrong et al. 2006, Servanty et al. 2014). PVA thus offers managers an opportunity to objectively assess future management actions by weighing population responses.

Shorebird populations are experiencing alarming declines in the US and globally (Brown et al. 2001, International Wader Study Group 2003, Colwell 2010), and are often the target of intensive management. For example, the Pacific Coast population of the Western Snowy Plover (Charadrius nivosus nivosus) that occurs within $80 \mathrm{~km}$ of the Pacific Coast from Damon Point, Washington to Bahia Magdalena, Baja Sur California (Figure 1, U.S. Fish and Wildlife Service 2007, Page et al. 2009) is federally threatened because of poor recruitment and survival (U.S. Fish and Wildlife Service 1993, U.S. Fish and Wildlife Service 2007, Thomas et al. 2012). Limiting factors include increasing predation from native and non-native predators (Neuman et al. 2004), human disturbance (Ruhlen et al. 2003, Lafferty et al. 2006), and habitat loss to development, exotic vegetation, and recreational use (Page and Stenzel 1981, U.S. Fish and Wildlife Service 1993, 2007, Page et al. 2009, Galbraith et al. 2002, Muir and Colwell 2010). After federal listing in 1993, land management agencies in Oregon implemented an intensive adaptive management program, including habitat restoration, seasonal recreation restrictions, and integrated predator management in an effort to recover Snowy Plovers in Oregon. Management has been effective; Snowy Plover populations in Oregon have grown by nearly an order of magnitude over the last 25 years (Table 1), although they remain a conservation-reliant species. Management actions improved survival at particular life 
stages (Dinsmore et al. 2014, 2017, Gaines et al. in prep; Chapters 2 through 4), but their effect on overall population growth has not been comprehensively analyzed. With limited resources available for management of a species approaching recovery, information on the effects of individual management actions on population growth are needed.

The Snowy Plover recovery plan identifies a recovery goal for Oregon and Washington of 250 birds (U. S. Fish and Wildlife Service 2007). Snowy Plovers are wellstudied along the Pacific Coast, but to date no PVA has focused on the Oregon population. Nur et al. (1999) conducted a range-wide metapopulation PVA of the coastal population, incorporating demographic and environmental stochasticity, as part of the Snowy Plover recovery plan (U.S. Fish and Wildlife Service 2007). In Nur et al.'s PVA, the Oregon birds were combined with the small population in Washington into Recovery Unit 1, one of six subpopulations. Nur et al. (1999) predicted that the range-wide metapopulation would gradually decline, but that all subpopulations were likely to persist for 100 years, albeit at low levels. However, few subpopulations in the range-wide analysis were intensively managed. Because of the intractability of improving adult survival, Nur et al. (1999) identified improvements in productivity as the most likely route to recovery, and recommended a minimum of 1.0 chick fledged per breeding male to maintain the range wide population size. Eberhart-Phillips and Colwell (2013) conducted a PVA of the small sink population in Northern California (Mullin et al. 2010) in the context of surrounding source populations in Oregon, San Francisco Bay, and Monterey Bay. They determined that under current management, the Northern California population was unlikely to reach recovery goals established in the Snowy Plover recovery 
plan (U.S. Fish and Wildlife Service 2007), but identified lethal predator management and recreation management as options that could facilitate recovery.

The Snowy Plover population along the Oregon coast is the largest north of the central California coast, and is at the northern end of the species' range (a small population occurs farther north, along the Long Beach peninsula in Washington). Environmental and management conditions in Oregon differ from those elsewhere in the range. Furthermore, vital rates often vary spatially and temporally, and effective conservation requires a thorough understanding of local population dynamics (Anders and Marshall 2005, McNew et al. 2012, Eberhart-Phillips and Colwell 2013). The Oregon population has been intensively monitored since 1990 and approximately $80 \%$ of the population is color-banded (Table 1). Recent survival analyses across the life cycle (Gaines et al. in prep; Chapters 2 through 4) provide an excellent opportunity to explore the effect of management on population growth in a threatened species. Additionally, an integrated predator management program that includes lethal removal has been in place in Oregon since 2002. Our survival analyses (Gaines et al. in prep; Chapters 2 through 4) showed that lethal nest predator management benefited not just the targeted life stages (nest and chick survival), but also adult survival. On the other hand, widespread use of nest exclosures appeared to have adverse effects on adult survival (Gaines et al. in prep; Chapter 5). Thus, a synthetic analysis of Oregon Snowy Plover survival and productivity as a PVA is needed, and here we use a stage-based matrix population model to evaluate the relative contribution of vital rates to population growth using elasticity analysis, and analyze the effects of lethal predator control on predicted future population trajectories. 
Our goals were to 1) assess relative contribution of demographic rates on population growth, 2) project population growth and viability 15 years into the future, and 3) compare projected population growth under different predator management scenarios. This model will inform Snowy Plover conservation in Oregon and allow mangers to efficiently maintain progress towards recovery. Additionally, the model could be modified to analyze other management effects, combined with information from other recovery units to explore metapopulation dynamics, or be used for species with similar life histories but less comprehensive demographic data.

\section{METHODS}

\section{Study area}

As part of a long-term monitoring project, we studied breeding Snowy Plovers from 1990 through 2014 at nine sites along a $137 \mathrm{~km}$ stretch of the Oregon coast (Figure 1). Although plovers occasionally nested (twice) at other Oregon beaches during the study period, these sites encompassed all regularly occupied coastal habitat in Oregon. Habitat included ocean beaches and sand spits, ocean overwash sites within sand dunes dominated by European beachgrass (Ammophila arenaria), open estuarine areas with sand flats, and several areas of restored habitat. Breeding season management for the Snowy Plover in Oregon was extensive and included habitat restoration and maintenance, recreation restrictions, and an integrated predator management plan that incorporated both lethal and non-lethal actions. Habitat restoration and maintenance involved removal of steep foredunes dominated by invasive European beachgrass to create wide, gently sloping, open nesting habitat. Public recreation was restricted in dry sand portions of 
Snowy Plover nesting beaches to minimize disturbance to incubating adults and improve nest survival. Predator management in Oregon included passive measures such as hazing and removal of garbage and carcasses from nesting beaches, and active control ranging from protective nest exclosures to lethal removal of problem predators (Dinsmore et al. 2014). Snowy Plovers exhibit high breeding site fidelity and natal philopatry (Page et al. 1983, Warriner et al. 1986, Paton 1994, Stenzel et al. 1994, Powell and Collier 2000, Stenzel et al. 2007). Although some dispersal occurs between states, the Oregon population is geographically remote; the nearest nesting sites in California and Washington are over $220 \mathrm{~km}$ away. Thus, we treated the Oregon population as demographically closed.

\section{Field methods}

We observed all banded and unbanded plovers and located nests at all sites during atleast-weekly surveys from early April until all broods fledged, typically mid-September each year (Dinsmore et al. 2014). We recorded sex of adults based on plumage and behavior (Page et al. 2009); sex was not identifiable in the birds' first year. We located nests by observing adult behavior and following plover tracks, and estimated hatching date by counting 29 days from clutch completion (Warriner et al. 1986, Page et al 2009). When nests were found with complete clutches we estimated anticipated hatch date by floatation (Westerskov 1950, Rizzolo and Schmutz 2007). All known nests were checked at least weekly to determine fate, more frequently as the anticipated hatch date approached. All hatch-year birds seen at any point after 28 days post-hatch were considered fledged (Warriner et al. 1986, Page et al. 2009). We began color-banding 
adults and chicks in 1990 and in most years approximately $80 \%$ of the adult population was banded (Table 1). See Dinsmore et al. (2017) for details of the banding program. Initial management to counter high levels of predation, short of lethal control (see above), began in 1990 (Dinsmore et al. 2014). Further steps to improve nest and fledging success began in 2002 with the initiation of an integrated predator management plan at Coos Bay North Spit, Bandon Beach, and New River that included lethal removal of plover predators (U.S. Department of Agriculture and U.S. Department of Interior 2002, Dinsmore et al. 2017). In 2004, lethal predator management was extended to all nine sites and continued for the duration of the study. Predator management was conducted by USDA APHIS-Wildlife Services in coordination with the Recovery Unit 1 Snowy Plover Working Team, and primarily targeted nest and chick predators, including American Crows (Corvus brachyrhynchos), Common Ravens (Corvus corax), nonnative red fox (Vulpes vulpes), and striped skunks (Mephitis mephitis). Other non-target predators, including Great Horned Owls (Bubo virginianus), Northern Harriers (Circus hudsonius), coyotes (Canis latrans), raccoons (Procyon lotor), and feral cats (Felis catus), were removed when they exhibited focused attention on plover nests through regular presence or hunting on a nesting area, and non-lethal control measures proved ineffective. Corvids comprised $90 \%$, red fox accounted for $5 \%$, and striped skunk made up $2 \%$ of the predators removed between 2002 and 2014. All other predator species accounted for less than $1 \%$ of the total removals (Table 2). Predator management activities began before plover nesting (typically in February each year) and continued through August. 
This work was permitted by Portland State University IACUC number

PSU13.11.25.1, U.S. Fish and Wildlife Service recovery permits TE839094 and TE39372B, U.S. Fish and Wildlife Service banding permits 21825 and 23854, and Oregon Department of Fish and Wildlife annual scientific take authorizations.

\section{Population model}

Snowy Plovers breed as second-year birds ( 11-12 months), and most breed annually thereafter (Warriner et al. 1986). Our age-specific survival analysis found lower survival in the birds' first year, but there was no support for age-related differences in survival after birds' second year (Gaines et al. in prep; Chapter 3). Thus, we developed a twostage life cycle diagram for first year (Age0) and adult (Age1+) life stages (Caswell 2001; Figure 2) based on a post-breeding census, birth-pulse population, and a one-year census interval. We used this diagram to produce a male-based matrix model (Caswell 2001, Morris and Doak 2002; Equation 1). We saw no significant variation in survival as adults aged (Gaines et al. in prep; Chapter 3), and thus we assumed adult survival was constant beginning with Age1+. We accounted for variable survival in the birds' first year by partitioning Age0 survival into chick survival from hatching to fledging and juvenile survival from fledging to the following spring (described more fully below). Our model is male-based because broods are typically reared by the male, and Snowy Plover demographic parameters can be estimated with greater certainty for males than for females (Warriner et al. 1986, Nur et al. 1999). Thus, the fecundity values in the matrix represent male offspring per male. Our model assumed that all males bred, an assumption largely supported by our field observations. Our study covered nine breeding beaches 
(Figure 1), but because adult birds moved between these sites, we treated the entire study area as one site.

Vital rates - We monitored banded Snowy Plovers during the breeding season from 1990 to 2014 (Dinsmore et al. 2014, Dinsmore et al. 2017, Gaines et al. in prep; Chapters 2 through 4) and vital rates derived from this work form the foundation of our population model (Table 3, Equation 1).

$$
\begin{gathered}
\boldsymbol{A}=\left[\begin{array}{ll}
F_{1} & F_{2} \\
P_{1} & P_{2}
\end{array}\right]=\left[\begin{array}{cc}
\varphi_{c} * \varphi_{j} * m & \varphi_{a} * m \\
\varphi_{c} * \varphi_{j} & \varphi_{a}
\end{array}\right] \text { (equation 1) } \\
\left.m=\left(c s * h * S_{n} * n * 0.5\right) \text { (equation } 2\right)
\end{gathered}
$$

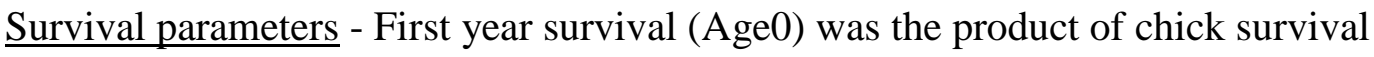
from hatching to fledging and juvenile survival from fledging to the following spring. We estimated mean daily chick survival $\left(\varphi_{c}\right)$ using the young survival from marked adults model (Lukacs et al. 2004) implemented in Program MARK (version 8.2, White and Burnham 1999), and encounter histories of 4,058 chicks from 1,603 broods. This method estimates mean daily survival and detection probability during the 28-day brood-rearing period, based on repeated brood counts associated with individually marked adults. We estimated mean chick survival using our most parsimonious model for daily brood survival $\left(\varphi\left(\right.\right.$ Age $5+$ Site $\left.+\mathrm{PM}+\mathrm{Hatch}^{2}+\mathrm{Cold}\right) p(\mathrm{TT})$, extended to a 28-day brood-rearing period. In this model, brood survival improved significantly after the chicks' fifth day, varied by site, was better with lethal predator management, was best during the peak breeding season, and was negatively affected by cold weather, particularly during the first five days of the brood period. We used the variance components procedure in Program MARK to separate process variance from sampling error in estimates of chick survival, 
and used only the process variance in the matrix model. We evaluated the effect of lethal predator management on chick survival by running this model with and without predator management, holding all other covariates at their mean values.

We estimated mean juvenile apparent survival $\left(\varphi_{\mathrm{j}}\right)$, accounting for detection probability, from fledging to the following spring using an age-specific Cormack-JollySeber (CJS; Cormack 1964, Jolly 1965, Seber 1965) model in Program MARK, with time dependence on the juvenile stage $(\varphi($ Age2 yr/.) $p($ Age2 yr/.)). We used encounter histories of 1,522 banded individuals hatched in Oregon that survived to fledge at 28 days to estimate juvenile survival, and corrected for slight overdispersion in the juvenile survival data by adjusting the variance inflation factor $(\hat{c})$ to 1.03 . We used this model to estimate juvenile survival, but estimated Age1+ survival separately (see below) because this allowed us to include additional adults that were not initially banded as chicks in Oregon in our analysis. We did not include sex in the juvenile model because we were only able to determine the sex of birds returning to Oregon as adults. We used the variance components procedure in Program MARK to separate process variance from sampling error in annual estimates of juvenile survival and used only the process variance in the matrix model. We estimated the effect of predator management on juvenile survival using the most parsimonious model from our juvenile survival analysis (Gaines et al. in prep; Chapter 3) that contained predator management as an effect on juvenile survival ( $\varphi($ Age PM/.) $p($ Age T/.)). This model explained variation in juvenile survival as a function of predator management, and in detection probability as a positive linear time trend. 
We estimated mean adult (Age1+) apparent survival $\left(\varphi_{\mathrm{a}}\right)$, accounting for detection probability, using a fully time-dependent $(\varphi(\mathrm{yr}) p(\mathrm{yr}))$ live recaptures CJS model in Program MARK and encounter histories of 1,069 banded birds observed as adults at least once in Oregon. We corrected for slight overdispersion in the adult survival data by adjusting the variance inflation factor $(\hat{c})$ to 1.21 . We did not include sex as a covariate in our adult survival analysis because previous analyses showed no significant difference in adult survival by sex for the Oregon population (Gaines et al. in prep; Chapter 4). We used the variance components procedure in Program MARK to separate process variance from sampling error in annual estimates of adult survival, and included only process variance in the matrix model. We estimated the effect of predator management on adult survival using the most parsimonious model from our adult survival analysis (Gaines et al. in prep; Chapter 4) that contained predator management as an effect ( $\varphi(\mathrm{PM})$ $p(\mathrm{~T}+\mathrm{Sex}))$. This model estimated higher survival for adults exposed to predator management. Detection probability of adults was best explained by a positive linear trend over time, and was higher for males than females.

Fecundity parameters - Fecundity parameters included the mean number of male chicks hatched per male $(m)$, and stage-specific survival to the following year. Productivity $(m)$ was the product of the mean number of nests attended to per male annually $(n)$, the mean clutch size (cs), the probability that a nest would survive the 29day incubation period $(S n)$, and the probability that an individual egg would hatch at a successful nest $(h)$. We assumed an even sex ratio at hatch (Székely et al. 2004, Stenzel et al. 2007, Eberhart-Phillips et al. 2017, Que et al. 2019), and so multiplied productivity by 
0.5. We used a fully time-dependent model $(\mathrm{S}(\mathrm{t})$ ), the nest survival model (Dinsmore et al. 2002), and the Markov Chain Monte Carlo (MCMC) procedure in Program MARK to estimate mean daily nest survival for 3,456 nests across the 155-day nesting season, and extended that to a 29-day incubation period. We used the delta method (Powell 2007) to calculate mean process variance of nest survival from MCMC estimates. We used observed data from monitoring at these 3,456 nests between 1990 and 2014 to estimate the mean and total variance of the annual number of nests attended to per male, the clutch size, and the probability that an individual egg would hatch from a successful nest.

Matrix model - To study the dynamics of the Oregon population, we first built a deterministic matrix model that included the mean values of the demographic parameters (Table 3). Initial stage abundances corresponded to the observed number of male chicks and adults in 1990 (12 chicks, assuming an equal sex ratio at hatch, and 37 adults). We calculated the matrix values from the vital rates as follows. We defined $P_{1}$ as first year survival; the probability that a newly-hatched bird survives to the following spring (Equation 1). $P_{1}$ is the product of chick survival to fledging $\left(\varphi_{\mathrm{c}}\right)$ and juvenile survival from fledging to the following spring ( $\varphi_{\mathrm{j}}$, Table 3$)$. We defined $P_{2}$ as adult annual survival of all birds Age1+ $\left(\varphi_{\mathrm{a}}\right)$. We estimated fecundity values based on the reproductive contributions of Age 0 birds $\left(F_{1}\right)$ and Age $1+\operatorname{birds}\left(F_{2}\right)$ in the next year. Fecundity values included the stage-specific probability of surviving to the next year $\left(\varphi_{\mathrm{i}}\right)$ and per-capita male productivity ( $m$, Equation 2 ). We did not have data to support separate productivity estimates for Age 0 and Age1+ birds, so we used the same estimates across stages. We assumed all birds attempted breeding (probability of breeding $=1.0$ ), which was largely 
supported by observation of color-banded individuals (Institute for Natural Resources, unpublished data). We projected the deterministic model forward 25 years $(1990-2014)$ using code modified from the package 'popbio' implemented in program R version 3.5.1 (deKroon et al. 2000, Caswell 2001, Morris and Doak 2002, Stubben and Milligan 2007, R Core Team 2018). We used this model to estimate the deterministic growth rate $\left(\lambda_{d}\right)$ with $95 \%$ confidence intervals, the stable stage distribution, and the elasticity of $\lambda_{d}$ to variation in the matrix elements and individual vital rates.

Elasticity analysis quantifies the proportional change in $\lambda$ as a function of a small, proportional change in matrix elements and thus identifies matrix values that contribute most to population growth (deKroon et al. 2000, Caswell 2001). Thus, elasticity analysis can be used to identify life stages that should be a focus of management (Caswell 2000, Caswell 2001). Although we also report elasticities of the individual vital rates, unlike elasticity of the matrix values, they cannot be interpreted as contributions to $\lambda$, and do not sum to 1 (Caswell 2001, Zuidema and Franco 2001). However, we include them here because their relative values help identify important vital rates.

We introduced environmental stochasticity to the model by allowing each vital rate to vary based on a probability distribution function described by the vital rates' mean and variance. We used a beta distribution for adult, juvenile, chick, nest, and egg survival rates, and a stretched beta distribution (limits $=0$ to 3 ) for the number of clutches per male and the clutch size (Morris and Doak 2002). We rarely observed clutch sizes > 3 eggs, and these clutches were almost never successful. We assumed offspring sex ratio remained stable. We simulated 10,000 iterations of the stochastic model in $\mathrm{R}$ to estimate 
the stochastic population growth rate $\left(\lambda_{\mathrm{s}}\right)$ from 1990 through 2014 with $95 \%$ confidence intervals. We then projected the model forward from 2014 through 2029 to estimate mean male population size in 2029 with $95 \%$ CI. We limit our projection to 15 years (2014 through 2029), a reasonable time frame for management decision-making, to limit propagation of error in model results (Beissinger and Westphal 1998). When projecting forward, we used the numbers of male chicks and adults observed in 2014 (279 and 188, respectively) for an initial stage abundance. We used 100 iterations of the stochastic model to show estimated population trajectories from 1990 through 2029, and compared these model estimates to observed population counts through 2018 to informally assess model performance.

The Snowy Plover recovery plan identifies a recovery goal for Oregon and Washington of 250 birds (U. S. Fish and Wildlife Service 2007). Assuming an equal sex ratio (Table 1), we report the percent of the 10,000 projections that fell below the recovery goal of 125 males. Small populations are more susceptible to extinction (Pimm et al. 1988, Morris and Doak 2002), so we identified a quasi-extinction threshold of 25 males and report the percent of 10,000 iterations that fell below this level. Our model assumed vital rates were not strongly correlated with each other. We found no support for density dependence in survival rates (Gaines et al, in prep; Chapters 3 and 4), and thus did not include density effects in our model. Because we lacked comprehensive data, we did not include immigration in the model, but observed rates were low.

We modified the stochastic model to predict the effects of varying levels of lethal predator management on population growth between 2015 and 2029, assuming other 
management actions (habitat maintenance and seasonal recreation restrictions) continued as in the past. We identified the effect of predator management on $0,25,50,75$, and $100 \%$ of the population by multiplying the predator management effect size for adult, juvenile and chick survival by $0.00,0.25,0.50,0.75$, and 1.00 and adding that to the respective vital rates estimated with no predator management. The effect of predator management on nest survival and mean number of nests per male were confounded with exclosure use (Dinsmore et al. 2014), and we saw no difference in clutch size or probability of individual eggs hatching at nests with or without predator management. Thus, we used the mean values and variances from the stochastic model for the productivity values when analyzing effects of predator management. When projecting forward, we used the numbers of male chicks and adults observed in 2014 (279 and 188, respectively) for an initial stage abundance. For each level of the predator management effects model, we ran 10,000 iterations and estimated mean $\lambda_{\mathrm{s}}$ and male population size in 2029. We report the percent of the iterations that fell below the U.S. Fish and Wildife Service recovery goal and the quasi-extinction threshold.

We built all survival models using the design matrix and the logit link function in Program MARK. We used an information-theoretic approach (Burnham and Anderson 2002) and model selection by Akaike's information criterion (Akaike 1992) corrected for small sample size and overdispersion $\left(\mathrm{QAIC}_{c}\right)$ to compare models for adult, juvenile, and chick survival. The nest survival model does not require correction for overdispersion so model selection was by $\mathrm{AIC}_{\mathrm{c}}$. We used the model with the lowest $\mathrm{AIC}_{\mathrm{c}} / \mathrm{QAIC}$ for inference and parameter estimation (Burnham and Anderson 2002), but removed from 
consideration models within $2 \mathrm{AIC}_{\mathrm{c}} / \mathrm{QAIC}$ units that added a parameter without improving model deviance to ensure that $\Delta \mathrm{AIC}_{\mathrm{c}} / \mathrm{QAIC}_{c}$ values were not the result of uninformative parameters (Arnold 2010). To separate process variance from sampling error, we used fully time-dependent survival models, not necessarily the most parsimonious models. We report means \pm standard error, and $95 \%$ CI unless otherwise specified.

\section{RESULTS}

Survival models for each stage class included annual variation, and the actual survival estimates (Table 3) closely matched those from our most parsimonious models that lacked time dependence (Gaines et al. in prep, Chapters 2 through 4). The deterministic population growth rate was 1.05 (95\% CI 1.01, 1.10). The deterministic model quickly reached a stable stage distribution of 0.52 for Age 0 birds and 0.48 for Age1+ birds. At the stable stage distribution, the standardized reproductive value of adults was 2.19 , indicating that Age1+ birds were more than twice as valuable to the population in terms of future productivity as Age0 birds. Elasticity analysis of the deterministic matrix revealed that adult survival contributed most to population growth, followed by first year survival and adult productivity (Table 4).

Our stochastic model projected a growing population at $\lambda_{\mathrm{s}}=1.03$ (95\% CI 1.03 , 1.04), based on 10,000 iterations of the model (Figure 3). As expected, the stochastic growth rate was lower than the deterministic estimate, and the CI of the stochastic estimate was much narrower. Under current management practices and environmental conditions, we projected the mean male population in 2029 at 473 individuals (95\% CI 
$466,481)$. Seventeen percent of the 10,000 iterations resulted in the population declining below the Recovery Unit 1 goal of 125 males at any time between 2014 and 2029. Only 3 $(<1 \%)$ of the iterations resulted in the population declining below our quasi-extinction level of 25 males during the same time period. A random sample of 100 iterations of the stochastic model showed predicted population growth through 2029 tended to fall below observed number of males from 1990 to 2018, suggesting our model was overly conservative (Figure 4).

Predator management had a strong effect on population growth (Table 5). Complete removal of predator management resulted in a declining population $\left(\lambda_{s}=0.97\right.$, $95 \% \mathrm{CI}=0.96,0.97)$, but our analysis indicated that predator management reduced to just over 50\% of current levels maintained a stable population (Table 5). With lethal predator management at $50 \%$ of current levels, $26 \%$ of the 10,000 iterations resulted in the population declining below recovery levels at any time between 2014 and 2029, and none reached quasi-extinction levels. At 50\% predator management, the model predicted a mean male population of $372(95 \% \mathrm{CI}=366,378)$ individuals in 2029. More conservatively, with predator management at $75 \%$ of current levels, we estimated a male population of $524(95 \% \mathrm{CI}=516,532)$ individuals, and only $13 \%$ of iterations fell below recovery levels at any point during the projection period.

\section{DISCUSSION}

Our study documented the relative contribution of varying vital rates on population growth of Snowy Plovers in Oregon. We projected population growth through 2029 (15 years after the end of our study), and compared predicted population growth under 
different predator management scenarios. Below, we discuss these findings and their effect on future conservation decision-making.

The Oregon population of Snowy Plovers grew over the last 30 years, as reflected in both observations and our models. Based on the stochastic model, under current management practices we expect Snowy Plovers in Oregon to continue to increase, expand their distribution to unoccupied beaches, and continue to serve as a source for smaller populations to the north and south (Colwell et al. 2007, Eberhart-Phillips and Colwell, 2013, Colwell et al. 2017, Scott Pearson pers. comm.). Indeed, in 2017 and 2018 banded plovers nested at beaches that had been unoccupied since at least the 1970s (Oregon Parks and Recreation Department, Institute for Natural Resources, unpublished data). In 2018, Snowy Plovers nested in every county along the Oregon coast. Although population growth observed through 2018 fell well within our model's projected values, our stochastic estimates were slightly low compared to observed population growth, particularly in later years (Figure 4). This may be because we did not include immigration in the model. We know there is limited dispersal between populations in WA, OR and CA, but did not have comprehensive immigration information to include in our model, and thus treated Oregon as a closed population. Although often overlooked in PVAs, immigration is a key vital rate in many populations (Beissinger and Westphal 1998, Schaub et al. 2013, Tauler et al. 2015, Colwell et al. 2017). An integrated model coupled with a Bayesian population viability analysis could estimate immigration rates and is an avenue for future work (Schaub et al. 2007, Saunders et al. 2018). Our estimates of variance for productivity parameters may have also biased projections low. These 
estimates included sampling variation, resulting in artificially high variance. High variances lead to suppressed population growth estimates (Beissinger and Westphal 1998, White 2000, Morris and Doak 2002). Finally, our adult and juvenile survival analyses report apparent survival and thus may be biased low. However, from a management perspective, if an error is to be made, it is better to be conservative and under- rather than overestimate growth.

As is seen in most relatively long-lived species, elasticity analysis of the Oregon population revealed that population growth relied more on survival, particularly adult survival, than on productivity (Saether and Bakke 2000, Dinsmore et al. 2010, Murphy et al. 2017). When using elasticity analysis to inform management, it is important that the targeted vital rate be amenable to improvement through management (Hiraldo et al. 1996, Manlik et al. 2017). Often, few management alternatives exist to improve adult survival; in these cases, less elastic vital rates may be a better target (Beissinger and Peery 2007, Manlik et al. 2016). However, in Oregon, lethal predator management was a particularly effective management option because it improved both productivity, through increased nest success, and survival across the life cycle.

Predator management was implemented in Oregon to improve nest and chick survival (U.S. Department of Agriculture and U.S. Department of Interior 2002, Dinsmore et al. 2014, 2017). However, predator management also benefited adult survival, the vital rate that contributed most to growth in this population (Gaines et al. in prep; Chapter 4). Our model demonstrated the effectiveness of the predator management program in Oregon; when lethal control was removed, the model predicted a rapidly 
declining population (Table 5). Lethal predator management is costly, both in terms of staff resources and public perception, and weighing these costs against the population benefits is an important topic for discussion. The predator management program in Oregon was targeted; great effort was extended to ensure only individuals that preyed on plover nests were removed (U.S. Department of Agriculture and U.S. Department of Interior 2002). This specificity was labor-intensive for Wildlife Services technicians, and required comprehensive breeding season monitoring to inform predator removal and evaluate its success. Our stochastic model suggested that predator management could be reduced, perhaps to as much as $50 \%$ of the traditional nesting sites, while still maintaining population growth. Any reduction in predator management should be closely monitored to ensure the population maintains recovery goals. It is also important to emphasize that our model assumed that other management actions - habitat maintenance and recreation management - continued as they have in the recent past. Although we did not explore the effect of these actions on population growth, our model could be modified to analyze their input on the population. Certainly, having suitable habitat protected from disturbance is required before new sites can be occupied.

Although our stochastic model incorporated demographic and environmental variation, we did not account for occasional bonanzas or catastrophes. Even growing populations are susceptible to extirpation from catastrophic events (Beissinger and Westphal 1998). Nur et al. (1999) assumed a catastrophe every 20 years causing a 50\% reduction in reproduction in their range-wide population model of Snowy Plovers. Eberhart-Phillips and Colwell (2013) found that severe winter weather catastrophes, 
specifically the intensity of cold winters rather than their frequency, strongly suppressed population growth in Northern California through decreased overwinter survival of Age0 and Age1+ birds. In Oregon, we found no evidence that colder-than-average winter weather affected survival of Age0 or Age1+ birds, although wetter-than-average winters depressed survival of Age1+ individuals (Gaines et al. in prep; Chapters 3 and 4). Future analyses of Oregon's long-term dataset could examine additional weather variables to assess the validity of incorporating weather as a catastrophe in future PVAs.

\section{Summary}

As a species approaches recovery goals, effective conservation requires the identification of key vital rates, the forces affecting them, and how they combine to predict population trajectories. Previous work has shown the importance of predator management to nest, chick, juvenile and adult survival (Dinsmore et al. 2014, 2017, Gaines et al. in prep; Chapters 2 through 4). Here, we combined vital rates estimated from multiple analyses into a population model for the well-studied Snowy Plover population in Oregon. We looked specifically at the effect of one management tool, lethal predator control, which is part of a comprehensive suite of management actions in Oregon. We documented a growing population and identified adult survival, followed by first year survival and adult productivity, as the vital rates to which $\lambda$ is most responsive. Future analyses could add a spatial component to the model by examining site-specific movement, survival, and productivity, possibly incorporating similar data from Washington and California to update the Nur et al. (1999) metapopulation analysis. Additionally, our model could be used to explore effects of other management actions such as habitat restoration or 
recreation management. Although management is best informed by comprehensive, local demographic data (Anders and Marshall 2005, McNew et al. 2012), this is not feasible for all populations or species. This model could be generalized to other species with similar life histories but little available demographic data, to make a priori predictions about proposed management actions. Our work showed that with concerted, sustained management, Snowy Plover populations can reach and exceed recovery goals, and that in Oregon, lethal predator removal was an important part of a suite of management actions.

\section{ACKNOWLEDGEMENTS}

We thank the many plover monitors who collected the data reported here. In particular, the long-term dedication of Mark Stern, David Lauten, Kathleen Castelein, and J. Daniel Farrar made these analyses possible. We are grateful for the ongoing support of the Oregon Snowy Plover Working Team, and the cooperation of USDA APHIS Wildlife Services. 


\section{TABLES AND FIGURES}

Table 1. Snowy Plover adult population estimates, percent of adult population banded, and percent of males in adult population along the Oregon Coast, 1990 - 2014. In some years, total population includes a small number of birds of unknown sex. From $1990-$ 1992 field crews did not report individuals observed by sex.

\begin{tabular}{|c|c|c|c|c|c|}
\hline Year & Male & Female & $\begin{array}{r}\text { Total adult } \\
\text { population } \\
\text { estimate } \\
\end{array}$ & $\begin{array}{r}\% \text { Adults } \\
\text { banded }\end{array}$ & $\%$ Males \\
\hline 1990 & & & 75 & 0.16 & \\
\hline 1991 & & & 44 & 0.36 & \\
\hline 1992 & & & 50 & 0.78 & \\
\hline 1993 & 36 & 36 & 72 & 0.68 & 0.50 \\
\hline 1994 & 42 & 41 & 83 & 0.75 & 0.51 \\
\hline 1995 & 60 & 60 & 120 & 0.83 & 0.50 \\
\hline 1996 & 69 & 65 & 134 & 0.74 & 0.51 \\
\hline 1997 & 68 & 72 & 141 & 0.65 & 0.49 \\
\hline 1998 & 55 & 41 & 97 & 0.74 & 0.57 \\
\hline 1999 & 45 & 50 & 95 & 0.85 & 0.47 \\
\hline 2000 & 50 & 59 & 109 & 0.87 & 0.46 \\
\hline 2001 & 54 & 57 & 111 & 0.86 & 0.49 \\
\hline 2002 & 46 & 50 & 99 & 0.88 & 0.48 \\
\hline 2003 & 50 & 52 & 102 & 0.93 & 0.49 \\
\hline 2004 & 68 & 68 & 136 & 0.89 & 0.50 \\
\hline 2005 & 73 & 80 & 153 & 0.90 & 0.48 \\
\hline 2006 & 83 & 95 & 178 & 0.79 & 0.47 \\
\hline 2007 & 84 & 97 & 181 & 0.71 & 0.46 \\
\hline 2008 & 87 & 100 & 187 & 0.73 & 0.47 \\
\hline 2009 & 98 & 101 & 199 & 0.78 & 0.49 \\
\hline 2010 & 110 & 122 & 232 & 0.82 & 0.47 \\
\hline 2011 & 125 & 122 & 247 & 0.84 & 0.51 \\
\hline 2012 & 145 & 145 & 290 & 0.88 & 0.50 \\
\hline 2013 & 164 & 140 & 304 & 0.88 & 0.54 \\
\hline 2014 & 188 & 150 & 338 & 0.80 & 0.56 \\
\hline
\end{tabular}


Table 2. Number of predators removed at Snowy Plover nesting sites in Oregon, 2002 - 2014.

\begin{tabular}{|c|c|c|c|c|c|c|c|c|c|c|}
\hline & Raven & Crow & $\begin{array}{r}\text { Red } \\
\text { fox }\end{array}$ & $\begin{array}{r}\text { Gray } \\
\text { fox }\end{array}$ & Raccoon & $\begin{array}{r}\text { Striped } \\
\text { skunk }\end{array}$ & $\begin{array}{r}\text { Feral } \\
\text { cat }\end{array}$ & Opossum & Coyote & $\begin{array}{r}\text { Great } \\
\text { Horned } \\
\text { Owl }\end{array}$ \\
\hline $2002^{a}$ & 12 & 14 & 6 & 2 & 12 & 5 & 1 & 1 & 0 & 0 \\
\hline $2003^{a}$ & 150 & 38 & 12 & 2 & 8 & 6 & 1 & 1 & 0 & 0 \\
\hline 2004 & 150 & 101 & 27 & 3 & 19 & 13 & 4 & 17 & 0 & 0 \\
\hline 2005 & 82 & 132 & 15 & 0 & 0 & 3 & 2 & 3 & 0 & 0 \\
\hline 2006 & 145 & 89 & 17 & 0 & 0 & 8 & 1 & 0 & 4 & 0 \\
\hline 2007 & 65 & 144 & 13 & 3 & 2 & 7 & 0 & 0 & 0 & 1 \\
\hline 2008 & 219 & 122 & 15 & 0 & 3 & 2 & 1 & 0 & 2 & 0 \\
\hline 2009 & 151 & 169 & 10 & 2 & 3 & 4 & 4 & 0 & 2 & 0 \\
\hline 2010 & 81 & 168 & 7 & 0 & 1 & 3 & 0 & 0 & 1 & 0 \\
\hline 2011 & 95 & 178 & 15 & 0 & 0 & 6 & 0 & 0 & 0 & 1 \\
\hline 2012 & 225 & 50 & 13 & 0 & 0 & 3 & 0 & 0 & 2 & 0 \\
\hline 2013 & 213 & 123 & 20 & 0 & 0 & 0 & 0 & 0 & 0 & 0 \\
\hline 2014 & 185 & 130 & 6 & 0 & 0 & 0 & 0 & 0 & 0 & 0 \\
\hline Total & 1773 & 1458 & 176 & 12 & 48 & 60 & 14 & 22 & 11 & 2 \\
\hline
\end{tabular}

${ }^{\text {a }}$ Predator removal occurred only at Coos Bay North Spit, Bandon, and New River in 2002 and 2003. 
Table 3. Snowy Plover mean vital rates and variances used in deterministic and stochastic models. Variance for $\varphi_{\mathrm{a}}, \varphi_{\mathrm{j}}, \varphi_{\mathrm{c}}$, and $\mathrm{S}_{\mathrm{n}}$ contain process variance only. Variance for $n, c s$, and $h$ include both sampling error and process variation.

\begin{tabular}{llrr}
\hline Parameter & Definition & Mean (SE) & Variance \\
\hline$\varphi_{\mathrm{a}}$ & Annual survival after age 1 & $0.709(0.014)$ & 0.002 \\
$\varphi_{\mathrm{j}}$ & Juvenile survival from fledging to age 1 & $0.531(0.017)$ & 0.002 \\
$\varphi_{\mathrm{c}}$ & Chick survival from hatching to fledging & $0.610(0.004)$ & 0.001 \\
$n$ & Number of nests per year & $2.081(0.083)$ & 0.070 \\
$c s$ & Clutch size; eggs per clutch & $2.671(0.011)$ & 0.452 \\
$S_{n}$ & Nest survival - 29 days & $0.445(0.004)$ & 0.070 \\
$h$ & Hatch rate & $0.864(0.005)$ & 0.044 \\
sex & sex ratio at hatch & 0.5 & constant \\
\hline
\end{tabular}


Table 4. Elasticity of mean matrix values and underlying vital rates for deterministic matrix model for Snowy Plover population in Oregon. Although we display elasticities for lower level vital rates, these cannot be interpreted as contributions to population growth and do not sum to 1 .

\begin{tabular}{lcc}
\hline & $\begin{array}{l}\text { Mean matrix } \\
\text { value/vital } \\
\text { rate }\end{array}$ & Elasticity \\
\hline First year fecundity $\left(F_{1}\right)$ & 0.35 & 0.11 \\
Adult fecundity $\left(F_{2}\right)$ & 0.76 & 0.22 \\
First year survival $\left(P_{1}\right)$ & 0.32 & 0.22 \\
Adult survival $\left(P_{2}\right)$ & 0.71 & 0.45 \\
Nests per year $(n)$ & 2.08 & 0.33 \\
Eggs per clutch $(e)$ & 2.67 & 0.33 \\
29-day nest survival $\left(S_{n}\right)$ & 0.44 & 0.33 \\
Probability egg hatches $(h)$ & 0.86 & 0.33 \\
Adult annual survival $\left(\varphi_{\mathrm{a}}\right)$ & 0.71 & 0.67 \\
Juvenile survival $\left(\varphi_{\mathrm{j}}\right)$ & 0.53 & 0.33 \\
Chick survival $\left(\varphi_{\mathrm{c}}\right)$ & 0.61 & 0.33 \\
\hline
\end{tabular}


Table 5. Projected effect of variable levels of predator management on the Oregon Snowy Plover population, 2014 - 2029. Based on 10,000 iterations of the stochastic growth model, we report mean population growth rates with $95 \%$ confidence intervals, estimated number of males in population in 2029 , the percent of iterations that fell below U.S. Fish and Wildlife Service recovery goal of 125 males at any point between 2014 and 2029 , and the percent of iterations that fell below a quasi-extinction threshold of 25 male during the same period.

\begin{tabular}{|c|c|c|c|c|}
\hline Management level & $\lambda_{\mathrm{s}}(95 \% \mathrm{CI})$ & $\begin{array}{r}\text { Estimated } \\
\text { male } \\
\text { population } \\
\text { size, } 2029 \\
\end{array}$ & $\begin{array}{r}\% \\
\text { Iterations } \\
\text { below } \\
\text { recovery } \\
\text { goal } \\
\end{array}$ & $\begin{array}{r}\% \\
\text { Iterations } \\
\text { below } 25 \\
\text { males } \\
\end{array}$ \\
\hline No predator management & $0.97(0.96,0.97)$ & 168 & $64 \%$ & $2 \%$ \\
\hline $25 \%$ predator management & $0.99(0.99,1.00)$ & 251 & $44 \%$ & $0.4 \%$ \\
\hline $50 \%$ predator management & $1.02(1.01,1.03)$ & 372 & $26 \%$ & $0.1 \%$ \\
\hline $75 \%$ predator management & $1.04(1.04,1.05)$ & 524 & $13 \%$ & $0.0 \%$ \\
\hline $100 \%$ predator management & $1.07(1.06,1.08)$ & 730 & $7 \%$ & $0.0 \%$ \\
\hline
\end{tabular}




\section{LIST OF FIGURES}

Figure 1. Map of Snowy Plover nesting sites in Oregon, 1990-2014.

Figure 2. Life cycle diagram for Western Snowy Plover population in Oregon.

Figure 3. Histogram of 10,000 iterations of Snowy Plover population growth rate $\left(\lambda_{s}\right)$.

Figure 4. 100 iterations of Snowy Plover stochastic growth model, 1990 - 2029. 


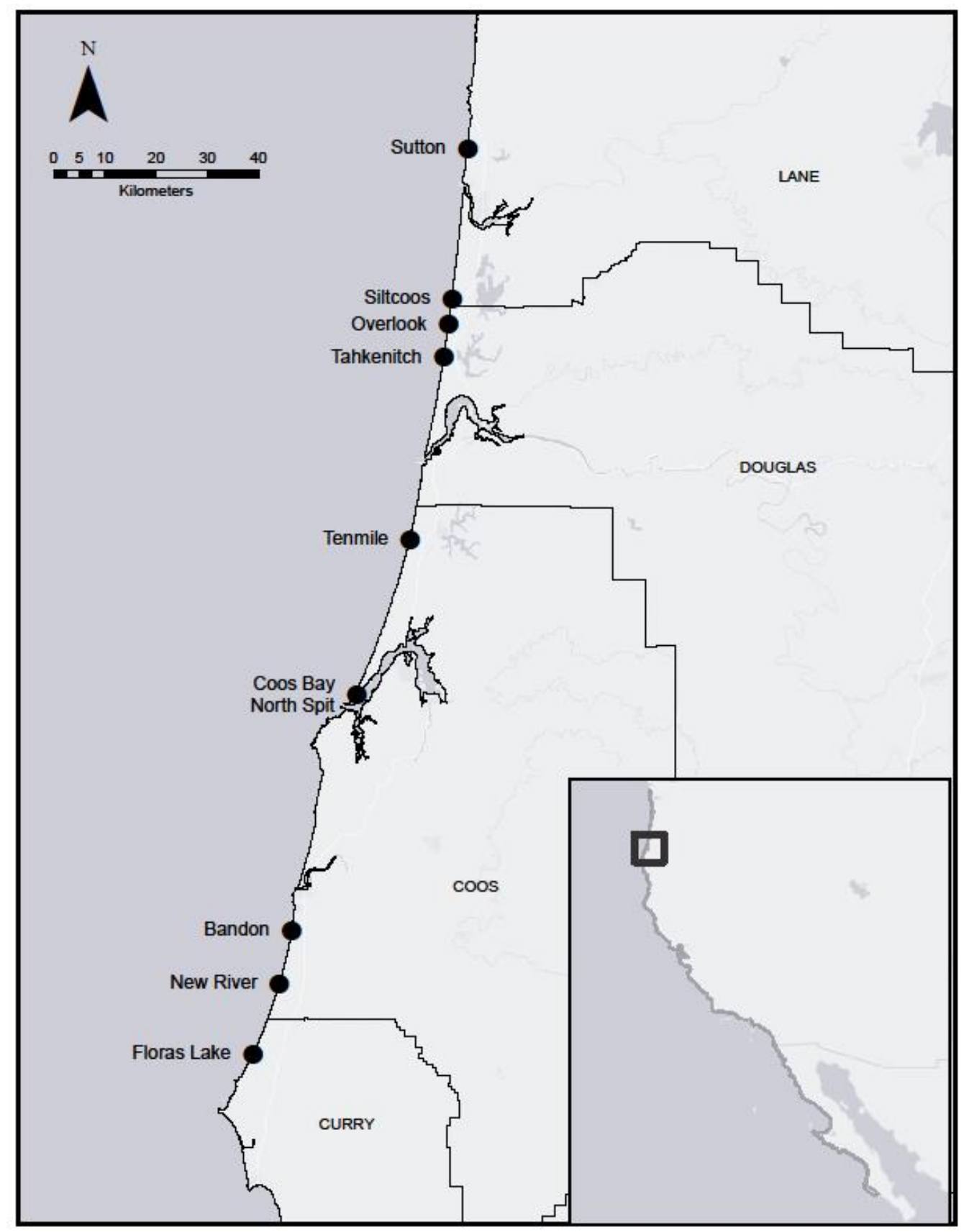

Figure 1. Snowy Plover nesting sites in Oregon, 1990-2014. Black dots include all regularly occupied nesting habitat during study period. Gray shaded line in inset map shows extent of Pacific Coast population distribution. Black box indicates map extent. 


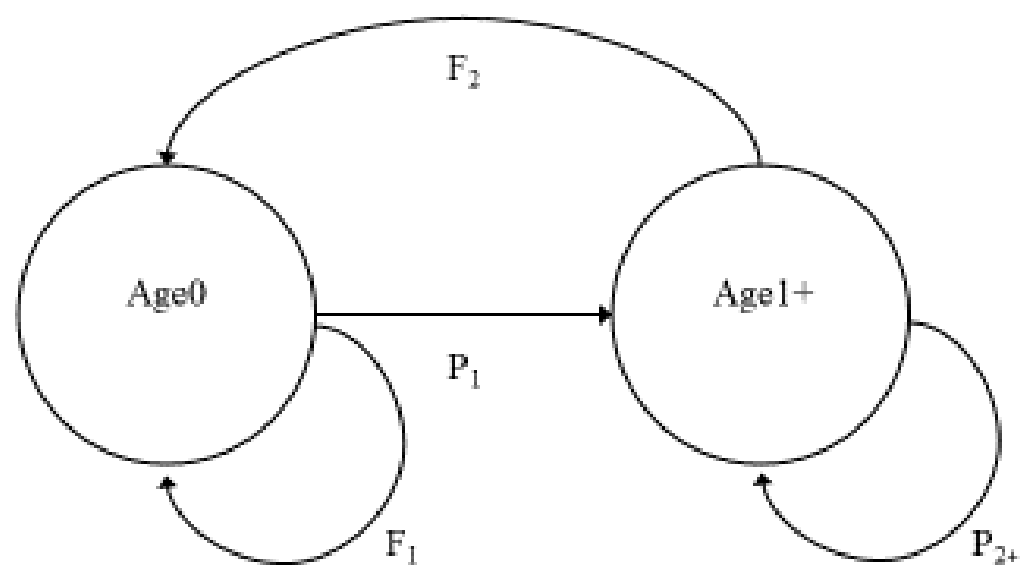

Figure 2. Life cycle diagram for Western Snowy Plover population in Oregon with postbreeding census and two life stages; first year birds (Age0) and adult birds (Age1+). Survival rates are shown for Age 0 birds $\left(\mathrm{P}_{1}=\right.$ probability that a first-year bird survives from hatching to age 1$)$ and Age $1+\left(\mathrm{P}_{2+}=\right.$ probability that an adult survives to the following year). Fecundity values represent the reproductive contribution of Age 0 birds $\left(\mathrm{F}_{1}\right)$ and Age1+ $\left(\mathrm{F}_{2}\right)$ within the next 12 months in terms of number of male offspring produced per male parent. These fecundity values include the probability of an individual surviving to the following spring, recruiting to the population, and breeding successfully. 


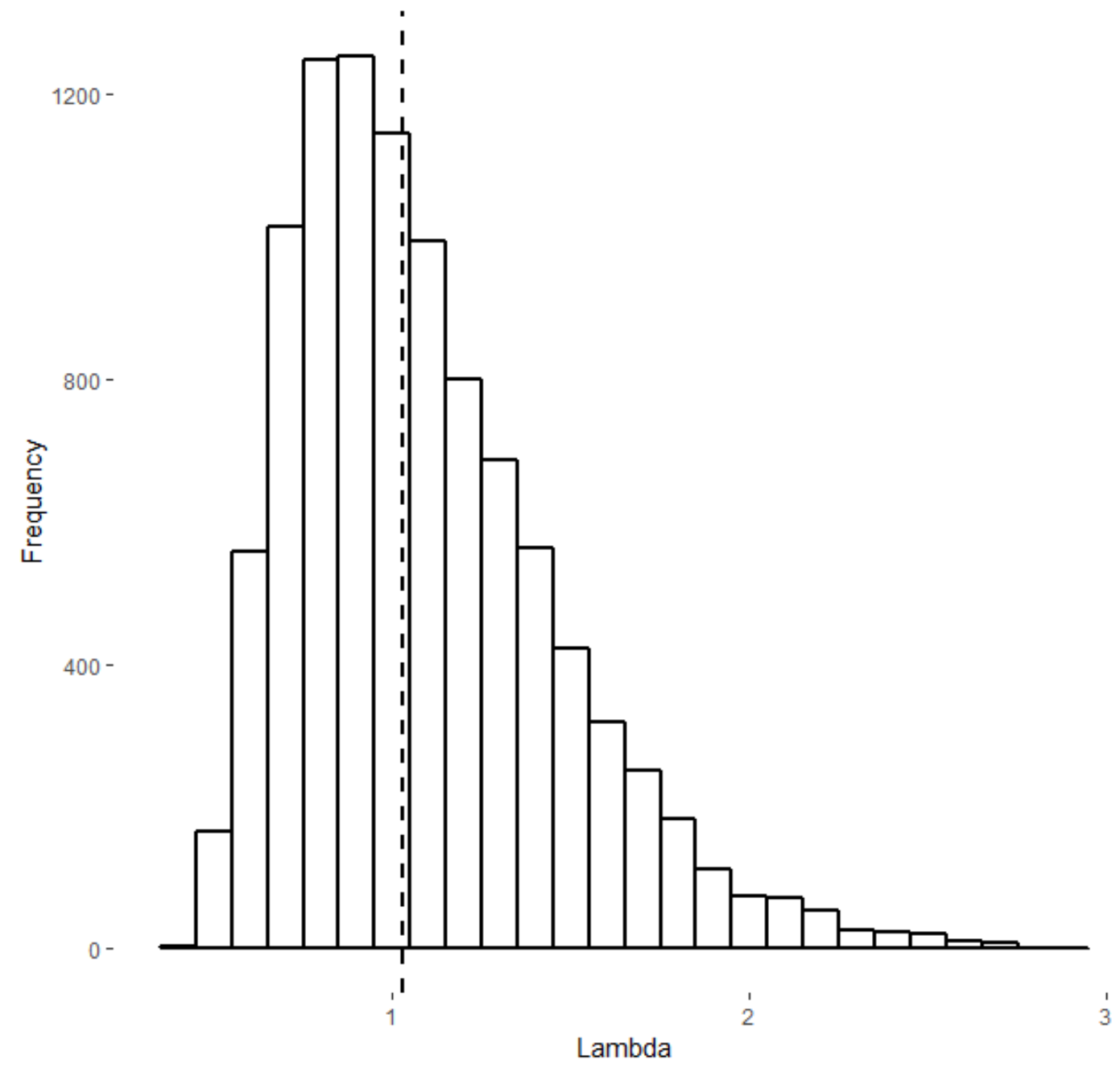

Figure 3. Histogram of population growth rate $\left(\lambda_{\mathrm{s}}\right)$ based on 10,000 iterations of stochastic model. Dashed line shows mean value of $\lambda_{\mathrm{s}}$. 


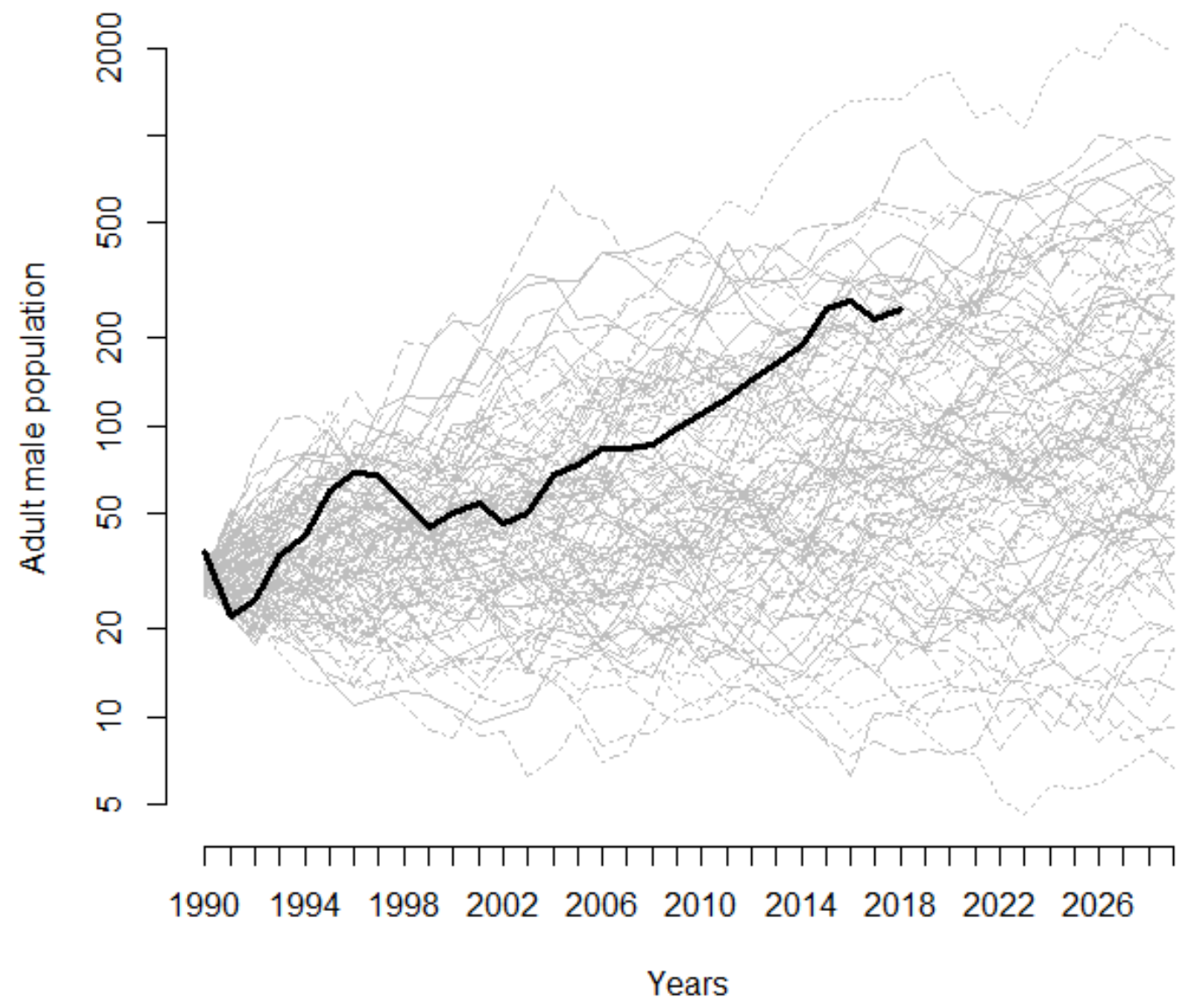

Figure 4. Snowy Plover adult male population growth, based on 100 iterations of stochastic model, 1990 - 2029. Bold black line shows observed male population growth, $1990-2018$. 


\section{LITERATURE CITED}

Akaike, H. (1992). Information theory and an extension of the maximum likelihood principle. Breakthroughs in statistics / Samuel Kotz, Norman L. Johnson editors.

Anders, A. D., and M. R. Marshall (2005). Increasing the accuracy of productivity and survival estimates in assessing landbird population status. Conservation Biology 19:66-74.

Armstrong, D. P., E. H. Raeburn, R. M. Lewis, and D. Ravine (2006). Estimating the viability of a reintroduced New Zealand Robin population as a function of predator control. The Journal of Wildlife Management 70:1020-1027.

Arnold, T. W. (2010). Uninformative parameters and model selection using Akaike's Information Criterion. The Journal of Wildlife Management 74:1175-1178.

Beissinger, S. R., and M. Z. Peery (2007). Reconstructing the historic demography of an endangered seabird. Ecology 88:296-305.

Beissinger, S. R., and M. I. Westphal (1998). On the use of demographic models of population viability in endangered species management. The Journal of Wildlife Management 62:821-841.

Brown, S. C., C. M. Hickey, B. Harrington, and R. Gill (2001). United States shorebird conservation plan. Manomet Center for Conservation Sciences.

Burnham, K. P., and D. R. Anderson (2002). Model Selection and Multi-model Inference. 2nd Edition. Springer-Verlag.

Caswell, H. (2000). Prospective and retrospective perturbation analyses: their roles in Conservation Biology. Ecology 81:619-627. 
Caswell, H. (2001). Matrix Population Models. Sinauer Associates Inc., Sunderland, MA. Colwell, M.A. (2010). Shorebird Ecology, Conservation, and Management. University of California Press, Berkeley, CA.

Colwell, M. A., S. E. McAllister, C. B. Millett, A. N. Transou, S. M. Mullin, Z. J. Nelson, C. A. Wilson, and R. R. LeValley (2007). Philopatry and natal dispersal of the western snowy plover. The Wilson Journal of Ornithology 119:378-385.

Colwell, M. A., E. J. Feucht, M. J. Lau, D. J. Orluck, S. E. McAllister, and A. N. Transou (2017). Recent Snowy Plover population increase arises from high immigration rate in coastal northern California. Wader Study 124.

Cormack, R. M. (1964). Estimates of survival from the sighting of marked animals. Biometrika 51:429-438.

Crouse, D. T., L. B. Crowder, and H. Caswell (1987). A stage-based population model for Loggerhead sea turtles and implications for conservation. Ecology 68:14121423.

de Kroon, H., J. van Groenendael, and J. Ehrlén (2000). Elasticities: A review of methods and model limitations. Ecology 81:607-618.

Dinsmore, S. J., G. C. White, and F. L. Knopf (2002). Advanced techniques for modeling avian nest survival. Ecology 83:3476-3488.

Dinsmore, S. J., M. B. Wunder, V. J. Dreitz, and F. L. Knopf (2010). An assessment of factors affecting population growth of the Mountain Plover. Avian Conservation and Ecology 5. 
Dinsmore, S. J., D. J. Lauten, K. A. Castelein, E. P. Gaines, and M. A. Stern (2014). Predator exclosures, predator removal, and habitat improvement increase nest success of Snowy Plovers in Oregon, USA. The Condor 116:619-628.

Dinsmore, S. J., E. P. Gaines, S. F. Pearson, D. J. Lauten, and K. A. Castelein (2017). Factors affecting Snowy Plover chick survival in a managed population. The Condor: $34-43$.

Eberhart-Phillips, L. J., and M. A. Colwell (2013). Conservation challenges of a sink: the viability of an isolated population of the Snowy Plover. Bird Conservation International:1-15.

Eberhart-Phillips, L. J., C. Küpper, T. E. X. Miller, M. Cruz-López, K. H. Maher, N. dos Remedios, M. A. Stoffel, J. I. Hoffman, O. Krüger, and T. Székely (2017). Sexspecific early survival drives adult sex ratio bias in snowy plovers and impacts mating system and population growth. Proceedings of the National Academy of Sciences: 201620043.

Galbraith, H., R. Jones, R. Park, J. Clough, S. Herrod-Julius, B. Harrington, and G. Page (2002). Global climate change and sea level rise: potential losses of intertidal habitat for shorebirds. Waterbirds 25:173.

Heppell, S. S., L. B. Crowder, and D. T. Crouse (1996). Models to evaluate headstarting as a management tool for long-lived turtles. Ecological Applications 6:556-565.

Hiraldo, F., J. J. Negro, J. A. Donazar, and P. Gaona (1996). A demographic model for a population of the endangered Lesser Kestrel in Southern Spain. The Journal of Applied Ecology 33:1085. 
International Wader Study Group (2003). Waders are declining worldwide. Conclusions from the 2003 International Wader Study Group Conference, Cádiz, Spain. Wader Study Group Bulletin 101:8-12.

Johnson, H. E., L. S. Mills, T. R. Stephenson, and J. D. Wehausen (2010). Populationspecific vital rate contributions influence management of an endangered ungulate. Ecological Applications: a publication of the Ecological Society of America 20:1753-1765.

Jolly, G. M. (1965). Explicit estimates from capture-recapture data with both death and immigration-stochastic model. Biometrika 52:225-247.

Lafferty, K. D., D. Goodman, and C. P. Sandoval (2006). Restoration of breeding by Snowy Plovers following protection from disturbance. Biodiversity \& Conservation 15:2217-2230.

Lukacs, P. M., V. J. Dreitz, F. L. Knopf, and K. P. Burnham (2004). Estimating survival probabilities of unmarked dependent young when detection is imperfect. The Condor 106:926-931.

Manlik, O., J. A. McDonald, J. Mann, H. C. Raudino, L. Bejder, M. Krützen, R. C. Connor, M. R. Heithaus, R. C. Lacy, and W. B. Sherwin (2016). The relative importance of reproduction and survival for the conservation of two dolphin populations. Ecology and Evolution 6:3496-3512.

Manlik, O., R. C. Lacy, and W. B. Sherwin (2017). Applicability and limitations of sensitivity analyses for wildlife management. Journal of Applied Ecology 55:1430-1440. 
McNew, L. B., A. J. Gregory, S. M. Wisely, and B. K. Sandercock (2012). Demography of greater prairie-chickens: Regional variation in vital rates, sensitivity values, and population dynamics. The Journal of Wildlife Management 76:987-1000.

Morris, W. F., and D. F. Doak (2002). Quantitative Conservation Biology: Theory and Practice of Population Viability Analysis. Sinauer Associates, Inc., Sunderland, MA.

Muir, J. J., and M. A. Colwell (2010). Snowy Plovers select open habitats for courtship scrapes and nests. The Condor 112:507-510.

Mullin, S. M., M. A. Colwell, S. E. McAllister, and S. J. Dinsmore (2010). Apparent survival and population growth of Snowy Plovers in coastal Northern California. Journal of Wildlife Management 74:1792-1798.

Murphy, S. P., T. Virzi, and F. Sanders (2017). Exploring differences in adult survival and site fidelity of migratory and non-migratory American Oystercatcher (Haematopus palliatus) populations. Waterbirds 40:32-43.

Neuman, K. K., G. W. Page, L. E. Stenzel, J. C. Warriner, and J. S. Warriner (2004). Effect of mammalian predator management on Snowy Plover breeding success. Waterbirds 27:257-263.

Nur, N., G. W. Page, and L. E .Stenzel (1999). Population viability analysis for Pacific Coast Snowy Plovers. [Online.] Available at http://www.fws.gov/pacific/ecoservices/endangered/recovery/snowyplover/Appen dix_D.pdf. 
Page, G. W., and L. E. Stenzel (1981). The breeding status of the Snowy Plover in California. Western Birds 12:1-40.

Page, G. W., L. E. Stenzel, D. W. Winkler, and C. W. Swarth (1983). Spacing out at Mono Lake: breeding success, nest density, and predation in the Snowy Plover. The Auk 100:13-24.

Page, G. W., L. E. Stenzel, J. C. Warriner, J. S. Warriner, and P. W. Paton (2009). Snowy Plover (Charadrius alexandrinus). The Birds of North America Online. https://doi.org/10.2173/bna.154

Paton, P. W. C. (1994). Survival estimates for Snowy Plovers breeding at Great Salt Lake, Utah. The Condor 96:1106-1109.

Pimm, S. L., H. L. Jones, and J. Diamond (1988). On the risk of extinction. The American Naturalist 132:757-785.

Powell, A. N., and C. L. Collier (2000). Habitat use and reproductive success of Western Snowy Plovers at new nesting areas created for California Least Terns. The Journal of Wildlife Management 64:24-33.

Powell, L. A. (2007). Approximating variance of demographic parameters using the delta method: a reference for avian biologists. The Condor 109:949-954.

Que, P., T. Székely, P. Wang, Q. Lu, W. Lei, Y. Liu, and Z. Zhang (2019). Offspring sex ratio is unrelated to parental quality and time of breeding in a multiple-breeding shorebird. Journal of Ornithology 160:1-10. 
R Core Team (2018). R: A language and environment for statistical computing. $\mathrm{R}$ Foundation for Statistical Computing, Vienna, Austria. URL https://www.Rproject.org/.

Rizzolo, D. J., and J. A. Schmutz (2007). Egg flotation estimates nest age for Pacific and Red-throated Loons. Waterbirds 30:207-213.

Ruhlen, T. D., S. Abbott, L. E. Stenzel, and G. W. Page (2003). Evidence that human disturbance reduces Snowy Plover chick survival. Journal of Field Ornithology 74:300-304.

Sæther, B.-E., and Ø. Bakke (2000). Avian life history variation and contribution of demographic traits to the population growth rate. Ecology 81:642-653.

Sandercock, B. K. (2003). Estimation of survival rates for wader populations: a review of mark-recapture methods. Wader Study Group Bulletin 100:163-174.

Saunders, S. P., F. J. Cuthbert, and E. F. Zipkin (2018). Evaluating population viability and efficacy of conservation management using integrated population models. Journal of Applied Ecology 55:1380-1392.

Schaub, M., O. Gimenez, A. Sierro, and R. Arlettaz (2007). Use of integrated modeling to enhance estimates of population dynamics obtained from limited data. Conservation Biology 21:945-955.

Schaub, M., H. Jakober, and W. Stauber (2013). Strong contribution of immigration to local population regulation: evidence from a migratory passerine. Ecology 94:1828-1838.

Seber, G. A. F. (1965). A note on the multiple-recapture census. Biometrika 52:249-259. 
Servanty, S., S. J. Converse, and L. L. Bailey (2014). Demography of a reintroduced population: moving toward management models for an endangered species, the Whooping Crane. Ecological Applications 24:927-937.

Sibly, R. M., and J. Hone (2002). Population growth rate and its determinants: an overview. Philosophical Transactions of the Royal Society of London B: Biological Sciences 357:1153-1170.

Stahl, J. T., and M. K. Oli (2006). Relative importance of avian life-history variables to population growth rate. Ecological Modelling 198:23-39.

Stenzel, L. E., J. C. Warriner, J. S. Warriner, K. S. Wilson, F. C. Bidstrup, and G. W. Page (1994). Long-distance breeding dispersal of Snowy Plovers in western North America. Journal of Animal Ecology 63:887-902.

Stenzel, L. E., G. W. Page, J. C. Warriner, J. S. Warriner, D. E. George, C. R. Eyster, B. A. Ramer, K. K. Neuman, and B. K. Sandercock (2007). Survival and natal dispersal of juvenile snowy plovers (Charadrius alexandrinus) in central coastal California. The Auk 124:1023-1036.

Stubben, C. J. and B. G. Milligan (2007). Estimating and analyzing demographic models using the popbio package in R. Journal of Statistical Software 22:11.

Székely, T., I. C. Cuthill, S. Yezerinac, R. Griffiths, and J. Kis (2004). Brood sex ratio in the Kentish plover. Behavioral Ecology 15:58-62.

Tauler, H., J. Real, A. Hernández-Matías, P. Aymerich, J. Baucells, C. Martorell, and J. Santandreu (2015). Identifying key demographic parameters for the viability of a 
growing population of the endangered Egyptian Vulture Neophron percnopterus. Bird Conservation International 25:426-439.

Thomas, S. M., J. E. Lyons, B. A. Andres, E. E. T-Smith, E. Palacios, J. F. Cavitt, J. Andrew Royle, S. D. Fellows, K. Maty, W. H. Howe, E. Mellink, et al. (2012). Population size of Snowy Plovers breeding in North America. Waterbirds 35:114.

U.S. Department of Agriculture and U.S. Department of Interior (2002). Predator damage management to protect the federally threatened Pacific coast population of the Western Snowy Plover. Prepared by USDA, APHIS, Wildlife Services Program and the Siuslaw National Forest; USDI, Fish and Wildlife Service Region 1 and Bureau of Land Management Coos Bay District; and in cooperation with the Oregon Department of Fish and Wildlife, and Oregon Parks and Recreation Department. Portland, OR.

U. S. Fish and Wildlife Service (1993). Determination of Threatened Status for the Pacific Coast Population of the Western Snowy Plover. Federal Register $58: 12864-12874$.

U.S. Fish and Wildlife Service (2007). Recovery Plan for the Pacific Coast Population of the Western Snowy Plover (Charadrius alexandrinus nivosus). In 2 volumes.

Warriner, J. S., J. C. Warriner, G. W. Page, and L. E. Stenzel (1986). Mating system and reproductive success of a small population of polygamous Snowy Plovers. The Wilson Bulletin 98:15-37. 
Westerskov, K. (1950). Methods for determining the age of game bird eggs. The Journal of Wildlife Management 14:56-67.

White, G. C. (2000). Population viability analysis: data requirements and essential analyses. Pages 288-331 in I. Boitani and K. Fuller, editors. Research Techniques in Animal Ecology: Controversies and Consequences. Columbia University, New York, New York, USA.

White, G. C., and K. P. Burnham (1999). Program MARK: survival estimation from populations of marked animals. Bird Study 46:S120-S139.

Zuidema, P. A., and M. Franco (2001). Integrating vital rate variability into perturbation analysis: an evaluation for matrix population models of six plant species. Journal of Ecology 89:995-1005. 


\section{CHAPTER 6. CONCLUSION}

Gabrielson and Jewett (1940) called the Snowy Plover "the pale little ghost of the sand dunes", an apt description for a bird that was almost lost from Oregon's beaches. By the 1970s Snowy Plovers were rare in Oregon (Wilson 1980), and in the early 1990s there were fewer than 50 birds nesting along the coast. Today, through intensive management and the sustained efforts of countless biologists, Snowy Plovers can again be found in open sand dunes in all counties along the Oregon coast, but maintaining this conservation success in the face of declining resources will be a challenge. This work facilitates informed conservation. It documents individual survival rates for Snowy Plovers at chick, juvenile, and adult life stages, and identifies environmental and management covariates affecting each. It complements and updates earlier analyses of nest and chick survival (Dinsmore et al. 2014, 2017). The population model brings these vital rates together to predict growth under current management and explore the effect of reducing lethal predator management on future population levels.

We found that chick survival, from hatching to fledging at 28 days, improved with age, varied by site, and was higher in years with predator management. Chicks' survival increased significantly after 5 days. We found a quadratic trend over the long brood-rearing season; chicks hatched at the peak of the season had highest survival to fledging. Chicks that experienced colder-than-average weather during their pre-fledging period had lower survival, particularly during their first 5 days. We found no significant effect of male parent age or wetter-than-average weather on chick survival. 
Juvenile survival from fledging to the following spring followed a negative trend over the early years of our study, before rebounding slightly after implementation of predator management across the study area, although this improvement did not outweigh the overall negative trend. We found no sex differences in juvenile survival, and no support for variation in juvenile survival based on other temporal and individual covariates. There was no evidence of effects based on number of chicks fledged annually, adult population size, climate, weather, sex, hatch date, or site on juvenile survival, and there was no evidence for differences in adult survival or encounter probability based on sex. Predictably, juvenile survival was significantly lower than adult survival.

During the course of our study, we saw increasing apparent adult survival. This increase was concomitant with implementation of lethal predator management and a decline in the use of nest exclosures. We also saw evidence that wetter-than-average winter weather depressed adult survival.

We used these survival analyses and observed productivity data in a matrix population model to assess the relative contribution of demographic rates on population growth, project population growth and viability 15 years into the future, and compare expected population growth under varying levels of predator management. The model showed that adult survival contributed most to overall population growth and forecasted a growing population though 2029 - nearly doubling the population in the next 10 years. Our analysis revealed the importance of predator management to maintaining a growing population, but indicated that the level of predator management could be safely reduced by as much as $50 \%$ while maintaining a positive population growth rate. 


\section{Future directions}

Predator management was implemented in Oregon to improve nest and chick survival (U.S. Department of Agriculture and U.S. Department of Interior 2002). However, our analyses show that the program provides survival benefits across the life cycle. Although lethal predator management has been an important factor in population growth, and is a focus of the work here, other management actions are also integral to the Oregon population's success. Along much of the Oregon coast, invasive vegetation has encroached on the dunes, stabilizing the plovers' ephemeral habitat and leaving a narrow strip of open sand habitat close to the water. Nests along these linear beaches are wedged between the waterline (and may be lost to overwashing during high tides) and the vegetation line (which provides cover for predators). Habitat restoration and maintenance creates wide, open expanses of nesting habitat. When incubating plovers are repeatedly flushed from their nest, eggs are left exposed to the elements, and the adults' movement may alert predators to the location of otherwise-cryptic nests. Recreation management and seasonal beach restrictions allow plovers to nest undisturbed. Both habitat restoration and recreation management result in higher productivity and survival (Ruhlen et al. 2003, Lafferty et al. 2006, Dinsmore et al. 2014). Future analyses should explore the effects of varying these actions on population growth.

The adult and juvenile Cormack-Jolly-Seber (Cormack 1964, Jolly 1965, Seber 1965) models used here (Chapters 3 and 4) estimate apparent survival, which is the product of true survival and permanent emigration. These models could be improved by collaborating with partners in other recovery units to incorporate dispersal information 
and estimate true survival. Additionally, dispersal information could improve the matrix model by providing vital rates for emigration and immigration. We are currently developing an integrated population model with Bayesian population viability analysis that includes estimates of immigration. Alternatively, a multi-state analysis incorporating movements between regions could help quantify dispersal and source/sink dynamics.

Our population model looked at population growth across all 9 traditional nesting sites. Subsequent analyses could add a spatial component to the model by examining sitespecific movement, survival, and productivity, possibly incorporating similar data from Washington and California to update the Nur et al. (1999) metapopulation analysis. This information could help managers identify sites that are most important to maintaining the population at recovery levels, and could be extended to compare growth among recovery units.

Comparatively little is known about Snowy Plover biology during the nonbreeding season, particularly in Oregon. Some plovers are sedentary in winter, while others migrate outside the state. Future analyses could estimate winter survival, dispersal, and habitat use, and may identify further management actions that would efficiently maximize growth.

Finally, although management is best informed by comprehensive, local demographic data (Anders and Marshall 2005, McNew et al. 2012), this is not feasible for all species. This model could be generalized to other species with similar life histories but little available demographic data, to make informed a priori predictions about proposed management actions. 
Leopold (1949) said "The last word in ignorance is the man who says of an animal or plant, "What good is it?"...To keep every cog and wheel is the first precaution of intelligent tinkering." Snowy Plovers are an integral part of a functioning coastal dune ecosystem in Oregon, and their conservation benefits other dune species, including oftenoverlooked native vegetation and invertebrates, by restoring the poorly stabilized, sparsely vegetated sand habitat these species require. This work furthers conservation of the Oregon coastal dune system by informing protection of a flagship species. 


\section{LITERATURE CITED}

Anders, A. D., and M. R. Marshall (2005). Increasing the accuracy of productivity and survival estimates in assessing landbird population status. Conservation Biology $19: 66-74$.

Cormack, R. M. (1964). Estimates of survival from the sighting of marked animals. Biometrics 51:429-438.

Dinsmore, S. J., D. J. Lauten, K. A. Castelein, E. P. Gaines, and M. A. Stern (2014). Predator exclosures, predator removal, and habitat improvement increase nest success of Snowy Plovers in Oregon, USA. The Condor 116:619-628.

Dinsmore, S. J., E. P. Gaines, S. F. Pearson, D. J. Lauten, and K. A. Castelein (2017). Factors affecting Snowy Plover chick survival in a managed population. The Condor 119:34-43.

Gabrielson, I. N., and S. G. Jewett (1940). Birds of Oregon. Oregon State Monographs. Studies in Zoology, 2, 650 pp.

Jolly, G. M. (1965). Explicit estimates from capture-recapture data with both death and immigration-stochastic models. Biometrika 64:225-247.

Lafferty, K. D., D. Goodman, and C. P. Sandoval (2006). Restoration of breeding by Snowy Plovers following protection from disturbance. Biodiversity \& Conservation 15:2217-2230.

Leopold, A. (1949). A Sand County almanac and sketches here and there. Oxford University Press, New York, USA. 
McNew, L. B., A. J. Gregory, S. M. Wisely, and B. K. Sandercock (2012). Demography of greater prairie-chickens: Regional variation in vital rates, sensitivity values, and population dynamics. The Journal of Wildlife Management 76:987-1000.

Nur, N., G. W. Page, and Stenzel, Lynne E. (1999). Population viability analysis for Pacific Coast Snowy Plovers. [Online.] Available at http://www.fws.gov/pacific/ecoservices/endangered/recovery/snowyplover/Appen dix_D.pdf.

Ruhlen, T. D., S. Abbott, L. E. Stenzel, and G. W. Page (2003). Evidence that human disturbance reduces Snowy Plover chick survival. Journal of Field Ornithology $74: 300-304$.

Seber, G. A. F. (1965). A note on the multiple recapture census. Biometrika 52:249-259.

U.S. Department of Agriculture and U.S. Department of Interior (2002). Predator damage management to protect the federally threatened Pacific coast population of the Western Snowy Plover. Prepared by USDA, APHIS, Wildlife Services Program and the Siuslaw National Forest; USDI, Fish and Wildlife Service Region 1 and Bureau of Land Management Coos Bay District; and in cooperation with the Oregon Department of Fish and Wildlife, and Oregon Parks and Recreation Department.

Wilson, R. A. (1980). Snowy plover nesting ecology on the Oregon coast. [Online.] Available at http://ir.library.oregonstate.edu/xmlui/handle/1957/10543. 